\title{
Über die Nerven in den Augenhänten.
}

\author{
Von \\ Prof. Dr. A. Agababow \\ in Kasan. \\ Mit Taf. IX-XII, Fig. 1-32.
}

In den letztverflossenen Jahren wurde die ophthalmologische Literatur durch eine ganze Reihe von Arbeiten bereichert, welche dem histologischen Studium über die Augennerven gewidmet sind. Ein näherer Einblick in die Ergebnisse dieser Arbeiten führt uns zu der Überzeugung, dass zahlreiche Fragen nunmehr durch bestimmte, positive Anschauungen vertreten werden, während anderseits manche andere Fragen nur durch weitere Untersuchungen einer endgültigen Lösung genähert werden können, und schliesslich auch noch neue, bisher ganz unerörtert gebliebene Fragen sich erheben.

Dieser Umstand bewog mich, im vorliegenden Aufsatze die Fortschritte unserer Kenntnisse in dem uns interessierenden Gebiete in Kürze zu verfolgen, und zugleich soll es mir daran gelegen sein, ein allgemeines Bild über die Verteilung und Endigung der Nerven in verschiedenen Augenhäuten zu entwerfen.

$\mathrm{Zu}$ besagten $\mathrm{Zwecken}$ benutzte ich sowohl die Daten der uns bis jetzt zur Verfügung stehenden Literatur als auch die Befunde, welche bei meinen früheren, ebenso wie auch bei den neuerdings wieder aufgenommenen Untersuchungen von mir gewonnen worden sind.

Da die Färbungsmethode der Nerven mittels des Methylenblaus meiner Ansicht nach die relativ vollkommensten Resultate liefert, will ich hier eine Beschreibung der zur Färbung der Augennerven angewandten Modifikationen dieser Methode einschalten.

Auf die andern Methoden - die Vergoldung und Silberimprägnation - gehe ich hier nicht ein, weil dieselben in der gleichen Art und Weise und unter den nämlichen Modifikationen behufs Färbung der Augennerven, ebenso wie auch an andern Organen und Geweben 
zur Anwendung kamen. Diese Methoden sind übrigens allgemein bekannt, und findet man eine ausführliche Beschreibung derselben in den meisten speziellen Handbüchern.

Vor der Einführung der Methode von Golgi und besonders der von Ehrlich-Dogiel in die histologische Technik, waren unsere Kenntnisse ron der Verteilung und Endigung der Nerven in den Augenhäuten unklar und lückenhaft. Nur die Goldmethode wurde damals für anwendbar gehalten. Allein es haften dieser Methode, selbst unter Benutzung ihrer verschiedenen Modifikationen, sehr grosse Mängel an. Die wesentlichsten derselben sind: erstens eine mit der Nervenfärbung zugleich eintretende Färbung auch noch anderer Elemente des umgebenden Gewebes, ferner der Umstand, dass die nachträgliche Untersuchung sich nur an Schnittpräparaten ausführen lässt, und endlich - eine sehr schwache und unvollständige Färbung der Nervenfasern in ihren feineren Verästelungen.

Relativ vollkommener ist die von Ramony Cajal abgeänderte Methode von Golgi, welche das umgebende Gewebe fast gar nicht mitfärbt, indem sie letzterem nur eine gleichmässig gelbliche Nuance erteilt. Die Nerven selbst aber treten sehr scharf in Gestalt schwarzer Fäden hervor. Indes gestattet auch die in Rede stehende, ebenso wie die Goldmethode, nur eine Untersuchung der Nerven an Schnittpräparaten. Nicht selten kommen in solchen Präparaten störende, das mikroskopische Bild verdeckende Silberniederschläge vor. Ein sehr wesentlicher Mangel dieser Präparate liegt endlich noch darin, dass die Nerven nicht gefärbt, sondern durch das Chromsilber imprägniert werden; infolge davon bekommt man das unmittelbare Verbalten der Nerven zu den Gewebselementen nicht zu Gesicht.

Frei von allen aufgeführten Mängeln ist die Ehrlich-Dogielsche Methode. Das Methylenblau ergibt eine deutliche, scharfe Färbung der Nerven bis in ihre feinsten Verzweigungen; das umgebende Gewebe wird durch Einwirkung des Glycerins hinreichend durchsichtig, und auf dem (durch das Ammoniumpikrat) gelblich gefärbten Gewebsgrunde treten die violetten Nervenfäden sebr deutlich hervor.

Was diese Methode besonders schätzenswert macht, das ist die Möglichkeit, die sie uns gewährt, die Nerven an Flächenpräparaten in dem ganzen Verlaufe von einem Nervenstämmchen an bis an den Endapparat einschliesslich den letzteren verfolgen zu können. Dank einer solchen differentiellen Färbung ist zugleich auch das Verhalten des Nervenfädchens zu den Zellenelementen des betreffenden Gewebes 
leicht zu erörtern. So ist es z. B. in dem glatten Muskelgewebe deutlich zu sehen, dass das Nervenfädehen sich nicht mit der Muskelzelle, d. h. weder mit dem Protoplasma noch mit dem Kerne derselben direlst verbindet, wie es früher bei Anwendung der älteren Untersuchungsmethoden angenommen wurde (Frankenhäuser, Arnold u. A.), sondern an der Oberfläche der Muskelzelle endet (Arnstein) - ein Verhalten, wie es allerdings in analoger Weise auch Kölliker, Löwit u. A. bereits an Goldpräparaten gefunden hatten, oder dass die Nerven, wie ich an den Muskeln des Ciliarkörpers und in der Tunica muscularis der Blutgefässe konstatierte, in Gestalt eines (pericellulären) Endnetzes an der Oberfläche einer jeden Zelle enden.

Allein das von Ehrlich vorgeschlagene Methylenblau lieferte bei Injelztion in das Blutgefässsystem des lebenden Tieres eine nur für kurze Zeit bestehende Nervenfärbung.

Dank den Arbeiten von Prof. Arnstein und seiner Schüler Smirnow und A. Dogiel wurden Mittel aufgedeckt, welche die Färbung dauerhaft fixierten ${ }^{1}$ ).

Besonders haltbar wird die Färbung durch Fixierung mittels einer gesättigten wässrigen Ammoniumpikratlösung (Dogiel).

Eine mit dem genannten Mittel fixierte Nervenfärbung in Methylenblau hält sich so ziemlich unverändert mehrere Monate, bisweilen sogar mehrere Jahre ${ }^{2}$ ). Mit der Einftihrung des genannteu Fixierungsmittels wurde die Nervenfärbung in Methylenblau zu einer wertvollen wissenschaftichen Methode für die Erforschung des Nervengewebes. Gegenwärtig muss sie als das beste Verfahren für die feinere Untersuchung der Verteilung und Endigung der Nerven sowie auch für die Untersuchung der Fortsätze der Nervenzellen anerkannt werden.

Von dieser Zeit datiert eigentlich eine neue Ära in der Histologie.

Es erschien nun eine ganze Reihe von Arbeiten über die feinsten Verzweigungen der Nerven und über Nervenendigungen von ver-

1) Arnstein schlug eine gesättigte Jodlösung in 1 prozentiger Jodkaliumlösung sowie Jodquecksilber vor.

Smirnow-Hoy ersches Pikrokarmin.

Dogiel, A. - eine gesättigte Ammoniumpikratlösung.

2) Anmerk. Ich besitze Präparate der Iris einer weissen Katze und eines Kaninchens vom Jahre 1891. An diesen, in Methylenblau gefärbten Präparaten sieht man auch jetzt noch mit genügender Deutlichkeit sowohl die stärkeren Nervenstämmchen, als auch deren feinste Verästelungen und sogar das oberflächliche Endretz.

v. Graefe's Archiv für Ophthalmologie. LXXXII, 2. 
schiedener Form, von welchen wir bis dahin fast gar keine Kenntnis gehabt hatten.

Im Gebiete der Ophthalmologie wurde diese Methode behurs der Erforschung der Nerven in den verschiedenen Teilen des Auges angewandt.

In dieser Richtung ausgeführte Cntersuchungen haben die folgenden Autoren veröffentlicht:

Prof. Arnstein, Zur Frage der Nervenendigungen in der Cornea. Sep--Abdr. aus: Arbeiten d. Naturforschergesellsch. an d. Univ. Kasan. Bd. XX. 1889 (in russischer Sprache).

Dogiel, A., Die Nerven der Cornea. Anat. Anz. Nr. 16 u, 17. 1890.

- Die Hornhautnerven des Menschen. Ophth. Bote (Westnik Ophthalmologii). 1891 (in russischer Sprache).

- Die Nervenendkörperchen (Endkolben W. Krause) in der Comea und Conjunetiva bulbi des Mensehen. Arch. f. mikrosk. Anat. Bd. XXXVII 1891.

- Über die nervösen Elemente in der Retina des Menschen. Arch. f. mikrosk. Anat. Bd. XXXVIII u. XL. - Anat. Anz. Bd. III.

- Die Nervenendigungen im Lidrande und in der Conjunetiva palp. des Menschen. Areh f. mikrosk. Anat. Bd. XLIV.

- Die Nervenendigungen in den Tränendrüsen der Säugetiere. Arch. f. mikrosk. Anat. Bd. XLII.

Stepanoff, Die Nerven der Iris. Diss. Tomsk 1892 (russisch).

Tepläschin, A., Zur Lehre von den histologischen Veränderungen der Retina nach Verwundungen. Diss. Kasan 1893 (russisch).

Agababow, A., Über die Nervenendigungen im Ciliarkörper bei Säugetieren und beim Menschen. Diss. Kasan 1893 (russisch).

- Uber die Nerven der Sklera. Kasan 1901 (russisch).

-.. - Arch. f. mikrosk. Anat. 1904.

Smirnow, A., Die weisse Augenhaut (Sklera) als Stelle der sensiblen Nervenendigungen. Anat. Anz. Bd. XVIII. 1900.

Nelkich, A, ther die Nervenendigungen im Ciliarkörper bei Vögeln. Anat. Anz. 1895 .

Hosch, Ehrlichs Methylenblaumethode und ihre Anwendung auf das Auge. Mitteil. aus d. norm. anat. Inst. in Basel und v. Graefe's Arch. f. Ophth. Bd. XXXVII, 3 .

Seidenmann, Histologische Untersuchung des Nervensystems der Chorioidea des Anges. Diss. St. Petersburg 1899 (russisch).

Andogski, X., Zur Frage über die Ganghenzellen der Iris. Arch. f. Augenheilk. 1897.

Eleonskaja, W., Utber die Nervenendigungen in der Sklera der Sångetiere. Diss. St. Petersburg 1911 (in russischer Sprache).

Wera Kirpitschewa-Leontowitsch, Zur Frage der Innervation der Iris beim Kaninchen. v. Graefe's Arch. f. Ophth. Bd. LXXIX, 3. 1911.

Gegenwärtig sind wir im stande, das Methylenblan nicht immer nach einer und derselben Methode, sozusagen schablonemmässig anwenden zu müssen, sondern wir können behufs einer erfolgreichen Nervenfäroung die eine oder die andere Modifikation der Methode zu Hilfe nehmen, wobei man den Charakter der Gewebsstruktur, die Dicke der Gewebsschicht, den grösseren oder geringeren Gefässreichtum des vorliegenden Gewebes usw. in Erwägung zieht. 
1. Anfangs wurde von Ehrlich selbst und dann auch von seinem Sehüler Aronson das Methylenblau in einer Lösung von 1:300 oder 400, d. h. in einer $1 / 3-1 / \%$ igen Lösung in das Blutgefässsystem des lebenden Tieres injiziert.

Prof. Arnstein, Smirnow u. A. erhielten eine gute Nervenfärbung bei Injektion konzentrierterer, namentlich 3 - und $4 \%$ iger Lösungen des Farbstoffes (als Lösungsmittel diente eine physiologische Kochsalzlösung). Hierbei wurde die Injektionsflüssigkeit vorhergehend bis zur Körpertemperatur des Versuchstieres erwärmt und filtriert.

Während meiner mehrjährigen Beschäftigungen in Prof. Arnsteins Laboratorium untersuchte ich die Nerven in den Augenhäuten nach verschiedenen Methoden und gelangte bierbei zu der Überzeugung, dass eine völlig genügende Nervenfärbung sowohl bei Injektion konzentrierter (2-3 bis $4 \%$ iger) als auch sehwächerer (namentlich $1 \%$ iger und noch schwächerer, bis $1 / 5 \%$ iger) Lösungen in die Blutbahn erzielt werden kann. Nimmt man noch schwächere Lösungen - von ${ }^{1 / 10}-\left.1\right|_{20} \%$, so tritt zwar ebenfalls eine Nervenfärbung ein, doch ist sie blass und erfordert mehr Zeit, d. h. sie erfolgt verhältnismässig spät.

2. Die Nervenfärbung in Methylenblau lässt sich auch bei einer lokalen Anwendung des Farbstoffes zuwege bringen. So injizierte Andogsky behufs Förbung der Irisnerven einige Tropfen einer $\left.{ }^{1}\right|_{20} \%$ igen Lösung des Farbstoffes in die Augenkammer oder aber in den Glaskörper des Kaninchenauges. Vor ihm hatte Tepläschin das nämliche Verfahren behufs Nervenfärbung der Retina angewandt (siehe S. 8 seiner Dissertation).

3. Prof. A rnstein erzielte eine gute Nervenfärbung (in der Cornea), wenn das Methylenblau in den enueleierten und über einem Glasgefäss hängenden Augapfel geträufelt wurde. Das Verfahren beschreibt Prof. Arnstein wie folgt. "Der Augapfel eines soeben getöteten Tieres (Katze, Hund oder Kaninchen) wurde aus der Augenhöhle enucleiert und dann hinter dem Äquator derart durchschnitten, dass das hintere Segment un ein Beträchtliches kleiner als das vordere war. Dann leerten wir den Skleralsack, d.h. wir entfernten Glaskörper und Linse, wobei die Retina and Chorioidea intakt blieben. Hierauf hängten wir den Corneoskleralsack mit Nadeln derart an einem Glasgefäss auf, dass die kreuzweise dureh die Sehnittränder der Sklera durchgestochenen Nadeln mit ihren Enden auf dem Glasrande auflagen. In den Skleralsack gossen wir eine 4-5\% ige Methylenblaulösung und binnen einer 1/4 Stunde wurde, nach vorhergehender Entfernung der Chorioidea, die Hornhaut ausgeschnitten" ... „War die Linse nicht herausgenommen worden, so tritt die Nervenfärbung, wenigstens beim Kaninchen, erst nach einer oder nach anderthalb Stunden ein."

Dieses Verfahren ist von Prof. Arnstein behufs Färbung der Hornhautnerven angewandt worden. Auf seinen Vorschlag benutzte ich dasselbe auch zur Färbung der Nerven in der Chorioidea. Hierbei wurde indes nur ein geringer Teil vom Glaskörper entfernt, die Linse unberührt in situ liegen gelassen. In vielen Fällen erhielt ich nicht nur eine Färbung der Nervenfasern, sondern auch die Ganglienzellen traten sehr dentlich hervor. Zu dem Behufe erwies sich aber eine schwäehere Methylenblaulösung, namentlich im Verhältnisse von 1:10000 als die geeignetste; hierbei wurde 
eine rascher eintretende Färbung erhalten, wenn das über dem Glasbecher hängende Auge etwa für 1 Stunde in den Thermostat kam. Das erwähnte Verbalten der Temperaturerhöhung war auch schon der Aufmerksamkeit der vorhergehenden Beobachter nicht entgangen.

Hieranf wurde das Ange in meridionaler Pichtung in zwei Teile zerschnitten, an jedem von ihnen laterale Einschnitte gemacht und, nach Entfernung des Glaskörpers and der Linse, das auf dem Objekttäăer ausgebreitete Präparat der mikroskopischen Kontrolle unterworfen. Nach Eintreten einer vollständigen Nervenfärbung wurde das Präparat in Ammoniumpikrat fixiert.

4. Sehr einfach und bequem ist die von A. Dogiel vorgeschlagene Methode der Nervenfärbung: ein auf dem Objektträger ausgebreitetes Stückchen des zu untersuchenden Gewebes wird mit einigen Tropfen einer $1 / 16{ }_{0}$ igen Methylenblaulösung befenchtet und in den Thermostat gebracht; in kurzen Zeitintervallen wird das Präparat bei schwacher Vergrösserung auf den Färbungsprozess kontrolliert, und sowie die gewünschte Färbung eingetreten ist, fixiert man letztere mit Ammoniumpikrat.

In betreff der Details und Modifikationen dieses Verfahrens empfehlen wir den Leitfaden ron A. Dogiel, betitelt: "Techuik der Methylenblautinktion des Nervensystems". 1902. St. Petersburg (russisch).

Bei der Untersuchung der Gewebe des menschlichen Körpers sowie speziell in pathologischen Fällen sind wir meiner Ansicht nach ausschliesslich auf das letztbescluriebene, als das einzig anwendbare Verfahren angewiesen. Dr. Tepläschin war der erste, welcher dieses Verfahren zu pathologischen Zwecken bei seinen experimentellen Untersuchungen der Retina nach deren Verletzung anwandte.

Prof. Dogiel und seine Schüler, sowie nachträglich auch andere Forscher, haben diese Methode behuts Nervenfärbung in verschiedenartigen Geweben und bei verschiedenen Tierspecies mit Erfolg benutzt.

Auch ich bediente mich dieser Methode behufs Färbung der Nerven im Ciliarkörper und in der Retina des menschlichen Auges, ebenso wie zur Nervenfärbung in der Chorioidea und Iris weisser Katzen und Kaninchen; ich muss notieren, dass verhältnismässig die besten Resultate im Ciliarkörper des Mensehen mit Hilfe der schwächeren Methylenblaulösungen, namentlich im Verhältnis von 1:5000 erreicht wurden.

5. In mehreren Fällen erhielt ich eine sehr prompte und reine Nervenfärbung in der Hornhaut, Iris und Conjunctiva nach Eintränfelung einer Nethylenblaulosung von 1:5000, 1:2000 in den Conjunctivalsack des lebenden Tieres.

Binnen 25-30 Minuten nach dem Einträufeln wird dem chloroformierten Tiere der vordere Teil des Augapfels herausgeschnitten und nach Konstatierung der Nervenfärbung in die fixierende Lösung gelegt.

6. Behufs Färbung kleiner Gewebsstücke kann auch das von Apathy vorgeschlagene Verfahren benutzt werden. Es besteht darin, dass Stückchen des betreftenden Gewebes in schwache Methylenblaulösungen (1:1000 bis 1: 100000) getaucht werden. Nach A pathys ejgenen Beobachtungen tritt die Nervenfärbung desto später ein, je schwädher die Farbstofflösung ist.

Alle Beobachter mit Ausnahme Apathys schreiben dem freien Zu- 
tritte des Sauerstoffes der Luft zu dem sich färbenden Gewebe die Bedeutung eines für den Erfolg notwendigen Momentes zu.

Und in der Tat hat man jedesmal Gelegenheit sich zu überzengen, dass eine Nervenfärbung dann eintritt, wenn das Präparat nicht mit dem Deckglase bedeckt und nur ein wenig von der Flüssigkeit befeuchtet, wenn also ein genügender Luftzutritt ermöglicht ist; ferner wird eine rasche und gleichmässige Färbung der Nerven begïnstigt, wenn in dem Präparate während des Experimentes eine der Körperwärme des Tieres nahestehende Temperatur unterhalten wird.

Zu diesem Behufe wird das Präparat für eine Zeitlang in den Thermostat gebracht, oder es wird die entsprechende Temperatur mit Hilfe eines heizbaren Objekttisches unterhalten. $\mathrm{Zu}$ einer genügenden Färbung sind 15 Minuten bis zu 1 Stunde und melr erforderlich, was sowohl von der Dieke des Gewebsstückes als auch ron der Färbungsmethode selbst abbängt; ist eine genügend vollständige Färbung eingetreten, so muss das Präparat unverzüglich in die fixierende Flüssigkeit übertragen werden, sonst verblasst die Färbung und verschwindet raseh.

Die soeben aufgeführten Bedingungen sind wohl zu berücksichtigen, da in einem aus dem Körper ausgeschnittenen Organe oder Organstückchen der für eine gute Nervenfärbung notwendige lebensfrische Zustand der Gewebe nicht lange erhalten bleibt. Dann aber tritt, noch ehe die differentielle Tinktion der Nerven erfolgen konnte, bereits eine postmortale Gewebsfärbung ein.

Es hat sich also das Methylenblau behnfs Nervenfärbung in verschiedener Anwendungsweise bewährt, und zwar: bei Injektion in die Blutgefässe sowohl in konzentrierten ( $3-4 \%$ igen, Arnstein) als auch in schwächeren, $1 / 3-1 / 4 \%$ igen (Ehrlich), ebenso wie auch in weit schwächeren (bis $1 / 20 \%$ igen) Lösungen, Seidenmann, Leontowitsch-Kirpitschowa; bei der Färbung ausgeschnittener, isolierter Stückchen auf dem Objektträger kamen ${ }^{1} / 16-1 / 15 \%$ ige (Dogiel), $\left.{ }^{1}\right|_{50}-1 / 100 \%$ ige (ich) Lösungen zur Anwendang, während Apathy Gewebsstückehen in Methylenblaulösungen von 1:1000, $1: 100000$ eintauchte.

Ebenso wurden schwache Methylenblaulösungen bei Injektion derselben in den Augapfel, in die vordere Angenkammer, in den Conjunctivalsack oder aber in den Glaskörper des (nach Arnsteins Methode) aufgehängten Corneoskleralsackes angewandt.

Zweifelsohne bietet die Nervenfärbung am ausgeschnittenen Organe oder Gewebsstückchen grosse Vorteile im Vergleich mit der Injektion des Farbstoffes ins Blut, besonders wenn es sich um eine Nervenfärbung in pathologisehen Fällen (Tepläschin) oder in Geweben des menseblichen Körpers handelt. Allein der Mangel dieser Methode liegt darin, dass infolge des Absterbens des ausgeschnittenen Gewebes, ausser der Nervenfärbung, mitunter aber sogar vor derselben eine Tinktion anderer Gewebselemente sich einstellt. Ausserdem vermag das Methylenblau bei lokaler Anwendung natürlich nicht gleichmässig. und gleichzeitig in die Tiefe des Gewebes einzudringen, wie dieses bei der Injektion in die Blutgefässe wohl erreicht wird, und beschränkt sich daher die Nervenfärbung am ausgeschnittenen 
Stückchen hauptsächlich auf die peripheren und mehr oberfächlichen Gewebspartien.

Das beste Fixierungsmittel für das Methylenblau ist das Ammoniumpikrat in gesättigter wässriger Lösung. Hier verbleiben die Präparate, je nach ihrer Grösse und Dicke, 2-3 bis 24 Stunden.

Doch muss in Betracht genommen werden, dass das Gewebe in dem Ammoniumpikrat sehwillt, lockert, die Epitheldecke sich leicht ablöst und dass ein so feines und zartes Gewebe wie die Retina sehr zerreisslich wird. Angesichts des Gesagten ist es vorteilhafter, derartige zarte Präparate wie die Netzhaut u. dgl. nach vollendeter Färbung auf dem Objektträger liegen zu lassen und auf demselben auch die Fixierung vorzunehmen; nach 2-4 Stunden wird die Fixierungsflüssigkeit durch ein Aufhellungsmittel namentlich durch Glycerin - ersetzt, wobei es zweckmässiger ist, das Glycerin zur Hälfte mit der fixierenden Ammoniumpikratlösung zu verdünnen. Dann kommt ein Deckglas auf das in dem Giycerin befindliche Präparat.

In wenigen Tagen ist die Aufhellung des Präparates soweit vorgeschritten, dass die Nerven bis in ihre feinsten Verzweigungen zutage treten.

Anstatt des Ammoniumpikrates empfiehlt Prof. Dogiel gegenwärtig: eine 5-8\% ige Ammoniummolybdatlösung; in dieser Lösung verbleiben die Präparate, je nach ihrer Dicke, 40 Min. bis 24 Stunden; darauf wird das Präparat $1 / 2-3$ Stunden lang in destilliertem Wasser ausgewaschen. Dann kommt es fuir eine kurze Zeit $(1 / 4-4$ Stunden) in absolnten Alkohol, schliesslich in Xylol und Kanadabalsam.

Das Ammoniummolybdat war bereits früher von Bethe vorgeschlagen worden, indes war das Verfahren des genannten Autors ein sehr kompliziertes. Es wurde vielfach nachgeprüft, erwies sich aber als wenig genügend, da es die Nervenfärbung schlecht fixierte.

Dagegen hat es sich herausgestellt, dass die Nervenfärbung bei dem so einfachen Verfahren, wie es Dogiel anwendet, dauerhaft fixiert wird und selbst nach der Härtung in Alkohol, Aufhellung in Xylol und Einschluss in Kanadabalsam nicht schwindet.

In der von Leontowitsch vorgeschlagenen Modifikation liefert das Ammoninmmolybdat zufolge der Ansicht von Dogiel keine befriedigenden Resultate.

\section{Die Ciliarnerven.}

Dank den Arbeiten ron E. Brücke ${ }^{1}$, H. Müller ${ }^{2}$ ), Krause ${ }^{3}$ ), Iwan off 4 ), Jerofejew ${ }^{5}$ ), Schwalbe u. A. wissen wir, dass die vom

1) Brücke, E., Anatomische Beschreibung des menschlichen Augapfels. 1847.

2) Müller, H., Über glatte Muskeln und Nervengeflechte der Chorioidea im menschlichen Auge. Gesammelte und hinterlassene Schriften zur Anatomie und Physiologie des Auges.

3) Krause, W., Anatomische Untersuchungen. 1861.

4) Iwanoff, Tractus uvealis. Traité complet d'ophtalmologie par Wecker et E, Landolt. T. II, 2.

5. Jerofejew, Zur Lehre von den Muskeln im Inneren des menschlichen Auges. Diss. 1880 (in russischer Sprache). 
Trigeminus, Oculomotorius und Sympathicus entstammenden Ciliarnerven, in einer Zahl von 8-14 (Iwanoff, 14-18, Jerofejew, 6 -8 n. Sernow) Ästchen aus dem Ganglion ciliare treten. Diese, als sog. Nervi ciliares breves, sowie die in Zahl von $2-3$ ron dem Ramus nasociliaris n. trigemini sich abzweigenden, sog. Nervi ciliares longi, nehmen ihren Weg zum Augapfel und durchbohren die Sklera unweit der Eintrittsstelle des N. opticus. Darauf dringen sie in das Innere des Augapfels und verlaufen zwischen Sklera und Chorioidea nach vorn.

Zufolge den Untersuchungen von Dr. I. E. Egorow ${ }^{1}$ ) verlieren sich einige aus dem Ganglion ciliare austretende Ästchen in den Nerrenscheiden des Optikus, im Fettzellgewebe, an den Gefässwänden und in den äusseren Augenmuskeln (loc. cit. S. 98).

Anmerkung. Vor dem Erscheinen der Arbeiten Brückes und H. Müllers existierten manche, einander widersprechende Ansichten betreffend die Ciliarnerven. Porterfield ${ }^{2}$ ) und $\mathrm{Kn} \bullet \mathrm{x}^{3}$ ), welche im Ciliarkörper bei Vogeln und Säugetieren Muskelfasern gefunden und dieselben "Musculus ciliaris" genannt hatten, behaupteten zahlreiche zu diesem Muskel verlaufende Nerven gesehen zu haben.

Hueck ${ }^{4}$ ( Weber ${ }^{5}$ ) u. A. haben im Ciliarkörper des Menschen Nerven gefunden. Valentin ${ }^{6}$ ) behauptet, dass man sich von dom Nervenreichtum der Chorioidea und des Ligamentum ciliare leicht überzeugen könne; und nach $\mathrm{L}_{1} \mathrm{u} \operatorname{schk} \mathrm{a}^{\mathrm{7}}$ ) erreichen die an der äusseren Oberfläche der Chorioidea verlaufenden Nerven den Ciliarkörper (Ciliarband) und verästeln sich teils in dem letzteren und in der Iris, teils in der Cornea.

Bochdalek ${ }^{8}$ ) und Pappenheim ${ }^{9}$ ) haben diese Nerven ebenfalls gesehen. Indes, keiner der aufgeführten Autoren beschreibt genauer den Verlauf und die Verteilung dieser Nerven. Daher erscheint es zweifelhaft, wie auch H. Müller mit Recht bemerkt, ob diese Autoren auch tatsäcblich nur Nerven beschreiben; besonders wenn man erwägt, dass z. B. Bochdalek den Ciliarmuskel für ein Ganglion und die Lamina fusca für einen Nervenplexus hält (siehe H. M üller, S. 205, Anmerk.). Anderseits teilt Fr. A rnold ${ }^{10}$ ) mit, er habe weder Zeit noch

1) Egorow, I, Über das Ganglion ciliare. Eine anatomisch-physiologische Untersuchung. Diss. Kasan 1886 (in russischer Sprache).

2) Porterfield, On the eye. Vol. II. Citiert nach Fr, Arnold.

3) Kox. Frorieps Notizen. Bd. VII. Ibid.

4 Hueck, De mutationibus oculi internis. Ibid.

5) Weber. Graefe's u. Walters Journ. Bd. XI. Ibid.

6) Valentin, Über den Verlauf und die letzten Enden der Nerven. Nova acta physico-medica Academiae Caesareae Leopoldino-Carolinae. T. XII. 1836.

7) Lu schka, H., Die Strukțur der serösen Härte des Menschen. 1851. S. 53.

${ }^{8}$ B Bochdalek. Prager Zeitschr. 1850. Citiert nach H. Müller.

9) Pappenheim, Gewebelehre des Auges. Ibid.

10) Arnold, Fr., Anatomische und physiologische Untersuchungen uber das Auge des Menschen. 1832. 
Mühe gespart und dennoch keinen einzigen Nervenfaden im Ciliarkörper gesehen. Daher werde er sulange an dem Vorhandensein dieser Nerven zweifeln, bis er sie selbst gesehen, und müsse vorläufig annehmen, dass der Ciliarkörper sowie auch die Chorioidea nicht mit Nerven versehen seien, wenigstens nicht mit solchen, die von den Ciliarnerven stammten (S. 59).

Während ihres ganzen Verlaufes im Inneren des Bulbus entsenden die Nervi ciliares breves zahlreiche, aus markhaltigen sowie auch marklosen Nervenfasern bestehende Aste. Diese Verästelungen teilen sich ihrerseits and ein Teil derselben bildet in der hinteren Augenhälfte einen Plexus, welcher der Aussenfläche der Chorioidea anliegt. Die feineren $Z$ weige verlieren sich in den Wänden der Blutgefässe (Arterien), indem sie zweifellos für die Gefässmuskulatur bestimmt sind (H. Muller, S. 206). In diesem Geflechte findet man einzelne wie auch in Gruppen vereinte Ganglienzellen (H. Müller, Schweigger).

Die ganze übrige Masse der Nervenäste legt einen langen Weg zwischen Sklera und Chorioidea zuriuck und erreicht so den Ciliarkörper, wo sich unter mehrfachen Teilungen und gegenseitiger Kreuzung der Nerven ein an der äusseren Fläche des Ciliarkörpers verbreiteter Plexus bildet(Orbiculus - plexus gangliosus - ciliaris, W. K rause). Die Nervi ciliares longi begeben sich zur Iris und nehmen nur beiläufig Anteil an der Bildung des Plexus gangliosus ciliaris (Jerofejew). Dieser Plexus enthält in seinen feinen ebenso wie auch in seinen stärkeren Stämmchen multipolare, häufiger birnförmige Ganglienzellen, deren Durchmesser etwa $12 \mu$ beträgt. Dieselben werden entweder einzeln oder in Gruppen zusammenliegend angetroffen (H. Müller, Krause).

Dieser Plexus sendet einzelne Nervenstämmchen in die Iris und in die Cornea, und in dem Ciliarkörper bleibt noch eine Anzahl von Nerven übrig, welche in den Ciliarmuskel eintreten und zwischen dessen Schichten endigen (Iwanoff). "Aus diesem Plexus," sagt Schwalbe (S. 196), ,zweigen sich feine Fäden ab, deren Enden im Nuskel unbekannt sind."

Dies sind in Kürze die von früheren Beobachtern auf Grund sorgfältiger Untersuchungen, obschon mittels wenig rollkommener Nethoden, gewonnenen Kenntnisse über den Verlauf und die Verteilung der Nervi ciliares.

\section{Die Nerven der Cornea.}

Seit der Entdeckung Schlemms ${ }^{1}$, welcher zuerst Nerven in

1) Schlemm, Canalis Schlemmii und Nerven der Cornea. Zeitschr. f. Ophth. Mả. I. 
der Hornhaut nachgewiesen hat, bis auf die Gegenwart lassen sich etwa 80 Arbeiten über die genannten Nerven aufzählen. Die Mehrzahl der einschlägigen Untersuchungen fällt auf die Zeit von Anfang der 60 iger bis Ende der 80 iger Jahre, d. h. seit der Anwendung der Cohnheimschen Chlorgoldmethode bis zur Einführung des Methylenblaus in die Histologie.

In der der Vergoldung vorhergehenden Periode lernen wir den Verlauf und die Verzweigung der stärkeren Nervenstämmchen in dem Hornhautgewebe kennen.

Während der Periode der weiteren Entwicklung der Goldmethode und Ausarbeitung ihrer verschiedenen Modifikationen werden auch die Teilungen der feineren Nervenfasern und -fäden bis in ibre Endigungen im Epithel der Beobachtung zugänglich, ja es wird selbst das Verhalten der Nerven zu den Gewebselementen der Cornea ins Auge gefasst. Hoyeri) und Cohnheim ${ }^{2}$ ) beschrieben den Durchtritt der Nerven durch die Membrana basalis (Reichert) aus dem Grundgewebe in die Epithelschicht. Cohnheim und Kölliker ${ }^{3}$ ) gaben eine Beschreibung der horizontalen Nervenfäden in den oberflächlichen Epithellagen.

Mit Einführung des Methylenblaus als einer histologischen Methode der Nervenfärbung erschienen in kurzer Zeit die Arbeiten zweier Autoren, welche sich bei der Entwicklung und Anwendung dieser Methode besonders hervorragende Verdienste erworben haben, nämlich: die Arbeit Prof. Arnsteins") "Über die Nerven der Cornea" bei Kaninchen, Frosch, Taube und Hund, und die von A. Dogiel ${ }^{5}$ ) "Über die Hornhautnerven des Menschen".

In den Händen dieser Autoren enthüllte die neue Färbungsmethode Nervenendformen, welche den vorhergehenden Forschern ganz unbekannt geblieben waren.

1) Hoyer, a) Über den Austritt von Nervenfasern in das Epithel der Hornhaut. Arch. f. Anat. u. Physiol. 1866. S. 180.

b) Über die Nerven der Hornhaut. Arch. f. mikrosk. Anat. Bd. IX. S. 220.

2) Cohnheim, Über die Endigung der sensiblen Nerven in der Hornhaut der Säugetiere. Arch. f. pathol. Anat. Bd. XXXVIII.

3) Kölliker, Über die Nervenendigungen in der Hornhaut. Würzburger naturw. Zeitschr. Bd. VI.

4) Arnstein. Protokolle der Naturforschergesellsch. an der Univ. Kasan. Jahrg. 1889 (in russischer Sprache).

5) Dogiel. Ophth. Bote (Westnik ophtalmologii). 1891 (russisch). Anat. Anz. 1890. Arch. f. mikrosk. Anat. 1891. 
Durch Golgis Methode wurde in diesem Gebiete nur wenig des wesentlich Neuen erbracht.

Unsere Kenntnisse über den Verlauf und die Verteilung der Nerven in der Hornhaut lassen sich folgendermassen zusammenfassen:

1. Die für die Cornea bestimmten Nervi eiliares liegen in der Sklera nach aussen vom Schlemmschen Kanal und bilden hier, am Hornhautrande, ein ringförmiges Geflecht (Plexus annularis). Ein Teil der Nervenfasern dieses Geflechtes durchbohrt an verschiedenen Punkten die Sklera in schräger Richtung, um von hier in die Conjunetiva einzudringen (Oberflächlicher Anteil von H. Virchow, loc. cit. S. 186), woselbst sie mit den eigenen Nerven der Conjunctiva sich verflechten und an der Bildung eines daselbst befindlichen Plexus teilnelmen. Aus dem letztgenannten Plexus zweigen sich marklose Fasern ab, welche in den Limbus corneae eintreten, woselbst sie mit den Nerven der oberfü̈chlichen Hornhautschichten sich verflechten und an der Bildung des Plexus subbasalis von Hoyer beteiligen.

2. Der grössere Teil der Nervenstämmehen dagegen tritt aus dem Plexus annularis ans und wendet sich in radiärem Verlauf in das Grundgewebe der Cornea, woselbst sie sich alshald zu einem Geflechte, dem sog. Grundplexus (Stromaplexus) vereinigen. Die in die Hornhaut eindringenden Nervenfasern verlieren ihre Markscheide bald nach jhrem Eintritte in die Cornea, namentiich in einer Entfernung von $0,3-0,5 \mathrm{~mm}$ von ihrer Eintrittsstelle (Schwalbe, Anat. d. Sinnesorg., S. 165).

Die Zahl der an der Hornhautperipherie in die genannte Haut eintretenden Nervenstämmchen beträgt beim Menschen nach Saemisch $\left.{ }^{1}\right) 40$ bis 45 , nach Krause $\left.{ }^{3}\right) 40-60$, nach Schwalbe etwa 60 , nach Dogiel ${ }^{3}$ ) 60-80. Bei dem Rinde, der Taube, dem Froseh zählt W. Krause im ganzen 15-20 solcher Stämmchen; beim Menschen liegen 40-50 der vorderen Hornhautfläche näher, während 20-30 Stämmehen tiefer, der hinteren Hornhantfläche näher gelagert sind (Dogiel).

Die gröberen Nervenstämmchen liegen in Kanälen (Nervenkanälen), welehe letzteren innen mit einem Endothel bedeckt sind und mit Saftlücken in Verbindung stehen.

Die feineren Nervenfasern verlanfen, gemäss der Ansicht einiger Autoren, ebenfalls in Kanälen, die man als zum System der Saftlïcken gehörig betrachten kann, während zufolge anderen Autoren (Ranvier) diese Nervenfasern innerhalb der Bindegewebsbündel verlaufen (Schwalbe, Anat. d. Sinnesorg., S. 165); nach H. Virchow werden die Nervenkanäle von der Grundsubstanz selbst begrenzt.

Die Details und eine Kritik der verschiedenen Ansichten über die Nervenkanäle gibt H. Virchow (Graefe-Saemisch. 2. Aufl. S. 213. Teil I. Bd. I. Kap. II).

ग) Saemisch, Beiträge zur normalen und pathologischen Histologie des Auges. Leipzig 1862.

2) Krause, W. Allgem. u. mikrosk. Anat. 1876.

3) Dogiel, A., Die Nerven der Cornea des Menschen. Anat. Anz. 1890. S. 483 . 
Aus dem Randgeflechte (Plexus annularis) treten, wie gesagt, Nervenstämmehen in die Cornea ein, um hier untereinander sich verflechtend mehrere, in versehiedenen Höhen der Hornhaut gelegene Plexus zu bilden (mehrschichtiger Plexus nach Hoyer, Plexus fondamental nach Ranvier, Grundplexus nach Schwalbe, Hauptgeflecht nach Dogiel).

In den tieferen Schichten besteht das Geflecht aus gröberen Nervenstämmehen und dringt weiter gegen das Zentrum der Cornea vor; in den mittleren und oberflächlichen Schichten dagegen werden die Nervenstärmmchen und -bündel immer feiner und feiner (Ranvier a. A.). Fast eine jede Schicht der Cornea besitzt, nach der Aussage Dogiels'), ein eigenes Geflecht, und nur in den hintersten, der Membrana Descemetii anliegenden Sehichten ist keines vorhanden.

D'ailleurs, sagt Waldeyer, on ne rencontre guère chez les animaux des couches, où ces réseaux à larges mailles feraient defaut.

In der Nähe der Bowmansehen Membran, mithin in den vordersten Hornhautschichten, findet sich ein Geflecht feiner Nervenfäden, welches Hoyer als Plexus subbasalis, Waldeyer ${ }^{2}$ ) als "Plexus à mailles étroites du stroma" beschreiht, während dagegen H. Virchow sagt, ,dass dies nichts anderes ist, als ein Teil des Popriagerüstes, sich aber durch reichliche Anastomosenbildung anszeichnet ${ }^{3}$ ).

Die sog. Rami oder Fibrae perforantes (Hoyer) sind diejenigen Nervenbündelchen oder -fäden, welche aus dem Grundplexus der Hornhaut austreten, in schräger Richtung die Bowmansche Membran durebbohren und an der äusseren Fläche dieser letzteren unter der Epithelsehicht sich ausbreiten, indem sie hier ein Geflecht - den Plexus subbasalis - bilden.

Von diesem Plexus zweigen feine Fädchen $a b$, die in die Epithelschichten eindringen und hier unter gegenseitiger Verflechtung zu einem zwischen den Epithelzellen liegenden Geflecht - dem Plexnis intraepithelialis (Hoyer) - zusammentreten.

Zur Untersuchung der Hornhautnerven ist das Methylenblau zuerst von Prof. Arnstein ${ }^{4}$ ) angewandt worden, indem er den Earbstoff in die Blutgefässe injizierte oder aber eine $4-5 \%$ ige Lösung desselben in den Sklerocornealsack einträufelte (das Nähere über die betr. Technik siehe höher oben). Bei Kaninchen, Frosch, Taube und Hund wies Arnstein nach, dass in den Bestand der Rami perforantes zwei Kategorien der Nervenelemente treten:

a) Die einen nehmen teil an der Bildung des Plexus subepithelialis und steigen dann aus diesem Plexus in Gestalt feiner Fäden

1) Dogiel. loc. cit. S. 492.

2) Waldeyer. Traité d'ophtalmologie p. Wecker et Landolt. T. II. p. 48.

3) Virchow, H. Handb. v. Graefe-Saemisch. 2. Aufl. S. 193.

*) Arnstein, Über die Nerven der Hornhaut. Protokolle d. Naturforseher gesellschaft an d. Univ. Kasan. 1890 (in russischer Sprache). 
in das Epithel empor, woselbst sie zu dem Plexus intraepithelialis sich verflechten. In den mittleren Epithellagen bilden sie ein Endnetz.

b) Die andern dringen, indem sie am Plexus subepithelialis vorbeigehen, direkt in das Epithel ein und treten nur zum Teil in den Bestand der pinselförmigen Endbüschel der Rami perforantes; von den ersteren unterscheiden sie sich durch ihre grössere Dicke, sowie dadurch, dass sie in Form von Anschwellungen oder Häkchen endigen (s. loc. cit. Fig. 5). Letztere liegen ganz oberflächlich im Epithel, ohne jedoch dessen Oberfläche zu überragen. (Mitunter sieht man an diesen Nervenendigungen kurze, gleichsam haarförmige Fädchen eine Degenerationserscheinung.)

"Ungeachtet dessen," sagt der Autor, „dass ich mich anfangs diesen freien Endigungen gegenüber sehr skeptisch verhielt, indem ich eine unvollständige Färbung vor mir zu haben glaubte, gelangte ich schliesslich dennoch zu der Überzeugung, dass diese relativ groben, gewundenen Fasern ein besonderes System der Nervenendigungen bilden, welches weder mit dem subepithelialen Geflechte noch mit dem hauptsächlich die mittleren Epithellagen durchsetzenden Endnetze verbunden ist...., sondern frei endet, indem es sich als ein System sehr charakteristischer, schon bei schwachen Vergrösserungen kenntlicher Gebilde herausstellt."

Mithin unterscheidet Prof. Arnstein in der Cornea Endapparate von zweierlei Art:

a) ein Endnetz, welches sich aus dem subepithelialen Plexus entwickelt und die tiefen Epithellagen einnimmt, und

b) freie Nervenendigungen, die weder mit dem Plexus subepithelialis noch mit dem intraepithelialen Netze verbunden sind (siehe loc. cit. S. $26-27$ ).

Die intraepithelialen Netze werden, wie Prof. Arnstein weiter erklärt, in dem mehrschichtigen Epithel konstant angetroffen.

In dieser Beziehung bietet die Epithelbekleidung der Cutis, der Schleimhäute und der Cornea wesentlich identische Verhältnisse dar.

Diese Nerven müssen den einfach sensiblen Nerven beigezählt werden. Als Reizeffekt der Nervenendigungen dieser Art erklärt sich, wach Prof Arnsteins Ansicht, der auf stäkeren Druck erfolgende Reflex.

Hingegen bedingen die geschlängelt verlaufenden, gröberen Nervenfäden mit ihren ganz oberflächlich ${ }^{1}$ ) gelagerten Endknöpfchen die

1) Analog der in kleinen Tasthaaren des äusseren Ohres und des Schwanzes 
höchst entwickelte Sensibilität, welche selbst nach leiser Berührung mit einem Härchen reflektorisches Blinzeln hervorruft.

Was den fraglichen Zusammenhang der Nerven mit den Hornhautzellen anlangt, so lässt sich nach Prof. Arnsteins Aussage konstatieren, dass die Nerven stets an den Zellen vorbeigehen, obne mit letzteren sich $\mathrm{zu}$ verbinden.

Eigentümliche Nervenendapparate sind von Prof. A. Dogiel') in der Cornea des menschlichen Auges nachgewiesen worden. Er tärbte die Nerven nach seiner eigenen Methode mittels einer ${ }^{1 / 16} \%$ igen Methylenblaulösung auf dem Objektträger. Er fand, dass Nervenfasern von verschiedener Dicke feine Ästchen entsenden und miteinander sich verflechten, derart kommt ein hauptsächlich im gefässhaltigen Anteil der Cornea liegender Randplexus zu stande.

Dieser Plexus besteht aus marklosen Nervenfasern, die von spärlichen markhaltigen Fasern begleitet werden.

Die letztgenannten Fasern treten aus den Nervenbündeln aus und lassen sich auch weiterhin auf ihrem mannigfach geschlängelten Wege verfolgen; sie dringen in die Substantia propria corneae ein, un dann aufs neue in die gefässhaltige Randzone zurückzukehren.

Auf diesem Wege teilen sich viele Fasern an den Ranvierschen Einschnürungen in 2-3 feinere Fasern; diese letzteren zerfallen ihrerseits wiederum in 2-3 kurze Endfäserchen (siehe die sub c) genannte Arbeit Dogiels ${ }^{1}$ ) (Fig. 1-5, 6, 7 u. 8), welche alsbald in Endapparate eintreten. Diese Endapparate nennt der Autor „Endknäuelchen". An der Eintrittsstelle in das Endknäuelchen oder aber noch in einer gewissen Entfernung von letzterem verliert die Terminalfaser ihre Markscheide.

Sowohl in der gefässhaltigen Randzone als auch in der Conjunctiva bulbi liegen diese Endkörperchen sämtlich unterhalb des Epithels.

Diejenigen Endkörperchen jedoch, welche über die Randzone hinaus in die Substantia propria vorragen, liegen unterhalb der Basalmembran und nur selten unmittelbar unter dem Epithel.

bei Mäusen und Ratten von Arnstein und darauf von Hoggan beschriebenen freien Nervenendigungen.

1) Dogiel, A., a) Die Nerven der Cornea. Westnik ophtalmologii. 1891 (russisch).

b) Die Nerven der Cornea des Menschen. Anat. Anz. 1890.

c) Die Nervenendkörperchen (Endkolben W. Krause) in dex Cornea und Conjunctiva bulbi des Menschen. Arch. f. mikrosk. Anat. Bd. XXXVII. 1891. 
Grösstenteils sieht man die Endkörperchen in Gruppen vereint, deren jede je 3-5 und mehr von diesen Gebilden aufweist. Sie sitzen wie Beeren an den Endästen eines oder zweier markhaltiger Nervenfasern.

In der gefässhaltigen Randzone wird eine grosse Anzahl, auf einer Strecke von $1 / 2 \mathrm{~mm}$ etwa 20 dieser Endapparate angetroffen.

Weit spärlicher sind sie in der Substantia propria corneae, dagegen wiederum häufiger in der Conjunctiva bulbi zu treffen. Ein jedes Endkörperchen wird von einer dünnen, mehrblättrigen Kapsel umschlossen, doch tritt diese letztere nur bei Fixierung in Flemmingscher, Müllerscher Flüssigkeit und ähnlichen, sowie nach Färbung der Schnitte mit Hämatoxylin oder Pikrokarmin hervor. Das Methylenblau dagegen dient ausschliesslich zur Darstellung der Nervenendigung.

In dem nicht lebensfrischen Hornhautgewebe vermisst man eine differenzierte Nervenfärbung, dann treten aber die Kerne der Bindegewebskapsel scharf herror.

Von den markhaltigen Nervenfasern zweigen sich 1-2 oder 3 Terminalfasern ab, die an einen Pol des Endkörperchens herantreten. Nachdem sie entweder in einiger Entfernung oder aber unmittelbar vor ihrem Eintritte in das Endkörperchen ihre Myelinscheide verloren haben, dringen sie in das letatere als nackte Achsencylinder ein. Hier teilen sie sich in $2-3$ feine varicöse Fäden, die ihrerseits in noch feinere Fädchen zerfallen, einander umwinden und einen dichten Knäuel bilden ( $4 B$ und $7 C^{\prime \prime}$ ); bei einer geringeren Anzahl der aus einem oder zwei Endästchen hervorgehenden Nervenfäden lrommt ein lockerer Endknäuel zu standé (Fig. $5 c^{\prime}$ und $7 \mathrm{D}$ ).

Einer oder zwei dieser Fäden setzen thren Weg weiter fort, un neve Endknäuel zu bilden.

Eine andere Art der Nervenendigungen stellen die „Endplättchen" dar. In der Substantia propria corneae, $1 / 2-2 \mathrm{~mm}$ weit vom gefässhaltigen Hornhautrande, verlieren die markhaltigen Fasern ihre Markscheide und zerfallen dann in 2-4 varicöse Fädchen, um schliesslich in Gestalt eines Plättchens zu enden. Diese Endplättchen erscheinen in der Flächenansicht als viereckige, unregelmässig abgerundete Gebilde mit gezackten Rändern. Thre Grösse ist verschieden.

Die in Form von Endknöpfchen frei endenden sowie die isoliert verlaufenden, sich windenden Nervenfäden hält der genannte Autor für ein Resultat unvollständiger Nervenfärbung (S. 612-613).

Abgesehen ron den soeben genannten Endapparaten beschreibt 
Prof. Dogiel in einer früheren Mitteilung (siehe Anat. Anz. 1890, S. 490) auch noch "Häkchen" und "Schlingen".

Als ich letzter Zeit meine früheren Untersuchungen über die Nerven in den Augenhäuten wieder aufnahm, beschäftigte mich gleichzeitig auch die Frage der Hornhautnerven beim Kaninchen. Behufs Nervenfärbung wurde von mir eine Methylenblaulösung von 1:100, $1: 200,1: 500-1: 1000$ in die Carotis injiziert ${ }^{1}$ ).

In meinen Hornhautpräparaten habe ich, auch bei gelungener und vollständiger Färbung, 1. freie Nervenendigungen gesehen. So gelang es mir, Nervenfädchen zu verfolgen, welche in eine kleine Endanschwellung in Gestalt einer Keule $\left(a_{1}\right)$ und eines Knöpfchens $(a)$ ausliefen. Sie zeichneten sich durch ihre scharfen Konturen aus und enthielten kleine Ansammlungen in Methylenblau tingierter Körnchen; 2. ferner fand ich Endigungen der Nervenfäden in Gestalt eines Häkchens $(l)$, dessen Ende nach Art einer varicösen Anschwellung sich verdickt, wobei jedoch diese terminale Verdickung die gewöhnlichen Varicositäten der Nervenfäserchen an Umfang übertrifft (siehe Taf. XII, Fig, 27, 28, 29). Vor den Fäden des intraepithelialen Endnetzes unterscheiden sich die frei endenden Nervenfäden nicht nur durch ihr stärkeres Kaliber und ihren varicösen Charakter, sondern auch dadurch, dass sie aus dem Plexus subbasalis hervorgehen und nach einem gewundenen Verlaufe - worauf auch Prof. Arnstein hinweist - in eine der oben benannten Endformen frei auslaufen. Sie liegen in den oberflächlichen Epithellagen; allein man trifft auch solche an, die tiefer unter dem intraepithelialen Netze $(d)$, fast in einem Niveau mit dem subepithelialen Geflechte, oberhalb der Bowmanschen Membran sich befinden.

Diese Endapparate treten schon bei schwacher Vergrösserung sehr kenntlich in Gestalt einer kleinen Verdickung oder eines Knöpfchens hervor (T'af. XII, Fig. 26a,l). Bei starker Vergrösserung (Taf. XII, Fig. 27, 28, 29) aber, besonders bei der Untersuchung mit dem Immersionssystem ${ }^{1}$ ), sieht man deutlich die eigentümliche, einer abgeplatteten Keule ähnelnde Form dieser Endigungen, sowie die scharfen Umrisse derselben; jedoch waren an diesen Endigungen selbst bei starken Vergrösserungen keine haar- oder fadenförmigen Fortsätze wahrzunehmen.

Diese Gebilde habe ich nicht in den peripheren, sondern vielmehr in den zentralen Hornhautpartien angetroffen. Auf ein

1) Das Hornhautpräparat vom Auge des Kaninchens wird, nachdem es eine Zeitlang unter dem Drucke eines Gewichtes gelegen hat, der Untersuchung mittels eines Ölimmersionssystems leicht zugänglich. 
Gesichtsfeld kommen etwa vier Endapparate dieser Art siehe Taf. XII, Fig, $26 a_{2} a_{1}, a_{1}, l$ ).

Auf Grund meiner soeben dargelegten Befunde bin ich iberzeugt, dass die Cornea mit freien Nervenendigungen derselben Art versehen ist, wie ich sie früher in der Sklera konstatiert habe.

Es gelang also mit Hilfe der Methylenblaumethode klarzustellen, dass beim Menschen in der peripheren Hornhautzone komplizierte subepitheliale Nervenendapparate - dichte und lockere Endknäuel und Endplättchen (Dogiel) angetroffen werden; ferner - bei kleineren Säugetieren (Kaninchen, Hund) und ausserdem bei Yögeln (Taube) und bei dem Frosche - Nervenendigungen von zweierlei Art in der Dicke des Hornhautepithels, nämlich ein intraepitheliales Endnetz und Endbäkchen (Arnstein); endlich - beim Kaninchen in den zentralen Hornhautpartien - Endknöpfchen, Endkeulen und hakenförmige freie Nervenendigungen (Agababow).

Unerforscht blieb es, ob das Epithel beim Menschen mit gleichen Nerrenendigungen wie bei Tieren versehen ist und umgekehrt, ob diese letzteren in der Hornhautperipherie analoge Endapparate besitzen, wie solche beim Menschen nachgewiesen worden sind').

Was die Endigungen der Nerven in der Substantia propria corneae - namentlich in der Dicke derselben - betrifft, so hatte man sich hierüber zur Zeit der Goldmethode nur vermutungsweise ausgesprochen; in den Arbeiten der neuesten Zeit aber finden sich keine Hinweise in bezug auf diese Frage. Ebenso ist auch die Frage der trophischen, d. h. zu den Hornhautzellen in Beziehung stehenden Nerven bis jetzt ungelöst geblieben.

Eines unterliegt keinem Zweifel, dass die Goldmethode nicht mehr geben konnte, als es den Forschern gelungen war mit deren Hilfe klarzustellen, nämlich: dass die Nervenfäden an die Zellen herantreten. Jedoch war es unmöglich, das Verhalten dieser Elemente zueinander aufzudecken, weil ja die Zelle wie auch der Nervenfaden durch das Goldchlorid in gleicher Weise gefärbt werden. Daraus erklärt sich die Meinungsverschiedenheit der Autoren: Kühne, Waldeyer, Ciaccio befürworteten den unmittelbaren Zusammenhang der Nerven mit den Stromazellen; Hoyer, Klein und andere Autoren lehnten einen solchen Konnex ab.

1) Auf meinen Vorschlag beschätigt sich die gegenwärtig im Laboratorium der Augenklinik zu Kasan arbeitende Arztin M. N. Miloslawskaja mit einer Untersuchung der oben berührten Fragen. 
Das Methylenblau ermöglicht es, den Sachverhalt wenigstens in dem Sinne genauer zu charakterisieren, dass der Nervenfaden weder mit dem Protoplasma noch mit dem Kerne der Stromazelle in Verbindung steht, sondern dass er - wie Prof. Arnstein sagt - an der Zelle vorbeigeht.

Fast dasselbe sagt auch Dogiel: Die Nervenfasern haben gar keine Beziehung zu den Hornhautzellen und legen sich nur an die Oberfläche oder an die Ränder der Zelle an (S. 493 „Anat. Anz." 1890).

Ganz bestimmte Angaben über die Endigungen der Nerven im Grundgewebe der Cornea vermissen wir aber auch bis heute. Die Untersuchungen der letzten Zeit weisen auf die Abwesenheit von Nerven in den hintersten Hornhautschichten und in der Descemetschen Membran hin.

Somit lässt es sich als festgestellt betrachten, dass die Cornea eine grosse Anzahl von Nerven und in verschiedenen Höhen etagenmässig in der Dicke der Hornhaut gelagerte Nervenplexus besitzt. Allein, was die Nervenendigungen betrifft, so sind dieselben nur in der Epithelschicht der Hornhaut genauer verfolgt worden.

Aus dem oben Dargelegten geht zweifellos hervor, dass unsere Untersuchungen in diesem Gebiete noch keineswegs zum Abschluss gelangt sind.

\section{Die Nerven der Sklera.}

Die Untersuchung der Nerven in der Sklera, dieser festen und fast undurchsichtigen bindegewebigen Haut, ist mit grösseren Schwierigkeiten verknüpft als die Untersuchung der Hornhautnerven. Selbst im Auge kleinerer Tiere ist besonders die innere Lage der Sklera pigmentiert. In den Augen grösserer Tiere aber, wie z. B. der Katze, des Hundes, Schweines, ebenso wie im menschlichen Auge, findet sich eine nicht geringe Menge des Pigmentes nicht nur in der innersten Lage, sondern auch mehr oder weniger in der Dicke der Sklera selbst. Es ist bei weitem nicht immer möglich, den Verlauf der Nerven auf so grossen Strecken, wie z. B. von einem markhaltigen Nervenstämmchen an bis in die Endigungen hinein, zu verfolgen. Dazu kommt noch, dass mit der Grösse des Tieres auch die Dicke des Skleralgewebes immer mehr zunimmt.

Es ist also leicht begreiflich, dass die Versuche einer Erforschung der SkleraInerven, besonders an der Hand der früheren Methoden, nicht besonders erfolgreich gewesen sein konnten. Da der 
grösste Teil der Ciliarnerven, nach ibrem Eintritte in das Innere des Augapfels, der Gefässhaut sich zuwendet, so erschien es naturgemäss, anzunehmen, dass die Sklera keine eigenen Nerven besitze, sondern dass die einzelnen Nervenstämmchen sie nur durchbohrten, ohne in eine direkte Verbindung mit ihr einzugehen. Diese Ansicht hatte in früherer Zeit ihre Vertreter. Später ist durch die sorgfältigen Untersuchungen Bochdaleksi) und Arnolds' ${ }^{2}$ festgestellt worden, dass die Sklera ihre eigenen Nerven besitzt. Helfreich $\left.{ }^{9}\right)$ beschrieb in der Sklera des Frosches die Verteilung feinerer Nerven, welche er für Nervenendigungen hielt; diese Befunde wurden nachträglich von Königstein ${ }^{4}$ ) bestätigt. Waldeyer ${ }^{5}$ ) hat an Goldpräparaten der Sklera des Menschen, in den oberfächlichen Lagen am Hornhautrande feine Nervenfädchen verfolgt, doch behauptet der Autor nicht, Endfäden der Nerven gesehen zu haben.

Somit liess sich die Endigungsart der Nerven in der Sklera bei Benutzung der Goldmethode nicht klarlegen; ebensowenig half uns in dieser Richtung die von $\mathrm{Bach}^{6}$ ) an den Augen neugeborener Kaninchen und am Menschenauge angewandte Methode von Ramon y Cajal.

Dieser Umstand bewog mich bereits in den Jahren 1891-93, als ich mich in dem Laboratorium von Prof. Arnstein mit dem Studium der Nerven des Tractus uvealis beschäftigte, eine Untersuchung der mit Methylenblau tingierten Nerven der Sklera vorzunehmen. Es gelang mir bald zu konstatieren, dass durchaus beweisende Bilder der Verteilung und Fndigung der Nerven an Flächenpräparaten der Sklera albinotischer Tiere, namentlich des Kaninchens und der Katze erhalten werden können. Eine genügend intensive und vollständige Nervenfärbung erhielt ich, wenn das Methyleublau in

1) Bochdalek, Über die Nerven der Sclerotica. Prager Vierteljahrsschr. Bd. XXIV. 1849.

2) Arnold, F., Anatomische und physiologische Untersuchungen über das Auge des Menschen, 1832 und Handb. d. Anat. d. Menschen. Bd. IT. 1851.

3) Helf reich, Über die Nerven der Conjunctiva und Sklera. Würzburg 1870.

4) Königstein, Über die Nerven der Sklera. r. Graefe's Arch.f. Ophth. Bd. XVIII, 2.

5) Waldeyer. Traité complet d'opht. par Wecker et Landolt. T. II. p. 60 .

6) Bach, Die Nerven der Augenlider und der Sklera beim Menschen und Kaninchen - nach Untersuchungen mit der Golgi-Cajalschen Methode. v. Graefe's Arch. f. Ophth. Bd. XVI, 3 und Arch.f. Angenheilk. Bd. XXXIIJ. S. 166. 1896 . 
einer 1-3\% igen Lösung in die Carotis eingespritzt worden war. Zweifellos lassen sich auch mit Hilfe schwächerer Lösungen des Farbstoffes gute Präparate herstellen.

Anmerkung. Die Resultate meiner Untersuchungen über die Skleralnerven sind bereits im Jahre 1893 im Text und in den Thesen meiner Arbeit „Über die Nervenendigungen im Ciliarkörper bei Säugetieren und Menschen" in Kürze veröffentlicht worden.

Im Texte beschreibe ich ein Nervenendnetz in der Lamina fusca. In den Thesen teile ich die von mir beabachteten Besonderheiten in der Verteilung der Skleralnerven mit.

So schrieb ich, in einem kurzen Resumé, wie folgt:

1. Markhaltige Nervenfasern laufen in verschiedenen Teilen der Sklera in Endanschwellungen aus.

2. Im Gebiete des Ciliarkörpers findet man im Skleralgewebe einen aus markhaltigen Fasern bestehenden Nervenring; nach vorn sowie nach hinten zweigen sich von letzterem einzelne Fasern ab, die nach Verlust ihrer Markscheide in Gestalt einer knopfförmigen Anschwellung enden.

3. An die Gewebselemente der Sklera treten feine varicöse Fädchen heran.

4. In der Lam. suprachorioidea s. fusca verlaufen markhaltige Nervenfasern, die nach Verlust ihrer Markscheide in varicöse Fäden zerfallen; letztere nehmen zum Teil ibren Weg zu den Pipmentzellen, während die übrigen dagegen ein aus feinsten körnigen Fädchen bestehendes Endnetz bilden.

Endlich gebe ich im Texte der genannten Arbeit eine auf eigenen Untersuchungen begründete, ausführliche Beschreibung der Ganglienzellen der Chorioidea und des Ciliarkörpers und führe die einschlägige Literatur möglichst vollständig an.

Im Jahre 1900 veröffentlichte Prof. Smirno ${ }^{1}$ ) im Anat. Anz. seine Untersuchungen über die Skleralnerven. Als Untersuchungsobjekte hatten ihm die Augen von Katzen, Hunden, Kaninchen sowie auch von Mensehen gedient.

Ausser der Silberimprägnation und Vergoldung (des Menschenanges) hatte Sminnow auch die Methylenblaumethode angewandt. Er beschreibt in der Sklera vasomotorische Nerven, ferner sensible Nervenendigungen, welche letzteren den Nervenendigungen in den Sehnen und Fascien ähneln, und schliesslich noch dem Zellkörper der Bindegewebszellen anliegende Terminalfasern; diese letzteren gehören, wie der Autor meint, wahrscheinlich zu den trophischen Nerven. In der Arbeit Smirnows finden sich indessen keine Hinweise auf die verschiedenen Formen der Endapparate in der Sklera.

Angesichts des soeben Besagten hielt ich es nicht für überflüssig, die Resultate meiner bereits früher ausgeführten Untersuchungen über die Innervation der Sklera, mit Beifügung einiger neuer, in den Jahren 1895-96 von mir gewonnenen Befunde, im Jahre 1901 drucken zu lassen ${ }^{2}$ ).

1) Smirnow, A., Die weisse Augenhaut (Sklera), als Stelle der sensiblen Nervenendigungen. Anat, Anz. Bd. XVIII.

2) Agababow, A., Über die Nerven der Sklera. Kasan 1901 (russisch).

- Die Nerven der Sklera. Arch. f. mikrosk. Anat. Bd. LXIII. 1904. 
Bei der Betrachtung meiner Präparate iiberzeugte ich mich, dass man mit Hilfe der Methylenblaufärbung die Skleralnerven im Auge albinotischer Tiere bis in ihre Endigungen hinein verfolgen kann.

Es stellte sich heraus, dass die Sklera reich mit eigenen Nerven versehen ist; soweit der Charakter ihrer Anordnung und ihre Endigungsart schliessen lässt, müssen die Skleralnerven wohl für verschiedene Funktionszwecke bestimmt sein.

Ausser den die Gefässe begleitenden marklosen Nerven sind hier auch markhaltige Fasern zahlreich vertreten. Von ziemlich starken markhaltigen Stämmchen zweigen sich in verschiedenen Punkten einzelne Nervenfasern ab; letztere ziehen anfangs in Gestalt isolierter Markfasern hin, verlieren aber darauf ihre Myelinscheide und setzen nun als feine varicöse Fäden ihren Weg weiter fort, um schliesslich nach kzürzerem oder längerem Verlaufe in einen Endapparat überzugehen.

Auf Grund meiner Untersuchungen gelang es mir, in der Sklera $\mathrm{zu}$ konstatieren:

1. Sensible Nerven. Sie endigen frei im Gewebe, ohne zu irgendwelchen Gewebselementen, wie z, B. zu den Zellen usw., in eine nähere Beziehung zu treten.

Diese Nerven sind reich an mannigfaltigen Formen von Endapparaten und werden in der Dicke der Sklera in verschiedenen Partien derselben angetroffen.

2. Trophische Nerven. Sie sind für die Stromazellen der Sklera bestimmt und enden an der Zellenoberfäche, ohne mit dem Protoplasma oder mit dem Zellkerne in Konnex zu stehen.

3. Die Vasomotoren gehören den Blutgefässen der Sklera und haben ihre Endigungen in der Gefässwand.

4. Die Nerven der Lam. fusca enden an der inneren Oberfläche der Sklera in der Schicht der Lam. fusca s. suprachorioidea; die Endigung dieser Nerven erscheint in Gestalt eines aus dünnen, feingranulierten Fädchen zusammengesetzten, sehr regelmässigen Netzwerkes.

1. Endigungen der sensiblen Nerven:

a) In Gestalt einer kleinen, knopf- oder keulenförmigen Anschwellung. In ihren Dimensionen übertrifft diese terminale Anschwellung die der gewöhnlichen Varicositäten; in ibrer Form ist sie den von uns in der Cornea (des Kaninchens) beobachteten Endigungen gleicher Art analog (siehe Taf. IX, Fig. 1, 2, 3a). 
b) In Form eines Pinsels. Diese Endigung besteht aus einer Anzahl pinselartig ausstrahlender, feiner varicöser Fäden, welche letzteren gleichfalls mit kleinen Terminalanschwellungen enden (siehe Taf. XI, $f$, Fig. 17). Die folgende Endigungsart, nämlich

c) die Endplatte (plaque) ist den von Dogiel in der Cornea des Menschen unter dem Namen "Endplättchen" beschriebenen Gebilden durchaus analog. Sie erscheinen in Gestalt dünner Plättchen von unregelmässiger Form mit unglatten, gleichsam angefressenen Rändern. Es kommen verschiedene grosse Endplättchen - grosse $\left(c_{1}\right)$ und kleine $(c)$ - zur Beobachtung (siehe Taf. XI, Fig. 18 u. 19).

Die Endapparate in Form ron Endkeulen, -knöpfchen und -platten haben wir an zahlreichen Präparaten der Sklera bei guter Nervenfärbung gesehen. In der ziemlich dünnen Sklera des weissen Kaninchens vermag man dieser Endformen nicht nur ansichtig zu werden, sondern man kann dieselben auch bei starker Vergrösserung, selbst mit dem Immersionssystem, genau und detailliert analysieren.

Die Endknöpfchen und Endkeulen treten dank ihren scharf umrissenen Konturen in Gestalt von Verdickungen sebr markiert hervor; in ihren Dimensionen übertreffen sie erheblich die gewöhnlichen Varicositäten der Nervenfäden und unterscheiden sich von ihnen auch durch ibre Form. Es sind weder haar- noch fadenförmige Fortsätze an diesen Anschwellungen wahrzunehmen, im Gegenteil, die Terminalfaser hat in dieser Anschwellung ersichtlich ihr Ende erreicht.

Diese Befunde führten uns zu der Überzeugung, dass wir hier einen Endapparat vor uns haben, welcher zur Kategorie der freien Nervenendigungen zuzuzählen ist.

Das Besagte bezieht sich gleichermassen auch auf die Gebilde, welche in meiner ersten Mitteilung als sogenannte "platte Verdickung" (plaque) beschrieben worden sind (siehe S. 706 der deutschen und S. 9 der russischen Arbeit).

Dank ihren ziemlich ansehnlichen Dimensionen, ihren scharfen Konturen und unregelmässigen, ausgezackten Rändern heben sich sowohl die grösseren $\left(c_{1}\right)$ als auch die kleineren (c) Endplatten dettlich ab.

Das Nervenfädchen geht in die Endplatte über und hört hier auf: es lässt sich nicht weiter verfolgen. Daher betrachte ich auch diese Gebilde als Nervenendapparate, als Endplatten.

Fr. Eleonskaya unterscheidet, wie ihre Beschreibung zeigt, zweierlei Plattenbildungen: die einen sind in die Kontinuität eines 
Nerven eingeschaltet und werden von ihr plattenförmige Erweiterungen genannt, die andern stellen wirkliche Endapparate, d.h. „Endplättchen" dar.

Zur Vermeidung von Missverständnissen ist zu bemerken, dass ich den Namen „plattenförmige Verdickung (plaque)" ausschliesslich den betreffenden Nervenendapparaten beigelegt habe, welche am peripheren Ende einer Terminalfaser liegend, als "Endplatten" zu bezeichnen sind.

So hat mich namentlich auch H. Virchow verstanden. In der 2. Aufl. des Handbuches von Graefe-Saemisch gibt dieser Autor eine kurze Zusammenfassung meiner Beschreibung der Skleralnerven und bezeichnet hier den in Rede stehenden Endapparat mit dem Namen "Endplättchen".

d) Netzförmige Endigung, ein sebr kompliziertes Gebilde in Gestalt eines verwickelten, unregelmässigen Netzwerkes. Aus diesem Netze gehen einzelne varicöse Fäden hervor, die ihrereits in ein Endknöpfchen, eine Endplatte oder eine pinselartige Endigung auslaufen.

In diesem Apparate kann man sämtliche einfache Formen der Nervenendigungen überschauen (siehe Taf. XI, Fig. 18 h).

e) Den oben angeführten Nervenendigungen sind noch die von Fr. Eleonskaya beobachteten und in ihrer Dissertation als sogenannte „Endbüsche" und "Endbäumchen" beschriebenen Formen beizuzählen.

Alle diese Endapparate liegen in verschiedenen Höhen in der Dicke der Sklera; sie finden sich sowohl in der vorderen als auch in der mittleren oder äquatorialen und ebenso auch in der hinteren Skleralzone, mit andern Worten, diese verschiedenartigen Nervenendigungen sind in allen Partien der Sklera verbreitet. Jedoch besonders zahlreich sind dieselben im vorderen Teile der Sklera, im Gebiete des Ciliarkörpers. Hier kommt in der Sklera ein ringförmiges Nervengeflecht zu stande (Taf. XI, Fig. 19), welches nach vorn und nach hinten einzelne varicöse Fäden sendet; letztere endigen in Gestalt der oben beschriebenen knopf- und keulenförmigen Verdickungen $(a)$ oder in Endplatten grösserer $\left(c_{1}\right)$ und kleinerer $(c)$ Dimension.

In Taf. XI, Fig. 19 sind feine varicöse Nervenfäden und deren Endigungen an der einen Seite eines Nervenbündels dargestellt; an der andern Seite des letzteren sind nur Teile der varicösen Fäden $(b, b)$ zu sehen, deren Endapparate nicht aufgezeichnet worden sind, da sie den bereits beschriebenen ähneln.

Das Vorhandensein einer so grossen Anzahl sensibler Nerven- 
endigungen in der vorderen Skleralzone ist unzweifelhaft nicht nur für die Sklera selbst, sondern auch für den Ciliarkörper von Bedeutung, insofern als der letztere bei grosser Empfindlichkeit und bei seiner wichtigen funktionellen Tätigkeit namentlich von der vorderen Seite gegen äussere Insulte verhältnismässig schwach geschützt ist.

In seinem Aufsatze gibt Prof. Smirnow, wie bereits gesagt, keine ausführliche Beschreibung der einzelnen Formen der Nervenendapparate, sondern weist nur darauf hin, dass die sensiblen Nervenendigungen hier sich ähnlich ausnehmen, wie überhaupt im derbfaserigen Bindegewebe.

\section{Trophische Nerven.}

So habe ich diejenigen Nerven genannt, welche zu den Zellen der Sklera in einer bestimmten Beziehung stehen. An meinen Präparaten gelang es mir zu konstatieren (siehe Taf. XI, Fig. 20), dass eine aus dem Nervenstämmchen austretende markhaltige Faser, nachdem sie eine Strecke zurückgelegt, ihre Markscheide verliert und dann in Gestalt varicöser Nervenfäden ihren Weg fortsetzt; oder aber die markhaltige Faser entsendet an der Stelle einer Ranvierschen Einschnürung einen oder zwei varicöse Seitenästchen. Im ersteren wie im letzteren Falle begeben sich die erwähnten Nervenfäden zu den Zellen der Sklera und gelangen an eine solche Zelle in einer Anzahl von 1-2 Fädchen; mitunter aber spalten sie sich in feinste Fädchen auf, gehen gabelförmig auseinander und enden an der Oberfläche einer Zelle (k). Bei guter Färbung ist es klar ersichtlich, dass der Nerv an der Zelle sein Ende findet, ohne in die Zellsubstanz oder gar in den Zellkern einzudringen, wie man es früher in bezug auf die Hornhautzellen vermutet hatte.

Die trophischen Nerven werden auch von Prof. Smirnow anerkannt.

Nur Eleonskaya bält es für unmöglich, die Existenz trophischer Nerven in der Sklera zuzulassen. Sie beruft sich darauf, dass in der, ihrer Struktur nach der Sklera so nahe stehenden Cornea ein direkter Zusammenhang des Nerven mit der Stromazelle nicht anerkannt wird. So weist sie auf Prof. Arnsteins Arbeit hin, welcher mit Hilfe des Methylenblaus sich davon überzeugt hat, dass der Nerv mit der Hornhautzelle keinen näheren Konnex eingeht, sondern an der Zelle nur vorbeizieht. Leider teilt Eleonskaya in bezug auf diese Frage keine eigenen Beobachtungen mit.

Freilich lassen auch meine Präparate ersehen, dass sich der Nerv 
weder mit dem Protoplasma noch mit dem Kerne der Skleralzelle direkt verbindet, sondern wir sehen, dass er an der Zelloberfläche endet. Hierin liegt namentlich der Hauptunterschied unserer Anschauung von der der früheren Autoren.

3. Die rasomotorischen Nerven.

Die Sklera ist nicht reich an eigenen Blutgefässen. Die hinteren sowie die vorderen Ciliararterien geben Äste ab, welche ein weitmaschiges episklerales 'Gefässnetz bilden. Am hinteren Augenpole, an der Eintrittsstelle der hinteren Ciliararterien bilden Zweige der genannten Arterien den Circulus arteriosus Zinnii. Vorn ist das episklerale Gefässnetz in einer den Hornhautrand umgebenden, 5 bis $6 \mathrm{~mm}$ breiten Zone besonders stark entwickelt. Das venöse Blut ergiesst sich in die vorderen Ciliarvenen, in die Venae vorticosae und hinten in die Venulae ciliares breves (Schwalbe, loc. cit. S. 170). Leber ${ }^{1}$ ) sagt über die Skleralgefässe des Menschen wie folgt: „Das Gewebe der Sklera selbst ist im allgemeinen sehr gefässarm, abgesehen von den Gefässen der Aderhaut, welche die Sklera nur passioren. In der Umgebung des Sehnerveneintrittes liegt in ihr eingeschlossen der für die Ernährung des intraokularen Sehnervenendes und der angrenzenden Retina bestimmte Circulus art. n. optici s. Zinniii. Eine viel reichlichere Entwicklung erlangt dagegen das episklerale und sklerale Gefässnetz im vordersten Abschnitte der Sklera, in der Umgebung des Hornhautrandes."

An der von der Ohorioidea befreiten Innenfläche der Sklera

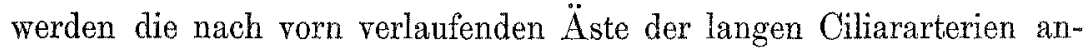
getroffen, und am hinteren Augenpole sieht man Stücke der hinteren Arterien mit anhaftenden Resten der Aderhant.

Die Gefässe erscheinen in ihrem ganzen Verlaufe von Nerven begleitet. Marklose Easern verflechten sich miteinander zu dem perivaskulären Plexus (s. Taf. XI, Fig. 22 u. 23), aus welchem feine Ästchen sich in die Gefässwand versenken, und einige von diesen Nervenfäden lassen sich bis in die Muskelschicht hinein verfolgen. Die Fig. 22 ist einem Präparate der Sklera entnommen, in welchem das Nervenstämmchen an der Stelle, wo es eine Arterie kreuzt, verbreitert und abgeplattet erscheint. In dieser Figur sehen wir auch Ganglienzellen, deren Abbildung leider nicht sehr gelungen ist.

1) Leber, Die Cirkulations- und Frnährungsverhälnisse des Auges. Handbuch der gesamten Augenheilkunde von Graefe-Saemisch. 2. Aufl. Bd. II. abt. 2. S. 60 . 
An den Arterien entlang werden in dem adventitiellen Geflechte mitunter vereinzelte Ganglienzellen angetroffen.

Sie sind von Smirnow, mir und Fritz beschrieben worden. In der Sklera des Menschen, unweit des Sehnerveneintrittes hat Fr. Eleonskaya in der Dicke eines Nervenstämmehens eine Ganglienzelle mit unvollständig gefärbtem pericellulären Netze gesehen.

In der Sklera begegnet man nur selten Ganglienzellen, während man dagegen in der Chorioidea, zumal bei jungen Tieren, sowohl vereinzelte als auch mehrere in Gruppen vereinte Ganglienzellen häufig antrifft.

Die genannten Zellen zeichneten sich durch alle ihre charakteristischen Merkmale aus und waren von den Kernen der Nervenfasern leicht zu unterscheiden (s. Taf. XI, Fig. 23).

Eine ausfïhrliche Beschreibung dieser Zellen gebe ich in dem Abschnitte über die Nerven der Chorioidea.

4. Die Nerven der Lam. fusca sclerae.

Von einem Nervenstämmchen (Taf. XI, Fig. 21, d) zweigen sich markhaltige Fasern ab, die nach Markverlust bald in feinste varicöse Fädchen zerfallen; letztere bilden ein geschlossenes, ziemlich regelmässig angeordnetes Netz an der Innenfläche der Sklera im Gewebe der. Lam. fusca. In den Knotenpunkten, wo die Fäden zusammenfliessen, treten gröbere körnige Verdickungen hervor. In den Schlingen dieses Endnetzes werden Endothelzellen (e) angetroffen.

Meines Wissens ist dies Endnetz noch von niemandem beschrieben worden. Es findet auch in den neuesten Arbeiten keine Erwähnung.

In meiner Arbeit "Über die Nerven des Ciliarkörpers" habe ich bereits im Jahre 1893 dieses Netz der Lam. fusca mit einem an der Vorderfläche der Iris befindlichen Netze, sowie auch mit dem Endnetze der Aussenfläche des Ciliarkörpers in Parallele gestellt.

Diese drei Netze sind sämtlich aus sehr feinen Fäden aufgebaut; an den Knotenpunkten tritt eine gröbere Varicosität der Fäden hervor; die Maschen dieser Netze sind von mehr oder weniger regelmässiger Form und unterscheiden sich einigermassen nur in ihrer Grösse, was möglicherweise von dem verschiedenen Charakter des Gewebes der Iris und der Lam. fusca abhängt. Sie sind an zahlreichen Präparaten der Sklera und Iris weisser Kaninchen und im Ciliarkörper weisser Katzen sehr gut sichtbar.

Das in der Lam. fusca beobachtete Nervenendnetz unterscheidet sich nicht wesentlich von dem ebenso benannten Endapparate, welcher sich im gleichartigen Gewebe der Lam. suprachorioidea an der 
Aussenfläche des Ciliarkörpers befindet. Nur darin besteht ein Unterschied, dass die zur Aussenfläche des Ciliarkörpers verlaufenden Nervenfasern nach Verlust ihrer Markscheide noch eine gewisse Strecke in Gestalt varicöser Fäden zurückzulegen haben, ehe sie ins Endnetz übergehen. Hingegen sieht man, dass die Nervenfasern an der inneren Skleralfäche sehr bald, fast unmittelbar nach Verlust ihrer Markscheide das Endnetz bilden.

Dieses ungleiche Verhalten der Terminalfasern findet vielleicht seine Erklärung darin, dass die markhaltigen Fasern des Ciliarkörpers von den in grösserer Tiefe befindlichen Nervenstämmchen sich abzweigen, wälrend dagegen in der Sklera die markbaltigen Fasern in der Nähe der inneren Oberfläche, d. h. mit dem Endapparate der Lam. fusca fast in einem Niveau liegen.

Wie bereits oben erwähnt, hat ausser den aufgeführten Autoren auch Bach $^{1}$ ) über die Nerven der Sklera geschrieben.

Er führte seine Untersuchungen nach der Golgi-Cajalschen Methode an Augen der Kaninchen und menschlichen Embryonen aus.

Der Autor hat, wie er sagt, den Eindruck bekommen, dass die Sklera nicht so nervenarm sei, wie man bis jetzt glaube.

Der Verlauf der Nerven zu den nicht so spärlichen Gefässen der Sklera spricht seiner Ansicht nach dafür, dass wir in der Sklera mit sympathischen Nervenfasern zu tun haben. Die der Arbeit beigegebene Abbildung ist nach mehreren Präparaten zusammengestellt.

Es ist noch zu notieren, dass die Ciliarnerven in ihrem Verlaufe selbst eine beachtenswerte Besonderheit darbieten, die zuerst von Axenfeld ${ }^{2}$ ), sodann von $\mathrm{Naïto}^{3}$ ), in Gemeinschaft mit Axenfeld ${ }^{4}$, ferner von Fritz ${ }^{5}$ ), sowie auch von Groenou w ${ }^{6}$ ) beschrieben worden ist. Es handelt sich namentlich um die intraskleralen Nervenschleifen, welche in vorderen Teile der Sklera, in deren Dicke, von den Ciliarnerven gebildet werden.

1) Bach, loc. cit.

2) Axenfeld. Ber. über d. 24. Vers. d. ophth, Ges. Heidelberg 1899. S. 116-124. - IX. intern. ophth. Kongress in Utrecht. Klin. Monatsbl. $f$. Augenheilk. 1902.

s) Naïto. Klin. Monatsbl. f. Augenheilk. Bd. XL, 2.

t) Axenfeld u. Naïto. Ber, über d. 30. Vers. d. ophth. Ges. Heidelberg 1904.

5) Fritz. Sitzungsber. d. kgl. Akad. d. Wissensch. in Wien. Mathem." naturw. Klasse. Bd. CXIII, 3.

6) Groenouw. Klin. Monatsbl. f. Augenheilk. Bd. XLIII, 1. S, 637. 


\section{Die Nerven der Iris.}

Vor der Einführung der Methylenblaumethode sind mit Hilfe des Chlorgoldes sehr eingehende Untersuchungen über die Irisnerven, besonders im Laboratorium von Prof. Arnstein, von A. Meyer ${ }^{1}$ ) und von $A$. Geberg ${ }^{2}$ ) ausgeführt worden.

Beschreibungen dieser Nerven auf Grund der Methylenblaufärbung geben: Stepanow ${ }^{3}$ ), Agababow ${ }^{4}$ ), darauf Andogsky $y^{5}$ und Wera Leontowits $\operatorname{ch}^{6}$ ).

Ein für das Studium der Anordnung und Verteilung der Irisnerven sehr geeignetes Bild gewähren uns Flächenpräparate. Hierzu dienen vor allem die Augen albinotischer Tiere: die Ratte (von Stepanow untersucht), des Kaninchens (Agababow, Andogsky, Leontowitsch) und der Katze (Agababow).

Der den Ciliarkörper ringförmig durchsetzende Grundplexus, der sogenannte Orbiculus ciliaris, sendet starke gemischte Nervenstämmchen aus, die in radiärer Richtung die Iris betreten; in der peripheren Zone der letzteren gehen sie bald dichotomische Teilungen ein und bilden hier das ringförmige, periphere Nervengeflecht. Aus letzterem zweigen sich ebenfalls stärkere Nervenstämmchen $a b$, die anfangs eine Strecke weit radiär verlaufen und darauf ihrerseits zu einem weitmaschigen Plexus zusammentreten; und so sieht man von der Peripherie zum Zentrum hin, bis nahe an den Sphinkter heran, 2-3 Reihen konzentrisch gelagerter grosser Schleifen (Arkadenreihen nach Andogsky). Nach Schwalbe ist der dem Sphinkter benachbarte Plexus am konstantesten.

Die ringförmig verlaufenden starken Stämmchen, welche den Grundplexus der Iris bilden, liegen in der Dicke derselben, vor den grösseren Gefässen in der Nähe der vorderen Fläche der Iris (ibid).

1) Meyer, A., Die Nervenendigungen in der Iris. Arch. f. mikrosk. Anat. Bd, XVIr.

2) Geberg, A., Über die Nervenendigungen in der Iris und im Ciliarkörper bei Vögeln. Diss. Kasan 1883 (russisch).

Über die Nerven der Iris und des Ciliarkbrpers bei Vogeln. Intern. Monatsschr. f. Anat. u. Histol. Br. I. 1884.

3) Stepanow, Die Nerven der Iris. Diss. Tomsk 1892 (russisch).

4) Agababow, A., Über die Nervenendigungen im Ciliarkörper bei Säugetieren und Menschen. Kasan 1893 (russisch).

5) Andogsky, N., Zur Frage über die Ganglienzellen der Iris. Arch. f. Augenheilk. 1897.

6) Kirpitschowa-Leontowitsch, W., Zur Frage der Innervation der Iris beim Kaninchen. v. Graefe's Arch. f. Ophth. Bd. LXXIX, 3. 1911. 
Aus diesen Nervenstämmchen treten einzelne Nervenfasern aus; letztere verlieren nach kürzerem oder längerem Verlaufe ihre Markscheide und setzen als blasse Achsencylinder ihren Weg weiter fort; die Nervenfasern, welche der dem Sphinkter benachbarte Plexus absendet, begeben sich hauptsächlich zu dem genannten Muskel, woselbst sie in Gestalt feiner markloser Achsencylinder zwischen den Bündeln der glatten Muskelzellen sich verlieren. In den hinteren Schichten der Tris sind die Nerven nur spärlich vorhanden; eine für glatte Muskulatur charakteristische Anordnung der Nervenfäden existiert an dieser Stelle nicht (Schwalbe, loc. cit. S. 210). Nach Meyer bilden die Nerven an der Vorderfläche der Iris Nervenendnetze von zweierlei Art, nämlich ein oberflächliches, sensibles und ein etwas tiefer gelegenes, für die Blutgefässe bestimmtes Endnetz, während dagegen die übrigen Nerven für den Sphinkter bestimmt sind. Er sagt: „In der Iris des albinotischen Kaninchens lassen sich mit Sicherbeit drei Arten von Nervenendigungen konstatieren: 1. ein motorisches Nervenendnetz im Sphincter pupillae; 2. ein sensibles Nervenendnetz an der vorderen Fläche der Iris, unmittelbar unter dem Endothel; 3, ein vasomotorisches Nervenendnetz an den Arterien und Kapillaren... Im Sphincter pupillae... verlaufen die Nerrenfäden zwischen den Muskelzellen und liegen ihnen unmittelbar an (man findet dieselben Bilder, wie sie von Lïwit $u$. A. für die glatte Muskulatur festgestellt wurden)."

Zur Färbung der Irisnerven wurde das Methylenblau zuerst von Stepanow angewandt. Als Untersuchungsobjekt wählte er die Iris der weissen Ratte und färbte nach Dogiels Methode auf dem Objektträger in einer $1 / 16 \%$ igen Lösung des Farbstoffes.

In den Augen des Menschen erhielt er selbst binnen 1-4 Stunden nach dem Tode keine vollständige Nervenfärbung.

Seine Befunde waren wie folgt.

1. Die die Iris betretenden, dieken und dünnen Nervenstämmchen (markhaltiger und markloser Fasern) teilen sich in Zweige von versehiedener Dicke; diese Verästelungen bilden einen weitmaschigen Plexus, "welcher von mir," sagt der Autor, "Grundplexus benannt worden ist." "Derselbe erstreckt sich von dem Ciliarrande der Iris bis zum äusseren Sphinkterrande; er liegt vor den grösseren Blutgefässen, indem er die mittlere Dicke der Grundsubstanz durchsetzt.

2. Aus dem Grundplexus gehen Zweige zur Vorderfläche der Iris; sie teilen sich wiederbolt während ihres Verlaufes und bilden einen feinmaschigen vorderen Nervenplexus. Zieht man die Maschenbildung, die Lage dieses Geflechtes sowie auch sein Verbalten zu den kleinen Blutgefässen in Be- 
tracht, so lässt es sich eher den vasomotorischen als den sensiblen Nervenpiexus anreihen, wie es Arnold, Fürst, Meyer u. A. annehmen.

3. Der Grundplexus gibt eine Menge feinerer Nervenästchen $a b$, die fast unmittelbar unter dem Epithel der hinteren Irisfläche, im Gebiete der Membr. Bruchii, in einzelne varicöse Fibrillen zerfallen und zu einem sehr diehten feinmaschigen hinteren Nervengeflechte zusammentreten. Letzteres erstrekt sich ähnlich dem vorderen Plexus, von dem Ciliarrande der Iris bis fast an den Pupillarrand des Sphinkters.

4. Sowohl der vordere wie auch der hintere Nervenplexus senden feinste varicöse Fädchen zum Sphinkter, woselbst diese Fäden in Fibrillen zerfallen und ein dichtes, für die Muskulatur des Sphinkters bestimmtes Nervennetz bilden. An der Bildung dieses Nervennetzes beteiligen sich sowohl markhaltige als auch marklose Nervenfasern.

5. In der Iris kommen Ganglienzellen in geringer Anzahl vor.

Mithin vermissen wir in der Arbeit Stepanows den Hinweis auf die Existenz sensibler Nerven in der Iris.

N. Andogsky färbte die Iris weisser Kaninchen, indem er eine $1 / 20 \%$ ige Methylenblaulösung in die vordere Augenkammer des enucleierten Bulbus einspritzte; 3-5 Minuten darauf wurde der vordere Teil des Auges abgeschnitten und die weitere Färbung und Fixierung nach den allgemein üblichen Regeln bewerkstelligt.

Die Frage der Ganglienzellen war Hauptgegenstand der Untersuchungen Andogskys. Doch gibt er auch eine kurze Beschreibung des Verlaufes und der Verzweigungen der Nerven in der Tris, und was das Nervennetz an der Vorderfläche der Membran betrifft, so betrachtet er dasselbe als einen sensiblen Nervenendapparat.

Im Bereich der Iris fand der Autor keine Ganglienzellen, or konstatierte nur die dreieckigen Kerne der Nervenfasern und verästelte Zellen im Irisstroma.

In dem oberflächlichen Nervennetze der Ciliarfortsätze dagegen treten seiner Ansicht nach gangliöse Gebilde in Gestalt bipolarer und multipolarer Nervenzellen hervor.

W. Kirpitschowa-Leontowitsch färbte die Irisnerven des weissen Kaninchens mittels Injektion einer Methylenblaulösung von 1:2000 in die Carotis nach vorhergehender Ausspülung des Blutgefässsystems mit warmer Ringerscher Flüssigkeit; Fixierung nach A. Leontowitsch ${ }^{1}$, darauf Alkohol, Benzol, Kanadabalsam.

Auf Grund ihrer Untersuchungen gelangt Fr. Leontowitsch

1) Das Verfahren von A. Leon tow itsch wird in der citierten Arbeit nicht mitgeteilt, da eine baldige Publikation desselben in Aussicht stehe. 
zu dem Schlusse, dass die Iris zwei Systeme von Nervennetzen besitzt, welche beide zu den Gefässen in Beziehung stehen.

Das eine umgibt die Gefässe in Gestalt eines feinmaschigen Netzes, welches an vielen Stellen unmittelbar in das Remaksche Netz der Vorderfläche der Iris übergeht.

Das andere, die Gefässe umwindende Netz ist weitmaschig und geht nicht in das oberflächliche Remaksche Netz über, sondern hängt mit den Nerveustämmchen zusammen.

An der hinteren Fläche der Iris findet sich gleichfalls ein Nervennetz; und schliesslich konstatiert Fr. Leontowitsch die Gegenwart von Ganglienzellen in der Iris.

In bezug auf die Inneration charakterisiert sich die Iris, nach Aussage der Fr. Leontowitsch, im allgemeinen durch einen so grossen Nervenreichtum, dass selbst eine jede Muskelzelle nicht von einem einzelnen, sondern von mehreren Nervenfäserchen umwunden wird.

Auch diese Arbeit enthält keine Angaben über die sensiblen Irisnerven, indem hier nur vasomotorische Nervennetze und motorische Nerven festgestellt werden.

Die Färbung der Irisnerven des Kaninchens und der Katze mittels des Methylenblaus wurde von mir ${ }^{1}$ ) schon vor vielen Jahren angewandt und die Resultate meiner Untersuchungen sind im Jahre 1893 in meiner Arbeit „Über die Nerven des Ciliarkörpers bei Säugetieren und Menschen" kurz mitgeteilt worden.

Der Farbstoff wurde damals in einer $1 \%$ igen Lösung in die Carotis des Kaninchens eingespritzt und ausserdem wurde von mir auch die Dogielsche Methode der Färbung auf den Objektträger an der aus dem Bulbus herausseparierten Iris angewandt; in letzterem Faile nahm ich schwächere Lösungen (1:5000-1:10000). Zur Fixierung diente eine gesättigte Ammoniumpikratlösung.

An zahlreichen Präparaten gelang es, zwei Nervenendnetze an der Vorderfläche der Iris zu erhalten.

Das eine liegt ganz oberflächlich unter dem Endothelüberzuge, das andere aber nimmt eine etwas tiefere Lage ein.

Diese beiden Netze unterscheiden sich sehr voneinander sowohl durch die Weite ihrer Maschen als auch durch die Konfiguration derselben, sowie auch durch die Dicke und Varicosität der Netzfäden selbst.

In dem tiefer gelegenen Netze schlossen sich die Maschen in

1) Loc. cit. 
ihrer Verlaufsrichtung den Kapillaren an; in den Knotenpunkten sowie auch in der Kontinuität der Nervenfäden traten dreieckige Gebilde (Kerne) hervor.

Die Richtung der Netzmaschen des oberflächlichen Nervennetzes war der des tiefer liegenden nicht kongruent; in dem oberflächlichen Netze waren keine Kapillaren wahrzunehmen, die Varicositäten waren hier gröber und das ganze Netz erscheint weitmaschiger und lässt sich bis an den Pupillarrand verfolgen.

Dieses oberflächliche, subendothelial gelegene Netz habe ich für ein uberflächliches sensibles, das tiefer liegende für ein vasomotorisches Nervenendnetz anerkannt.

Gegenwärtig kann ich auf Grund erneuter Untersuchungen nur das wiederholen, was früher von mir beschrieben wurde.

Hierbei füge ich noch hinzu, dass dieses oberflächliche Netz von den Verzweigungen markhaltiger Nervenfasern gebildet wird. Diese letzteren geben noch während ihres Verlaufes von der Peripherie zur Pupille, an den Ranvierschen Einschnürungen herrorgehende, varicöse Fäden $a b$, die in das besagte Endnetz übergehen (siehe Taf. XII, Fig. 32). Weiterhin, im Gebiete der Pupille zerfallen die markhaltigen Fasern selbst in varicöse Fädchen, welche letzteren gleichfalls in das Endnetz eintreten. Von diesem Netze zweigen sich einzelne Fäden $a b$ und lassen sich in ihrem weiteren Verlaufe eine Strecke weit verfolgen, doch gelingt es nicht zu entscheiden, ob diese letztgenannten Fäden frei auslaufen oder aber ihrerseits aufs neue zu einem Netzwerke zusammentreten.

In der beigegebenen Taf. XII, Fig. 30 ist eine Arterie (ar) abgebildet, welche von dem perivaskulären Nervenplexus $(p l)$ umwunden wird. Vor dem Blutgefässe befindet sich das markhaltige Nervenstämmchen $(a)$; eine noch oberflächlichere Lage nimmt das die Kapillaren umbüllende Nervennetz $(n v)$ ein.

Vor dem soeben genannten Nervennetze, ganz oberflächlich unter dem Endothel ausgebreitet, liegt das sensible Endnetz $(s n)$ (Taf. XII, Fig. 31 u. 32), dessen einzelne Fäden aus markhaltigen Fasern $(n f)$ sich abzweigen.

Die dem M. sphincter pupillae zugehörenden motorischen Nervenfäden sind, wie meine Methylenblaupräparate erschliessen lassen, parallel zwischen den einzelnen Muskelbündeln angeordnet, d. h. so, wie es auch A.Meyer beschrieben hat. Was aber die den Sphinkter innervierenden Endapparate selbst betrifft, so kann ich darüber vermutungsweise dasselbe aussagen, was ich über die Nervenendigungen in 
dem M. ciliaris und in der Gefässmuskulatur gesagt habe (siehe den Abschnitt über die Innervation des $M$. ciliaris).

An der hinteren Fläche der Iris des Kaninchens bemerkt man radiäre Falten; sie verlanfen von der Peripherie zum Zentrum und reichen fast bis an das Gebiet des Sphinkters. In ihrer Richtung entsprechen sie den Ciliarfortsätzen und stellen Fortsetzungen dieser letzteren dar.

Ebenso wie in den Ciliarfortsätzen finden sich auch in diesen Irisfalten etwas grössere sowie auch kapillare Blutgefässe, die von marklosen Nervenfasern und feinen, netzförmig verbundenen Nervenfäden umbüllt werden. Hier beobachten wir ebenfalls Zellkerne an den Teilungsstellen der marklosen, Remaksehen Fasern.

Diese Kerne unterscheiden sich sehr von den Ganglienzellen sowohl durch ihre geringere Grösse als auch durch ihre Form.

Während die in der Dicke und in den hinteren Lagen der Iris hinziehenden Nervenfasern in ihrem Verlaufe eine grosse Menge von Kernen aufweisen, werden dagegen Ganglienzellen bier nur sehr spärlich, fast nur in einzeinen Exemplaren angetroffen und beziehen sich solche Befunde hauptsäcblich auf die Iris junger Kaninchen.

Münch) erörterte bei seinen Untersuchungen die Frage der Innervation der Stromazellen in der Iris. Weder Ramon y Cajals Methode noch das Methylenblau lieferten ihm, wie er selbst sagt, genügende Resultate. Am besten gelang ihm die Färbung der Nerven und der Iriszellen nach vorheriger Fixierung der Iris in Sublimat oder Formalin. Die Paraffinschnitte wurden mit Phosphormolybdänsäure behandelt, in Ammoniakspiritus alkalisiert und in konzentrierten wässrigen Lösungen von Methylenblau, Methylgrün, -violett, Toluidinblan oder Thionin gefärbt.

Mehr zu empfehlen ist das Methylgrün. Es wurden übrigens ausser den Nerven auch die Muskeln gefärbt.

Münch unterseheidet in der Iris "Stromazellen" von zweierlei Art, pigmentierte, mit stark entwickelten Fortsätzen versehene, und nicht pigmentierte kleine Zellen; sie haben einen grossen Kern und ein spärliches Protoplasma. Diese letzteren hält der Autor für Nervenzellen, die zu den Endverzweigungen des sympathisehen Systems in Beziehung stehen. Diese zwei Zellentypen sind in der Iris des Mensehen schwer zu unterscheiden, leicht gelingt dies dagegen bei den Affen (Maeacus nemestrinus und Rhesus).

Ferner sagt der Autor: „Es war mir eine Freude, die Bilder v. Csickys zu sehen, in denen ich fast meine eigenen Innervationsbilder wiedererkannte" usw.

"Johann v. Csicky," sagt er, "untersuchte: die Nervenendapparate

1) Münch, Über die Innervation der Stromazellen der Iris. Zeitsehr. f. Augenheilk. Bd. XYV. S. $130-147.1905$. 
der glatten Muskelzellen des Blutegels und der Froschblase nach der Vergoldungsmethode von Thanhoffer und Löwit, sowie nach der Methylenblaufärbung, und kam zu folgendem Ergebnisse: und zwar:

Die Art der Nervenendigung geschieht unter sehr verschiedenen Formen

a) in den von Ranvier entdeckten motorischen Flecken;

b) in Platten;

c) in Form eines einfachen Kontakts im Sinne Gscheidlens, derart, dass die Nervenfasern im Verlaufe an den Muskelzellen mit einzelnen Knötehen in Berührung kommen;

d) nicht nur an den Muskelzellen, sondern auch an den Kernen und selbst in den Kernen sind solche Nervenendigungen vorzufinden . . ."

Somit scheint Münch die Ansicht v. Osickys vollkommen zu teilen. In Wirklichkeit aber stellt diese Ansicht, wie wir weiter unten (im Abschnitt über die Nerven des Ciliarmuskels) sehen werden, keineswegs eine bestimmte und einheitliche Auffassung dar, sondern sie ist gleichsam eine Sammlung mehrerer verschiedenartiger Ansichten über die Endigung der Nerven in der glatten MuskulaturAnsichten, die von verschiedenen Forschern und zu verschiedenen Zeiten geäussert worden sind.

Eine fast von allen Beobachtern hervorgehobene Erscheinung kann ich meinerseits bestätigen, nämlich den auffallenden Nervenreichtum, der uns in der Iris entgegentritt.

Die gesamte Masse der Nervenstämmchen, -fasern, -täden und -endnetze erzeugt selbst in der dünnen Kanincheniris ein so kompliziertes Bild der Verteilung und des Verlaufes der Nerven, dass es auf den ersten Blick einem verworrenen Gemenge ungleich dicker Fäden ähnelt, in welchem eine Orientierung sehr schwierig scheint.

Verhältnismässig leichter gelingt es, sich in dem Verlaufe und der Anordnung dieser Nervenästchen zurechtzufinden, wenn die Nervenfärbung nicht gleichmässig in der ganzen Dicke der Tris fortschreitet, d. h. wenn man die Untersuchung nicht nach der Injektionsmethode, sondern auf dem Objektträger nach Dogiel rornimmt.

Auf letzterem Wege erzielen wir eine in den oben liegenden, d. h. der Luft mehr ausgesetzten Schichten fruher eintretende Nervenfärbung. Hat man z. B. die Iris mit ihrer vorderen Fläche nach oben auf dem Objektträger ausgebreitet, so färben sich vor allem die Nerven dieser freiliegenden, d. h. vorderen Fläche.

Legt man ein zweites Präparat der Iris mit nach aufwärts gekehrter hinterer Fläche auf das Objektglas, so tritt hier zunächst in dieser letzteren eine Nervenfärbung ein. 
Ausser den Nervenendnetzen und den für den Sphinlter bestimmten motorischen Nervenfäden gelang es uns, in dem Irisstroma keine andern Endigungen aufzudecken, welche etwa den in Bindegewebsmembranen beschriebenen freien Endigungen analog wären; auch von andern Autoren sind solche Endigungen in der Iris noch nicht beschrieben worden. Doch berechtigt uns dieser Umstand noch nicht, die Möglichkeit ihrer Existenz auszuschliessen.

\section{Die Nerven des Ciliarkörpers,}

Untersuchungen über die Innervation des Ciliarkörpers nach der Ehrlich-Dogielschen Methode sind meines Wissens vor mir noch von niemandem ausgeführt worden. Die mittels des Osmiumtetroxyds und des Chlorgoldes ausgeführte und im Jahre 1883 publizierte Arbeit von A. Geberg ${ }^{1}$ ) betraf hauptsächlich die Nervenendigungen der Muskelfasern in der Iris und dem Ciliarkörper bei Vögeln. Seine Befunde sind aber für das Auge der Säugetiere nicht direkt zu verwerten, da die in Rede stehende Muskulatur bei den Vögeln aus quergestreiften Muskelfasern besteht.

Angesichts des Besagten lege ich hier die Resultate dar, welche mir meine mit Hilfe der Golgi-Cajalschen und Ehrlich-Dogielschen Methode unternommenen Untersuchungen in bezug anf die Nerven des Ciliarkörpers bei Säugetieren und Mensehen ergeben haben.

Erwähnt sei noch, dass in der Folgezeit (1895) Dr. Melkich²) die Methylenblaumethode behufs Untersuchung der Nerven des Ciliarkörpers bei Vögeln anwandte und hierbei sensible Endapparate fand, welche den von mir beim Menschen aufgedeckten analog waren. Ferner nennen wir noch Bietti ${ }^{3}$ ), welcher im Jahre 1897 mit Hilfe der Golgi-Cajalschen Methode Untersuchungen über die Nerven des Ciliarkörpers bei Säugetieren angestellt hat.

Das Karinchenauge ist, wie wir gleich bemerken müssen, ein für Untersuchungen der Innervation des Ciliarkörpers ganz ungünstiges Objekt.

Der Accommodationsmuskel ist sehr scawach entwickelt und der Ciliarkörper in toto beträchtlich dünner und kleiner als im Auge

1) Loc. git.

2) Melkich, Zur Kenntnis des Cilarkörpers und der Iris bei Vögoln. Arat. Anz. Bd. X. Nr. 1. Mitgeteilt von Prof. Arnstein in Kasan.

3) Dott. Bietti, A., Sulla distribuzione e teminazione delle fibre nervose nel corpo ciliare. Pavia 1897. 
anderer Tiere, wie z. B. der Katze, des Schweines, Affen und des Menschen.

Der Musc. ciliaris des Kaninchens besteht ähnlich wie bei andern Nagern aus dünnen und spärlich verstreuten Muskelbündeln von 1-1,1 mm Länge [nach W ürdinger $\left.{ }^{1}\right)$ ]; sie sind der Sklera parallel angeordnet $\left.\left[\mathrm{Krause}^{2}\right)\right]$.

Dagegen erreicht der Ciliarmuskel der Raubtiere, wie z. B. der Katze, verhältnismässig grössere Dimensionen.

Seine starken, 2,7-3,4 $\mathrm{mm}$ langen Muskelbündel (Würdinger) verlaufen in meridionaler und radiärer Richtung; ausserdem findet man Muskelbündel, die nach vorn zur Iriswurzel verlaufen, und endlich noch solche, die in schräger oder äquatorialer Richtung den Ciliarkörper durchsetzen und zu gegenseitiger Verbindung der meridionalen und radiären Bündel dienen [Flemming $\left.{ }^{3}\right)$ ].

Den höchsten Entwicklungsgrad erreicht der Ciliarmuskel bei Affen und Menschen.

Sie besitzen ausser den meridionalen und radiären noch cirkuläre Muskelbündel, welche letzteren im vorderen inneren Winkel des Ciliarkörpers liegen [H. Müller $\left.{ }^{4}\right)$ ].

Das Schwein besitat ebenfalls cirkuläre Muskelbündel wie der Mensch, doch liegen sie nicht im vorderen inneren Winkel, sondern zwischen den meridionalen Muskelbündeln, näher zur Sklera [Leukart $\left.{ }^{5}\right)$ ].

Rufen wir uns noch ins Gedächtnis zurück, dass das Balkenwerk des Ciliarmuskels von Bindegewebsziigen durchflochten wird; ferner, dass die innere Fläche des genannten Muskels von einer Bindewebsschicht bedeckt ist, welche den nach innen sich erhebenden Ciliarfortsätzen als Ausgangspunkt oder gleichsam als Wurzel dient; und endlich, dass die Oberfläche der Ciliarfortsätze von einer Pigmentund einer Cylinderepithelschicht bedeckt ist. Auf der äusseren Seite des Ciliarmuskels bis zum Skleralwulst des Sehlemmschen Kanals liegt lockeres suprachorioideales Gewebe (Schwalbe, Anat. d. Sinnesorg., S. 193-195).

1) Würdinger, Zeitschr, f. vergleich. Augenheilk. Bd. IV. S. 136, 1886.

2) Krause, Die Anatomie des Kaninchens. Leipzig 1884.

3) Flemming, Über die Ciliarmuskeln der Haussäugetiere. Arch. f. mikrosk. Anat. Bd. IV.

*) Müller, H., Über einen ringförmigen Muskel am Ciliarmuskel des Nenschen und über den Mechanismus der Accommodation. Gesammelte and hinterlassene Schriften zur Anat. u. Physiol. des Auges.

5) Leukart, Chorioidea mit Corpus ciliare und Iris. Graefe-Saemisch, Fiandb. 1. Aufl. Bd. I, 2. 
Der Ciliarkörper ist reichlich mit Nerven und Gefässen versehen, die in den Bindegewebszügen sowie auch in den Muskelbündeln ihre Lage haben.

Bei solchen Bedingungen ist es schwierig, die Verästelungen der Nerven in den Gefässen, dem Bindegewebe und den Muskeln des Ciliarkörpers des Kaninchenauges voneinander zu unterscheiden und im einzelnen zu verfolgen.

Nach der Ausfithrung einer Reihe von Untersuchungen an den Augenhäuten von Kaninchen ging ich also behufs des Studiums der Nerven des Ciliarkörpers zum Auge albinotischer und pigmentierter Katzen über und fertigte auch Präparate von frischen Menschenaugen, indem ich (am häufigsten wegen Iridocyclitis und Glaucoma absolutum) enucleierte Augäpfel benutzte. Kein geringes Hindernis bot auch hier das in grösserer oder geringerer Menge im Bindegewebe entwickelte Pigment dar, welches mir besonders bei den pigmentierten Tieren grosse Schwierigkeiten machte.

Zur Untersuchung dieser Objekte benutzte ich verschiedene Methoden: die Vergoldung, die Golgi-Cajalsche und Ehrlich-Dogielsche Methode.

Die überzeugendsten Bilder der Innervation des Ciliarkörpers erhielten wir bei der Behandlung nach Golgi-Cajal und EhrlichDogiel.

Dank diesen Methoden gelang es uns, im Ciliarkörper verschiedenartige Nervenendapparate kennen zu lernen, welche sich voneinander sowohl durch ihre Form und Lage, als auch durch ihren Charakter und ihre Beziehungen zu dem umgebenden Gewebe unterscheiden.

Es lassen sich diese Nervenendigungen folgendermassen klassifizieren:

1. Endapparate der motorischen Nerven des M. ciliaris.

2. Vasomotoren der Ciliarkörpergefässe.

3. Endapparate sensibler Nerven.

4. Endapparate der Lam. suprachorioidea, welche letztere die A ussenseite des Ciliarmuskels als eine lockere Bindegewebslage bedeckt.

1. Nur infolge davon, dass das Methylenblau die Nerven bis in ihre feinsten Verästelungen hinein elektiv färbt, gelang es uns, an unsern Präparaten die Terminalgebilde der motorischen Nerven im Ciliarmuskel des Katzenauges und darauf auch im Auge des Menschen zur Anschauung zu bringen.

Im Auge der albinotischen Katze wurden die Nerven des M. ci- 
liaris durch Injektion des Farbstoffes ins Blut gefärbt, an Menschenaugen dagegen wandten wir die Färbung auf dem Objektträger nach Dogiel an, jedoch wurde die Lösung schwächer genommen als es Dogiel empfiehlt, nämlich 1,0 Methylenblau auf $5000 \mathrm{ccm}$ einer physiologischen Kochsalzlösung.

Im ersteren wie im letzteren Falle erhielten wir anfangs an einer ganzen Reihe von Präparaten ganz analoge Bilder der Muskelinnervation, wie sie von Kölliker ${ }^{1}$ ) (in der Harnblase des Frosches), Löwit'2) u. A. beschrieben wurde, d. h. die Nervenfäden verlaufen zwischen den Muskelzellenreihen; ohne in die Zellen einzudringen, verbinden sie sich mit letzterer oder richtiger, sie hören an der Zelle, im Gebiete des Kernes auf.

Ähnlich wird die Endigungsart beschrieben: von L. Gerlach ${ }^{3}$ ) (in der Gallenblase), R. Gscheidlen ${ }^{4}$ ) in der glatten Muskulatur des Frosches und Salamanders(Chlorgoldmethode), A.Meyer ${ }^{5}$ ) im Sphincter iridis des Kaninchens (Chlorgold), Arnstein ${ }^{6}$ ) im Magen und in der Harnblase (Methylenblau), Erik Müller ${ }^{7}$ ) im Magen und Darm (Golgi-Methode), Retzius ${ }^{8}$ ) (Methylenblau- und Golgi-Methode) und Andern.

Jedoch war an keinem einzigen von unsern Präparaten je etwas zu sehen, was als ein unmittelbarer Zusammenhang des Nervenfädchens mit dem Protoplasma, dem Kerne oder gar dem Nucleolus der Muskelzelle zu deuten wäre, wie es von Arnold ${ }^{9}$ ), Frankenhäuser ${ }^{10}$ ),

1) Kölliker, A., Über die letzten Endigungen der Nerven in den Muskeln des Frosches. Würzburger naturwiss. Zeitschr. 1862.

2) Löwit, Die Nerven der glatten Muskulatur. Aus dem LXXI. Bd. des Sitzungsber. d. kgl. Akad. d. Wissensch. 3. Abt. April-Heft 1875.

3) Gerlach, L., Über die Nerven der Gallenblase. Zentralbl. f. med. Wissensch. Nr. 36. 1876 ,

4) Gscheidlen, R., Beiträge zur Lehre von der Nervenendigung in den glatten Muskelfasern. Arch. f. mikrosk. Anat, Bd. XIV. 1877.

5) Meyer, Andr., Über die Nervenendigungen in der Tris. Zentralbl. f. d. mediz. Wissenseh. Nr. 7. 1878.

6) Arnstein, K., Die Methylenblaufärbung als histologische Methode. Anat. Anz. Nr. 5 u. 17. 1887.

3) Müller, Erik, Zur Kenntnis der Ausbreitung und Endigungsweise der Magen-, Darm- und Pankreasnerven. Arch. f. mikrosk. Anat. Bd. XL. 1892.

${ }^{8)}$ Retzius, G., Zur Kenntnis der motorischen Nervenendigungen. Biologische Untersuchungen. Neue Folge. III. 1892.

9) Arnold, Die Gewebe der organischen Muskeln. Leipzig 1869.

10) Frankenhäuser, Die Nerven der Gebärmutter und ihre Endigung in den glatten Muskelfasern. Jena 1867. 
Hertz' ${ }^{1}$, Klein2), Popow ${ }^{3}$ ) und auch ron Obregiat) angenommen wurde.

Ungeachtet dessen, dass der letztgenamite Autor die Nerven der glatten Darmmuskulatur bei Hunden nicht nur mit Hilfe der Essigsäure und des Chlorgoldes, sondern auch mit Methylenblau untersucht hat, kommt er doch zu dem Ergebnisse, dass die Nervenfasern in der Muskelzelle den Kern derselben durchsetzt und innerhalb der Zelle endet.

Ebensowenig trafen wir die von Krause ${ }^{5}$ ) beschriebene Endigungsart; dieser Autor sagt, „dass die doppeltkonturierten Nervenfasern mit besonderen Endapparaten, die wahrscheinlich plattenförmig - Endplatten - sind, in einem glatten Muskel aufhören" (S. 7). Ebenso sehen wir an unsern Präparaten weder die von Ranvier.i) noch die von Lawdowsky7) beschriebenen Nervenendigungen; der erstere sagt: "Nls (les nerfs) se terminent à la surface des cellules musculaires par une extremité renflée, souvent digitiforme (tache motrice)", während Lawdowsky ",knopf- oder buckelförmige" Endanschwellungen gefunden bat.

Wie man aber an Präparaten aus dem Auge der Katze (Taf. IX, Fig. 1) und des Menschen (Taf. IX, Fig. 3) wahmimmt, verlaufen zahlreiche feine Nervenfäden zwischen den Muskelzellen und hören an verschiedenen Punkten, doch stets ausserhalb der Zelle auf, indem ihr Ende entweder einem der Zellpole oder aber im Gebiete des Kernes der Zelloberfläche anliegt. Zwischen dem Nervenfaden und

1) Hertz, H., Zur Struktur der glatten Muskelfasern und ihre Nervenendigungen in einem weichen Uterus-Myom. Arch. f. pathol. Anat. u. Physiol. Bd. XLVI. 1869.

2) Klein, Tissus of the nervous system. Handbook for the Physiological Laboratory. 1873.

3) Popow, Die Nerven der Gallenblase. Joun. f. normale und pathol. Anat, Pharmakol. u. klin. Medizin, redig. v. Prof. Rudneff. Bd. VI. 1872 (russisch).

4) Obregia, Über die Nervenendigungen in den glatten Muskelfasern des Darms beim Hunde. Verhandl. d. intern. mediz. Kongr. Bd. II, 1. 4.-9. Aug. 1890. Cit. nach Jahresber. f. Anat. u. Physiol. 1891.

5) Krause, Die Nervenendigungen in den glatten Muskeln. Arch. f. Anat, Physiol, u. wissensch. Med. Nr. 1. 1870.

$\left.{ }^{6}\right)$ Ranvier, Terminaison des nerfs dans les muscles lisses. Traité technique d'histologie, p. 851.1875.

7) Lawdowsky, Weitere Beobachtungen uber die Nervenendigungen anf Grund der vitalen Fürbungsmethode. Supplen, zn Memoiren d. kgl. Akad, a. Wissensch. Nr. 2. 1889 (russisch). 
dem Kerne tritt deutlich ein Zwischenraum hervor, welcher dem die beiden Gebilde trennenden Protoplasmasaume entspricht.

Es unterliegt keinem Zweifel, dass wir hier, wo das Nervenfädchen aufhört und nicht weiter $\mathrm{zu}$ verfolgen ist, noch nicht die wahre Nervenendigung vor uns haben. Und in der Tat, die nämliche Fig. 3, Taf. IX, welche dem M. ciliaris eines Menschen entnommen ist, ermöglicht uns auch den weiteren Verlauf eines solchen Fadens zu verfolgen, und bei $d$ sehen wir, wie der dünne varicöse Faden sich gabelig spaltet und wie die Teilästchen die Zelle von beiden Seiten umfassen.

Noch deutlicher ist das Verhalten des Nerven zur Muskelzelle in der Taf. IX, Fig. 5 zu erkennen, woselbst die Nervenfärbung mit Methylenblau und die nachfolgende Fixation mit einer Mischung von Ammoniumpikrat und Pikrokarmin erhalten worden war. Dank einem solchen Verfahren haben die Kerne eine hellrote, das Protoplasma aber eine zartgelbe Färbung angenommen (letztere konnte wegen der zarten Nuance leider nicht abgebildet werden).

Die Zeichnung ist einem Präparate des Ciliarkörpers entnommen, welches mit dem Rasiermesser aus freier Hand in Querschnitte zerlegt worden war. (Das Präparat war mit einem Deckglase bedeckt und ein kkleines Gewicht darauf gelegt worden; durch den mehrmonatlichen Druck war eine Verdichtung und Härtung des Gewebes eingetreten, und nun konnte man das zwischen Holundermarkplättchen eingeschlossene Präparat in ziemlich dünne Schnitte zerlegen.)

Hier sieht man Muskelzellen im Längsschnitt $(d, e)$ sowohl als auch im Querschnitt $(g)$. In beiden Fällen ist es ersichtlich, dass das feine (violett gefärbte) Nervenfädchen in $2-3$ sehr feine Teilungsäste zerfällt, welche an der Peripherie der Zelle hinziehend, die letztere umfassen; hierbei konnte man bei günstigen Lageverhältnissen konstatieren, dass die Nervenfäden in einem gewissen Abstande vom Kerne, an der Oberfläche der Zelle verlaufen.

Taf. IX, Fig. 4 stellt einen Teil desselben Präparates bei starker Vergrösserung dar (Zeiss, Homog. Imm. 2,0 Oc. 8, $T$ 15,0).

Hier sieht man, dass eine jede Zelle von mehreren feinsten Nervenfäden allseits umflochten wird; diese Nervenfäden verbinden sich miteinander an ihren Krouzungspunkten, wobei letztere durch eine gröbere Varicosität, die einer knotenförmigen Verdickung ähnelt, charakterisiert sind. Es stellt sich also heraus, dass die Nervenfäden an der Peripherie der Zellen verlaufen und sich auf diesem Wege miteinander zu einem Nervennetze verbinden. 
Also wird eine jede Muskelzelle von einem Netze sehr feiner Nervenfäden umflochten; hierbei stehen die Nervennetze der Nachbarzellen noch durch 2-3 Fädchen untereinander in Verbindung.

Ein gleiches Innervationsbild finden wir auch in der Muskelschicht der Gefässe des Ciliarkörpers und der Iris (Taf. X, Fig. 16); auch hier wird eine jede Muskelzelle von einem, dem soeben beschriebenen ganz ähnlichen Nervennetze (d) umsponnen, welch letzteres durch den Verbindungsaden $(f)$ mit dem benachbarten Nervennetze zusammenhängt.

Dieses so konstant auftretende Innervationsbild berechtigte uns bereits im Jahre 1893 zu der Aussage, dass die motorischen Nerven im Ciliarmuskel und in der Tun. muscularis der Gefässe in Gestalt eines pericellulären Netzes enden, wobei letzteres eine jede Muskelzelle umspinnt. Mit grosser Wahrscheinlichkeit können wir annehmen, dass eine solche Endigungsart der Nerven eine für die motorischen Nerven der glatten Muskulatur allgemeine Erscheinung ist. Folglich lässt sich auch in dem Sphincter iridis sowie in andern glatten Muskeln das Vorhandensein eines dem beschriebenen ähnlichen Nervenendnetzes voraussetzen.

D. A. Timofejew ${ }^{1}$ ), gegenwärtig Professor der Histologie an der Universität Kasan, äussert sich in seiner Dissertation über die betreffende Frage wie folgt (vgl. loc. eit. S. 125-126):

„Meine diesbezüglichen Untersuchungen betreffen die glatten Muskeln der Epididymis, des Vas deferens, der Samenblase, Prostata und anderer Teile der Geschlechtsorgane . . .

An sehr guten Methylenblaupräparaten gelang es mir mitunter sowohl bei Säugetieren als auch beim Menschen, die Endigungsart der Terminalfäden in ähnlicher Weise za beobachten, wie es von Retzius (die feinsten Nervenfäden liegen den Muskelzellen an und enden hier ohne irgendwelche Terminalansehwellungen) und von Agababow (in pericellulärem Netze) beschrieben worden ist. Es gelang mir zu konstatieren, dass die am Rande der Muskelzelle entlang laufenden und von früheren Beobachtern als Terminalfasern betrachteten Nervenfaden ihrerseits noch feinere varicöse, sich verästelnde Collateralfäden entsenden, die die Muskelzelle allseits umfleelten; meiner Ansicht nach ist die Frage sehwer zu entseheiden, ob diese sich verflechtenden Fäden ein Endnetz oder aber einen Endplexus bilden, da Beobachtungsfebler in dieser Beziehung leicht möglich sind."

1) Timofejew, D. A., Über die Yervenendigungen in den männlichen Genitalorganen bei Säugetieren und Menschen. Kasan 1896 (russisch). 
2. Die vasomotorischen Nerven der Blutgefässe des Ciliarkörpers weisen keine Unterschiede von den Vasomotoren in andern Gebieten des Tractus uvealis auf; das aus marklosen Nervenbündeln bestehende perivaskuläre Geflecht gibt dünne Fasern $a b$, welche während ihres Verlaufes zur Gefässwand in feinere Fäden zerfallen, und solcherweise in die Dicke der Gefässwand sich versenken, um auf die oben beschriebene Weise in der Muskelschicht zu enden.

Ganglienzellen gelang es uns im Ciliarkörper der Katze und des Menschen nur vereinzelt und weit voneinander abliegend anzutreffen.

Frühere Beobachter dagegen haben diese Zellen, obschon ebenfalls in spärlicherer Anzahl als in der Chorioidea, doch immerhin je 2-3 Zellen beisammen liegend gefunden.

In ihrer Grösse stehen diese Zellen ebenfalls den Ganglienzellen der Chorioidea nach [Jerofejew $\left.{ }^{1}\right)$.

Die Zellfortsätze, in einer Anzahl von zwei bis drei, fanden einige Autoren [Jerofejew und Geberg $\left.\left.{ }^{2}\right)\right]$ in Verbindung mit marklosen Fasern, andere, wie z. B. H. Müller ${ }^{3}$ ), enthalten sich bestimmter Angaben darüber. So sagt H. Müller: "Ich habe bisher allerdings diese Fortsätze nicht unzweifelhaft in dunkelrandige Nervenfasern verfolgt" (S. 198).

Schweigger ${ }^{4}$ ) fand in einem Falle, dass die Ganglienzellen mit blassen Nervenfasern sich verbinden, in einem andern Falle lagen sie in dem Verlaufe eines markhaltigen Nervenstämmchens.

$\mathrm{Zu}$ notieren ist noeh, dass diese Untersuchungen an Zupfpräparaten angestellt wurden, und deshalb war es nicht immer möglich, den Zusammenhang der Zellfortsätze mit den nächstliegenden Nerven und Gefässen festzustellen.

Geberg untersuchte an Osmium- sowie auch an Chlorgoldpräparaten die Nerven der Iris und des Ciliarkörpers bei Vögeln. Seinen Angaben zufolge finden sich in spärlicher Anzahl Ganglienzellen in den Nervenplexus zwischen den Bündeln des Ciliarmuskels, ebenso wie auch in der peripheren Zone der Iris. Die in letzterer sich vor-

1) Jerofejew, Zur Lehre von den intraokularen Muskeln des Menschell. Diss. St. Petersburg 1880. S. 20 (russisch).

2) Geberg, loc. cit.

3) Müller, H., Über Ganglienzellen im Ciliarmuskel des Menschen. Gesammelte und hinterlassene Schriften zur Anat. u. Physiol. des Auges.

4) Schweigger, C., Über die Ganglienzellen und blassen Nerven der Chorioidea. v. Graefe's Arch. f. Ophth. Bd. VI, 2. S. 320-323. 
findenden Ganglienzellen sind unzweifelhaft - die im Geflechte des Musc. ciliaris mit grosser Wahrscheinlichkeit --, als zu den Gefässnerven gehörig zu betrachten.

Retzius ${ }^{1}$ ) hat an seinen, nach Golgi behandelten Präparaten weder im Ciliarkörper noch in der Iris Ganglienzellen gefunden.

In den Ciliarfortsätzen.

Eine Untersuchung der Nerven ist nur an den Augen albinotischer Tiere, besonders des Kaninchens, müglich.

Eine sehr reine Nervenfärbung erhäit man nach Dogiels Methode; auf dem Objektträger, oder in dem Sklerocornealsack, nach Arnsteins Methode.

Man kann das Studium der Nerven entweder an den abgeschnittenen und auf dem Objektträger ausgebreiteten Ciliarfortsätzen vornehmen, oder aber man bringt dieselben in ihrem unversehrt erhaltenen Zusammenhange mit dem Ciliarkörper unter das Mikroskop.

Mitten unter recht zahlreichen Blutgefässen erblickt man eine Masse markloser Nervenfasern (siehe Taf. X, Fig. $8 a$ u. $b$ ).

Letztere umgeben die Gefässe in Gestalt perivaskulärer Nervenplexus, aus welchen feine Fasern und Fäden sich abzweigen, um in die Dicke der Gefässwand einzudringen.

An den Teilungsstellen der Nerven, mitunter aber auch in ihrer Kontinuität sieht man Gebilde von ovaler oder dreieckiger Form mit abgerundeten Ecken (siehe ibid. Taf. X, Fig. 8c). Solche Gebilde kommen in grosser Anzahl an jedem Präparate des Ciliarkörpers, der Chorioidea und der Iris vor. Sie begleiten stets marklose (Remaksche) Nervenfasern, mit welchen, wie wir gesehen haben, auch die Ganglienzellen in Verbindung stehen.

Allein diese Gebilde unterscheiden sich scharf von den Ganglienzellen: sie besitzen weder einen protoplasmatischen Zellkörper, noch Fortsätze, während hingegen die Nervenzellen mit Fortsätzen versehen sind, welche in marklose Nervenfasern übergehen.

Daher sind wir, im Gegensatz zu der Ansicht Grünhagens), geneigt, diese Gebilde eher für Kerne der Nervenscheide als für Ganglienzellen zu halten.

Ausser den Vasomotoren gelang es uns in den Ciliarfortsätzen nicht, noch anderer Nerven ansichtig zu werden.

1) Retzius, G., Biologische Untersuchungen, 1893.

2) Grünhagen, Die Nerven der Ciliarfortsätze des Kaninchens. Arch. f. mikrosk. Anat. Bd. XXII. 
Nur die Methylenblaumethode ermöglichte uns eine Darstellung aller der soeben genannten Gebilde, nämlich: des Nervenendnetzes der motorischen Nerven, der Vasomotoren, der Ganglienzellen und der denselben etwas ähnelnden Kerne der Nervenfaserscheiden.

3. Ausserdem aber gelang es uns im Ciliarkörper, in der Dicke des Bindegewebes freiliegende Nervenendapparate nachzuweisen; wir fanden dieselben sowohl in den Bindegewebszügen zwischen den Balken des Musc. ciliaris, als auch in der Bindegewebsschicht, welche den genannten Muskel von innen bedeckt. Die Form dieser Nervenendigung sowie die Abwesenheit von Verbindungen derselben mit einem der umliegenden Teile und ihr Zusammenhang mit markhaitigen Fasern veranlassen uns, dieselbe für einen TerminalApparat sensibler Nerven zu halten.

Diese Endapparate sahen wir sowohl an Querschnitten des nach Golgi-Cajal behandelten Ciliarkörpers, als auch an Flächenpräparaten des letzteren bei Methylenblaufärbung. - Als Untersuchungsobjekt diente uns der Ciliarkörper der Katze und des Mensehen.

So sehen wir an einem Querschnitte des nach Golgi imprägnierten Ciliarkörpers der Katze folgendes (siehe Taf. IX, Fig. 6):

Im Ciliarkörper, näher zu dessen Aussenfläche, liegt ein markhaltiges Nervenstämmchen (a), welches ziemlich dicke Nervenbündel aussendet; eines $(b)$ verläuft nach vorn, das andere (kurz abgeschnittene) versenkt sich in die Tiefe des Ciliarkörpers. Unweit vom letztgenannten Nervenbïndel sieht man isolierte myelinhaltige Fasern nach verschiedenen Richtungen hinziehen.

Eine jede von ihnen legt eine gewisse Streeke zurück und zerfällt dann in varicöse Fäden; letztere stellen, indem sie sich mannigfach miteinander verflechten, ein ziemlich kompliziertes Gebilde dar, welches seinerseits verästelte und in varicöse Verdickungen auslaufende Nervenfäden entsendet.

Bei stärkerer Vergrösserung sind diese Gebilde in Taf. X, Fig. 13 abgebildet. Hier sehen wir bei $A, B, C, D$ die mit den entsprechenden Endapparaten endigenden markhaltigen Nervenfasern.

Bei $C$ und $D$ sind die Endapparate ersichtlich zum Teil abgeschnitten und treten daher nicht in der so komplizierten und vollendeten Form hervor wie bei $A$. Bei $B_{1}$ ist der Endapparat wahrscheinlich auch etwas schräg abgeschnitten; jedoch behält er immerhin einen ganz bestimmten, obschon weniger komplizierten Charakter.

In bezug auf ihre Lage, welche sich zum Teil auch aus der, bei schwacher Vergrösserung gezeichneten Fig. 6, Taf. IX beurteilen 
lässt, kann man sagen, dass diese Endapparate in den Maschen der radiären Muskelbündel sich befinden.

Gleichartige Gebilde finden sich auch zwischen den, der Aussenfläche des Ciliarkörpers näher gelegenen, meridionalen Balken des Ciliarmuskels.

Sie sind an Flächenpräparaten des Ciliarkörpers walnzunehmen, wenn letztere mit seiner Aussenfläche nach oben auf dem Objektträger ausgebreitet ist.

Einem Präparate des Ciliarkörpers der Katze (die Nerven sind hier mit Methylenblau gefärbt) sind die Fig. 2 (Taf. IX) abgebildeten zwei Endapparate entnommen; der eine erscheint in Form eines dicht verzweigten Bäumchens mit zahlreichen varicösen, in verschiedenen Richtungen sich schlängelnden Fäden, welche frei in varicösen Anschwellungen endigen; der andere Endapparat trägt einen gleichen Charakter, doch besteht er aus minder zahlreichen varicösen Terminalfäden.

Aus den markhaltigen Nervenstämmehen ( $a$ ) geht eine ebenfalls markhaltige Faser $(b)$ hervor; letztere sendet während ihres Verlaufes hier und $\mathrm{da}$, an den Stellen der Ranvierschen Schnürringe abgehende Fäserchen, welche sogleich in varicöse Fäden zerfallen und den soeben beschriebenen gleiche Endapparate bilden.

Bei stärkerer Vergrösserung sind diese „Endbäumchen" in Fig. 10 (Taf. X) abgebildet.

Gleichartige Endapparate finden wir auch in den meridionalen Bündeln des Ciliarmuskels im Auge des Menschen. Siehe Fig. 11, Taf. X, A. (Die markhaltige Faser a zerfällt nach Verlust ihrer Markscheide in das Endbäumchen $A$.)

Hier sehen wir die varicösen Fäden auf eine grössere Strecke verstreut; sie enden gleichfalls frei mit varicösen Anschwellungen. Das ganze „Endbäumchen" hat eine mehr ausgebreitete, oder richtiger, in die Länge gezogene Form als bei der Katze. Ausserdem sieht man, dass von der markhaltigen Faser (bei $l$ ) einzelne varicöse Fädchen sich abzweigen; letztere verflechten sich miteinander und bilden eine in die Länge gezogene "Endschlinge".

$\mathrm{Bei} \approx$ sieht man eine Nervenendigung in Form einer kleinen Endplatte.

Die Markfaser $d$ konnte nicht bis zum Endapparate verfolgt werden.

Mithin werden im Ciliarkörper der Katze und des Menschen Nervenendapparate beobachtet, welche in den Maschen des Muskel- 
netzes eingebettet sind. Wir haben dieselben „Endbäumchen“ genannt. Im Auge des Menschen erscheint das Endbäumchen mehr in dio Länge gezogen und reichlicher verästelt als bei der Katze.

Bei der Katze sowie auch beim Menschen sind diese Endigungen weder räumlich noch flächenhaft bestimmt umgrenzt; im Gegenteil, die einzelnen varicösen Fäden dieser Endigungen ziehen in geschlängeltem Verlauf nach verschiedenen Richtungen und in verschiedenen Flächen dahin. Diese Nervenendapparate lagem frei innerhalb der Bindegewebszüge und sind nicht in Kapseln eingeschlossen.

Im Gebiete der meridionalen Muskelbündel haben die Endbäumchen eine mehr abgeplattete, in dem der radiären Bündel dagegen eine mehr abgerundete Form.

An den Querschnitten des nach Golgi imprägnierten Ciliarkörpers der Katze findet man in der, die Innenfläche des Musc. ciliaris bedeckenden und den Ciliarfortsätzen als Wurzel dienenden Bindegewebsschicht noch andere Nervenendapparate. Hier (siehe Fig. 12, 14 u. 15, Taf. X) erweist sich ein jeder dieser Endapparate, gleich den früher beschriebenen, als die terminale Verästelung einer markhaltigen Nervenfaser, welche sich von einem der Aussenfläche des Ciliarkörpers anliegenden Nervenstämmchen abzweigt.

In Fig. 12, Taf. X, teilt sich die markhaltige Faser $(a)$ in zwei, die in Fig. 14, Taf. $\mathrm{X}$ abgebildete dagegen in drei Ästchen; ein jedes Teilungsästchen unterliegt seinerseits wiederholten Teilungen und bildet schliesslich einen Endapparat, welcher aus dünnen, grobvaricösen Fäden zusammengesetzt ist (siehe $A, B, C$, Fig. 12 und 14, Taf. X).

Diese Endapparate sind in einer Reihe angeordnet, und zwar nicht einander parallel, wie die vorher beschriebenen, sondern fast in einer Linie, welche der Breite und Verlaufsrichtung der betreffenden Bindegewebsschicht entspricht. Dort aber, wo die genannte Schicht an Breite zunimmt, sieht man die Endapparate in etwas divergierenden Richtungen hintereinander liegen (Fig. 12, $A$ u. B, Taf. X).

In Fig. 15, Taf. $\mathrm{X}$ ist ein solcher Endapparat dargestellt. Er erscheint in Gestalt eines dichten Endbusches. Er lag (nahe bei $b$ ) in dem Fig. 14, Taf. X abgebildeten Präparate, im Gebiete der hinteren-inneren Bündel des Ciliarmuskels.

Mithin zeigen die im Bindegewebsstroma des Ciliarkörpers eingebetteten Endapparate, ungeachtet ihrer verschiedenen, variierenden Form, dennoch etwas Übereinstimmendes und Charakteristisches - 
sie ähneln sämtlich den als "Endbüschehen" oder "Endbäumchen" beschriebenen Nervenendigungen. Jedoch haben sie entweder ein etwas abgeplattetes oder aber mehr abgerundetes Aussehen, was zum Teil von den Formverhältnissen des umgebenden Gewebes, zum Teil vielleicht von Reagentieneinwirkung abhängen mag. So finden wir zwischen den meridionalen Bündeln des Ciliarmuskels etwas abgeplattete (Taf.XII, Fig. $24 H$ u. $B_{1}$ ), zwischen den radiären Bündeln desselben mehr abgerundete und zugleich etwas in die Länge gezogene Endbäumchen (Taf. XII, Fig. $25 A$ u. $B$ ); in der schmalen Bindegewebsschicht der Innenfläche des Ciliarmuskels endlich liegen diese Endapparate fiächenhaft verstreut (Taf. XII, Fig. $25 \mathrm{E}$ ).

Soweit das topographische und morphologische Verhalten dieser Endapparate, sowie ibre Beziehungen zu den umgebenden Geweben eine Schlussfolgerung gestatten, müssen wir dieselben als sensible Nervenendigungen ansprechen. Bei jeder Kontraktion des Ciliarmuskels sind dieselben einem grösseren oder geringeren Drucke ausgesetzt. Wahrscheinlich spielen diese Endapparate eine Rolle bei dem Accommodationsakte, indem es durch ihre Vermittelung ermöglicht wird, den Accommodationsgrad jedem gegebenen Falle anzupassen. Die im Wurzelgebiete der Ciliarfortsätze gelegenen Endigungen mögen wohl für die Aufnahme von Schmerzempfindungen bestimmt sein.

An der, von dem lockeren suprachorioidealen Bindegewebe bedeckten Aussenfläche des Ciliarkörpers findet sich ein aus feinsten Fäden bestehendes Nervenendnetz (siehe Taf. IX, Fig. 9).

Mit Hilfe der Mikrometerschraube lässt sich konstatieren, dass dieses Netz über den meridionalen Bündeln des Ciliarmuskels gelagert ist. Im Niveau des genannten Muskels sieht man ein markhaltiges Nervenstämmchen $(a)$, dessen Nervenfasern an den Stellen der Schnïrringe (c) varicöse Fäden entsenden; letztere gehen sodann (bei $f$ ) in das Endnetz über.

Die Übergangsstelle der grob varicösen Fäden in das Netz trat sehr deutlich hervor (sie ist in der Zeichnung mit $f$ bezeichnet).

Das Endnetz $A, B, C$ nimmt die oberflächlichste Lage (nach aussen vom Ciliarkörper) ein, darauf tauchen die etwas tiefer unter dem Netze liegenden, grob varicösen Fäden $(d)$ auf, und noch tiefer, wie bereits gesagt, in der Dicke der Muskelbündel, verläuft das markhaltige Nervenstämmchen $(a)$ sowie die von dem letzteren sich abzweigenden isolierten ' markhaltigen Faseru $(b)$.

Um die Deutlichkeit des Bildes nicht zu beeinträchtigen, ist der 
markhaltige Nervenstamm nicht über die ganze Länge des Gesichtsfeldes aufgezeichnet und das Endnetz nur an den peripheren Partien des Gesichtsfeldes dargestellt worden.

Dieses oberflächliche Nervenendnetz haben wir an einem Flächenpräparate rom Ciliarkörper einer albinotischen Katze erhalten; die Nerven sind mittels Injektion einer 3\% igen Methylenblaulösung tingiert und dann in Ammoniumpikrat fixiert worden.

Dieses Endnetz besteht aus äusserst dünnen, fein-varicösen Fäden, die an ihren Kreuzungspunkten gröbere, gleichsam knotenartige Varicositäten tragen. In ihrer Lagerung sowie in dem Charakter ihres Maschenwerkes ähnelt die in Rede stehende Endigungsform dem bereits aben beschriebenen Endnetze an der Vorderfläche der Tris, gleichwie auch dem an der Innenfläche der Sklera - in der Lam. fusca s. suprachorioidea - beschriebenen Endnetze. Der einzige Unterschied besteht darin, dass in der Tris das Endnetz etwas weitmaschiger ist und dass in der Sklera die myelinhaltige Nervenfaser ihre Markscheide fast unmittelbar vor ihrem Übergange in das Endnetz verliert.

In den Augenhäuten des Kaninchens haben wir ebenfalls alle diese drei Arten der netzförmigen Nervenendigung beobachtet.

Dr. Melkich untersuchte die Nerven des Ciliarkörpers bei Vögeln mit Hilfe der Methylenblaumethode. Er fand im Gewebe des Ciliarkörpers ähnliche Endapparate der sensiblen Nerven, wie sie von mir im Auge der Säugetiere und des Menschen beschrieben worden waren.

Das Vorhandensein solcher Endapparate der sensiblen Nerven wurde in der Folgezeit (im Jahre 1897) von Dr. Bietti ${ }^{1}$ ) bestätigt. Dieser Autor hat nach der Golgischen Methode gearbeitet.

Er beschreibt folgende Formen der Nervenendigungen im Ciliarkörper:

a) terminazioni nervose arboriformi;

b) una rete nervosa a larghe maglie che abbraccia tutto il corpo ciliare;

c) un plesso nervoso nell' estremo limite tra il corpo ciliare e la coroidea.

\section{Die Nerven der Chorioidea.}

Die ersten ausführlicheren Daten über die Nerven der Chorioidea verdanken wir $H$. Müller und sodann Schweigger. Wie bereits erwähnt, geben die zwischen der Chorioidea und Sklera verlaufenden Ciliarnerven (nach H. Müller), für die ganze hintere Hälfte der Chorioidea bis zum Eintritte der Venae vorticosae, feine aus markhaltigen und marklosen Fasern bestehende Ästchen ab. Diese bilden

1) Bietti, A., Sulla distribuzione e terminazione delle fibre nervose nel corpo ciliare. Ann. di Ottalm. XXVII. p. 225. 
in dem Suprachorioidealgewebe einen Plexus, welcher vereinzelte sowie auch gruppenweise vereinte Ganglienzellen beherbergt. Von diesem Plexus zweigen sich feine $\ddot{A}$ stchen markloser Fasern ab, um sich den Arterien zuzuwenden.

Die eigenen Aderhautnerven sind für die Gefässmuskulatur bestimmt, es sind dies also vasomotorisehe Nerven.

An der Oberfä̈che der Gefässe trifft man vereinzelte Ganglienzellen an, die sich den soeben genannten Nerven beigesellen. Weiter unten geben wir eine Beschreibung der Ganglienzellen.

Man muss gestehen, dass die nachfolgenden Untersuchungen zu diesen Daten nur wenig Neues hinzugefügt haben.

Die Chorioidea besteht hauptsächlich aus Blutgefässen $\rightarrow$ stärkeren Arterien und deren feinen Verästelungen, Kapillaren und Venen -, sowie aus dem Zwischengewebe, welches seiner Struktur nach dem suprachorioidealen Bindegewebe analog ist. Bei der Untersuchung der Chorioidea sind es namentlich die Blutgefässe, welche fast ausschliesslich das Interesse des Beobachters beanspruchen.

Alle neueren Untersuchungsmethoden - die Vergoldung, die Golgische Methode und das Methylenblau - bringen vornehmlich die Vasomotoren zur Anschauung. Wir wissen auch bis jetzt noch nicht bestimmt, ob es Nerven in den perivaskulären Bahnen gibt und ob die Chorioidea sensible Nerven besitzt. Hieraus erklärt sich zweifellos auch der Umstand, dass in den Handbüchern auch jetzt noch die Angabe gefunden wird, es seien in der Chorioidea keine sensiblen Nerven vorhanden.

$\mathrm{Ob}$ dies sich wirklich so verhält, oder ob in der Chorioidea, wie wir glauben annehmen zu dürfen, ein aus feinsten Nervenfädchen aufgebautes Endnetz existiert, ähnlich wie es in der Suprachorioidea an der Aussenfläche des Ciliarkörpers, oder was dasselbe besagt, in der Lam. fusca von uns nachgewiesen wurde, - das müssen genauere spezielle Untersuchungen uns lehren.

Die vasomotorischen Nerven in der Chorioidea hat Retzius ${ }^{1}$ ) sehr sorgfältig untersucht. Die einschlägigen, nach der Golgischen Methode vollführten Untersuchungen ron $\mathrm{Bietti}{ }^{2}$, sowie die von Bardelli ${ }^{3}$ ), welcher die Nervenendigungen in der Chorioidea bei

1) Retzius, G., loc, cit.

2) Bietti, A., Le fibre nervose della coroidea studiate col metodo di Golgi. Annotazioni d'istologia normale. Annali di Ottalm. XXVI.

3) Bardelli, Sulla distribuzione e terminazione dei nervi nel tratto uveale. Annali di Ottalm. XXVIIL. p. 102. 1898. 
Kaninchen und menschlichen Embryonen studierte, haben, soweit die uns zugänglichen literarischen Data schliessen lassen, nicht viel zur Klärung der uns interessierenden Frage beigetragen.

Neuerdings beschäftigte sich Seide $\operatorname{man}^{1}$ ) mit der Untersuchung des Nervensystems der Chorioidea bei Kaninchen und Ratten.

Er injizierte eine ${ }^{1} / 20 \%$ ige Methylenblaulösung in die Carotis, oder er spritzte, indem er die Hornhaut durchstach, eine ${ }^{1} / 10 \%$ ige Lösung des Farbstoffes in das Innere des Augapfels. Fixierung in Ammoniumpikrat. Die Chlorgoldmethode ergab ihm keine genügenden Resultate.

Der Autor gelangte zu dem Schlusse, dass weder die Chorioidea noch die andern Teile des Uvealtractus freie Nervenendigungen besitzen. Seiner Ansicht nach gehören die Nervenfasern der Chorioidea grössenteils, wo nicht ausschliesslich, zu den motorischen und vasomotorischen Nerven; ferner sollen sensible Nerven in der Chorioidea histologisch nicht konstatiert worden sein.

Ganglienzellen sind in der Chorioidea von H. Müller ${ }^{2}$ ), Krause ${ }^{3}$ ), Schweigger ${ }^{4}$ ), Saemisch ${ }^{5}$, darauf auch von Jerofejew ${ }^{6}$ ) und Iwanoffi ) beobachtet und beschrieben worden; mit Hilfe des Methylenblaus sind die betreffenden Ganglienzellen von mir ${ }^{8}$ ) bei Kaninchen dargestellt worden.

Die Ganglienzellen sehen, nach der Beschreibung der genannten Autoren, birnförmig, eckig oder oval aus, sie enthalten einen grossen runden Kern mit Kernkörperchen und ein feinkörniges Protoplasma. Sie werden entweder vereinzelt, in grösserer Entfernung voneinander abliegend angetroffen; indes kommen nicht selten auch 2, 3 und sogar bis 20 Zellen beisammenliegend vor. Im letzteren Falle bilden sie Ganglien, welche den Verzweigungen der Ciliarnerven aufliegen oder in den Nervenstämmchen eingeschlossen sind. Jedoch sind so vielzellige Ganglien ein sehr seltener Befund. Nur Jerofejew fand nicht

1) Seidemann, Histologische Untersuchungen über das Nervensystem der Aderhaut des Auges. Diss. St. Petersburg 1899 (russisch).

2) Müller, H., loc. eit.

3) Krause, W., Anatomische Untersuchungen. 1861.

4) Schweigger, C., loc. eit.

5) Saemisch, T, Beiträge zur normalen und pathologischen Anatomie des Auges. Leipzig 1862.

$\left.{ }^{6}\right)$ Jerofejew, loc. cit.

7) Iw an off. Handb, d. ges. Augenheilk. v. Graefe-Saemisch. Tractus uvealis. - Traité complet d'opht. Wecker et Landolt. T. II, 2.

8) Agababow, A., Über die Nervenendigungen im Ciliaxkörper bei Säugetieren und Menschen. Diss. Kasan 1893 (in russischer Sprache).

v. Graefe's Archiv für Ophthalmologie. LXXXIII. 2. 
selten in der Aderhaut der Neugeborenen im suprachorioidealen Nervenplexus Ganglien, die sogar bis zu 30 Zellen enthielten (loc. cit. S. 20).

Die Ganglienzellen stehen, nach Ansicht der oben aufgefuhrten Autoren, mit den vasomotorischen Nerven in Verbindung.

G. Retzins gelang es mit Hilfe der Golgischen Methode nicht, Ganglienzellen im Tractus uvealis aufzudecken, und ebenso führten die mit Methylenblau angestellten Beobachtungen Seidemanns in derselben Frage zu negativen Resultaten.

Bei meinen Untersuchungen konnte ich mich überzeugen, dass eine reine und distinkte, ja man kann sagen, elegante Färbung der Ganglienzellen in der Chorioidea in den Fällen eintritt, wemn das Methylenblau in möglichst schwachen Lösungen $(1: 5000-1: 10000)$ nach Dogiels Methode, auf dem Objektträger, oder nach Arnstein, im Corneoskleralsacke angewandt wurde.

Unter solchen Bedingungen traten die Ganglienzellen mit allen ihren charakteristischen Merkmalen hervor, d. h. sie waren birnförmig oder von eckiger, gleichsam dreieckiger Form (mit abgerundeten Ecken); sie enthielten einen grossen bläschenförmigen Kern und waren mit zwei, selten drei Fortsätzen versehen. Einzelne Zellen erschienen von regelmässig abgerundeter Form (Fig. 23, Taf. XId. Nerven d. Sklera).

An den gruppenweise liegenden Zellen bemerkt man, dass sie an den aneinander stossenden Flächen etwas komprimiert erscheinen.

Auf die Zellenform ist ersichtlich auch die Zahl der Fortsätze von Einfluss: die bipolaren Zellen zeigen eine länglich ovale, die mit drei Fortsätzen versehenen eine unregelmässig dreieckige Form. Sehr häufig begegnet man birnförmigen Zellen mit zwei Fortsätzen, welche gleichsam an einem und demselben Zellpole ihren Ursprung nehmen, oder aber es ist nur einer von diesen Fortsätzen gut sichtbar, während dagegen der andere nur undeutlich oder selbst gar nicht sichtbar ist.

$\mathrm{Zu}$ bemerken ist noch, dass die Zellfortsätze sich schwächer färben als die Zellen selbst und ein wenig dicker erscheinen als die sie begleitenden marklosen Nervenfasern. Dunkler gefärbt tritt gewöhnlich die Ursprungsstelle der Fortsätze hervor; hier, nicht selten aber auch anderwärts in der Nervenzelle sind körnige Ansammlungen. des Farbstoffes wahrzunehmen.

Häufiger war der Befund von einzeln liegenden Ganglienzellen in dem Ciliarkörper, in der Chorioidea sah man gewöhnlich $2-3$, seltener 5,6 und noch mehr beisammenliegende Zellen; nie haben wir sie in einer so grossen Anzahl (bis 30) vereint angetroffen, wie es. 
Jerofejew gefunden hat; ebensowenig haben wir sie in Nestern eingelagert gesehen, wie es Saemisch beschreibt (siehe loc. cit. S. 26).

In allen von uns beobachteten Fällen, in welchen die Ganglienzellen gefärbt erschienen, waren sie der Gefässwand, namentlich den grösseren Arterien angelagert; einzelne Zellen sahen wir in der Kontinuität der Gefässstämme und in Gruppen vereint an den Teilungsstellen der Gefässe.

Ferner trat es klar hervor, dass der eine der Zellfortsätze sich in die Gefässwand versenkt, während dagegen der andere sich den das Blutgefäss umflechtenden marklosen Nervenfasern hinzugesellt.

Schliesslich müssen wir bemerken, dass die Ganglienzellen in weit grösserer Anzahl bei jungen, 2-3 Monate alten Tieren vorkamen, wie es übrigens auch I wan off (loc. cit. S. 262) notiert, und dass sie hier eine mehr regelmässige Form besassen.

Bei Tieren von 5-6 Monaten und mehr war die Zahl der Zeilen, auch bei ganz gleicher Behandlung der Präparate, eine geringere, und ausserdem kamen neben den Zellen von charakteristischer Form auch noch solche vor, die etwas verändert aussahen.

In Erwägung der Tatsache, dass wir derart deformierten Zellen im Auge des Kaninchens nicht selten begegneten, und dass H. Müller (loc. cit. S. 189) solche Zellen auch im. Auge des Menschen und zwar bei einer andern Untersuchungsmethode gesehen hat, können wir diese Gebilde nicht als eine zufällige Erscheinung betrachten.

Sehr bedeutsam und beachtenswert scheint uns der Erklärungsversuch H. Müllers, welcher geneigt ist, diese veränderten Zellen als Übergangsstadien von den Ganglienzellen zu den Kernen zu betrachten, welche letateren den Nervenfasern in ihrem Verlaufe hier und da anliegen.

Fassen wir jetzt alles zusammen, was uns über die Nerven in den Augenhäuten bekannt ist, so muss folgendes hervorgehoben werden:

1. Unzweifelhaft besitzt eine jede von den Augenhäuten ihre eigenen Nerven.

2. In einer jeden Augenhaut bilden die Nerven, bevor sie sich im Gewebe verästeln, anfangs ein cirkuläres oder ringförmiges Geflecht aus markhaltigen Fasern, welchen eine gewisse Anzahl markloser Nerven sich beigesellt. Derart finden wir:

a) Ein Nervengeflecht in der Chorioidea, um den hinteren Augenpol herum. 
b) Ein Nervengeflecht im Ciliarkörper, in der Dicke desselben, näher zu dessen äusserer Oberfläche.

c) Die Nerven der Iris bilden einen ringförmigen Plexus im Gebiete der Iriswurzel.

d) Ebenso sehen wir einen ringförmigen Nerrenplexus im vorderen Abschnitte der Sklera, in der Nähe der sklero-cornealen Grenzlinie.

e) Ein ringförmiger Nervenplexus findet sich auch in der Cornea, in deren Randzone.

Sehr wahrscheinlich ist, dass auch an dem hinteren Pole der Sklera ein cirkulärer oder ringförmiger Nervenplexus existiert.

3. Ferner bilden die Nerven in den mit einem Epithel oder Endothel bedeckten Augenhäuten ein Endnetz aus feinsten Nervenfäden. Solche Nervennetze finden sich:

Im Hornhautepithel, in der Endothellage des suprachorioidealen Gewebes (an der Innenfläche der Sklera und an der Aussenfläche des Ciliarkörpers).

Nur an der hinteren Fläche der Cornea sind keine Nerven nachgewiesen worden.

4. Die bindegewebige Substantia cornea, die Sklera und die bindegewehige Grundsubstanz des Ciliarkörpers sind auch mit freien Endigungen der sensiblen Nerven versehen.

Die Cornea besitzt in ihrer peripheren Zone, in der Epithelschicht sowie auch subepithelial gelagerte, dichte und lockere Endknäuel (Dogiel), „Endknöpfchen" im Hornhautepithel (Arnstein); Endknöpfchen, Endkeulen sowohl in den peripheren als auch in den zentralen Partien des Hornhautepithels (Agababow).

In der Sklera, in verschiedenen Höhen allgemein verbreitet, jedoch am reichlichsten im vorderen Abschnitt (Smirnow, Agababow) sensible Endapparate in Gestalt von:

Endknöpfchen, Endkeulen, pinselförmigen Endigungen, netzförmigen Endigungen (Agababow); platten Terminalverdickungen, Endplättchen (Agababow) oder „Plättchen" (Eleonskaja); „Endbüsche“ (Eleonskaja).

In der Iris ist nur ein Nervenendnetz beschrieben, jedoch auch dieses nicht von allen Beobachtern gesehen worden.

Angesichts der überaus grossen Empfindlichkeit des Irisgewebes sind wir berechtigt, hier noch andere bis jetzt nicht aufgedeckte Endigungsformen der sensiblen Nerven voraussetzen zu dürfen. 
In dem Ciliarkörper.

In dem Bindegewebe des Ciliarkörpers sind Endapparate der sensiblen Nerven in Gestalt von Endbäumchen und Endbüschen eingelagert.

In der Chorioidea

sind sensible Nerven nicht nachgewiesen worden; allein auch hier kann eine, den Nervenendnetzen der Lamina suprachorioidea analoge Endigungsart mit Wahrscheinlichkeit vorausgesetzt werden.

5. Ausserdem werden in allen gefässhaltigen Geweben vasomotorische Nerven beobachtet, wobei in den perivaskulären Nervenplexus Ganglienzellen vorkommen.

6. Wo Muskelgewebe vorhanden ist, dort finden sich auch motorische Nerven: in der Muskelschicht der Gefässe, im M. ciliaris, im Sphincter pupillae.

7. Die zu andern Gewebselementen in Beziehung stehenden Nerven, wie z. B. die der Hornhautzellen, sind noch nicht bekannt; dagegen sind die Nerven der Skleralzellen, sogenannte trophische Nerven, von Agababow und Smirnow beschrieben worden.

Aus den oben angeführten Daten ist ersichtlich, dass unsere Kenntnisse von der Verteilung und Endigung der Nerven sich Hand in Hand mit der Entwicklung und Vervollkommnung der Untersuchungsmethoden des peripheren Nervensystems allmählich erweitert haben.

So sehen wir, dass im Anfang der Entwicklung der histologischen Technik, als zur Darstellung der Nerven verschiedene Säuren - die Salpetersäure, sog. Osmiumsäure und hauptsächlich Essigsäure - angewandt wurden, unsere Kenntnisse insoweit fortschritten, als es sich um den Verlauf und die Anordnung der gröberen Nervenstämmchen und Nervenbündel der Ciliarnerven handelte.

In der zweiten Periode, namentlich seit der Einführung der Vergoldungsmethode durch Cohnheim, eröffnete sich die Möglichkeit, auch die feinen Verästelungen zu studieren, und in manchen Geweben, wie z. B. in der Cornea und Iris, selbst die Form der Endapparate ins Auge zu fassen.

Gegenwärtig erleben wir ersichtlich die dritte Periode. Dank dem Vorgange Ehrlichs. und Dogiels, stellen wir mit Hilfe des Methylenblaus detaillierte Untersuchungen an über die verschiedenen Formen der Endapparate fast sämtlicher Augenhäute. 
Ramon y Cajals Methode lässt sich vollständig weder in die zweite noch in die dritte Periode einreihen. Diese Methode gestattet unzweifelhaft eine vollkommenere Differenzierung der Nerven, als das Chlorgold, und liefert in manchen Teilen der Augenhäute, wie z. B. im Ciliarkörper, scharf ausgeprägte Bilder der Nervenendapparate. Nichtsdestoweniger hat diese Methode doch gewisse Mängel und steht der Methylenblaumethode in mancher Beziehung nach. Sie kann meines Erachtens als eine Ergänzung der Ehrlich-Dogielschen Methode dienen. Indem wir die erhaltenen Befunde mit der einen sowie mit der andern Methode prüfen, vermögen wir unser Urteil uber die wahre Form der Nervenendigungen besser zn berichtigen. Während indessen die früheren Methoden bereits eine genügende Verwertung gefunden haben, können wir in bezug auf das Methylenblau sagen, dass diese Methode, obschon rollkommener als die andern, Joch noch keineswegs rollständig ausgenutzt worden ist. Es unterliegt keinem Zweifel, dass die Methylenblaufärbung uns mehr zu geben vermag, als wir gegenwärtig über die Nerven in den Augenhäuten wissen.

So z. B. scheint es uns unwahrscheinlich, dass die Sklera, die früher für ganz nervenlos gehalten wurde, in Wirklichkeit eine grössere Menge verschiedenartiger Nervenendapparate besitzen sollte, als die Iris und die Cornea. Zwar ist in den letztgenamnten Augenhäuten eine ziemlich beträchtliche Anzahl starker Nervenstämmchen und Nervenplexus konstatiert worden, allein was die Nervenendapparate anbelangt, so sind letztere für die Cornea nur in den oberflächlichen Schichten und an der Peripherie, für die Iris aber nur in den Muskelbündeln, den Gefässen und in der subendothelialen Gewebslage (Endnetz) nachgewiesen worden.

\section{Literaturverzeichnis.}

Arnstein, K., Die Niethylenblaufärbung als histologische Methode. tnat. Anz. N.. 5 แ. 17.1887.

- Zur Frage der Nervenendigungen in der Cornea. Sep.-Abdr. aus Arbeiten a. Naturforschergesellsch. an d. Univ. Kasan. Bd. XX. 1889 (in russischer Spr.).

- Über die Chorioidea. Grundzüge zur mikrosk. Anat. Bd. II.

Agababow, A., Über die Nerrenendigungen im Ciliarkörper bei Säugetieren und bei Menschen. Diss. Kasan 1893 (russisch) und intern. Monatsschr. Anat. u. Phys. 1897.

- Über die Nerven der Sklera. Aich. f. mikrosk. Anat. 1904.

- Kasan 1901 (russisch). 
Andogski, N., Zur Frage über die Ganglienzellen der Tris. Arch. f. Augenheilk. 1897.

Arnold, Fr., Die Gewebe der organischen Muskeln. Leipzig 1869.

- Anatomische und physiologische Untersuchungen über das Auge des Menschen. 183\%.

- Handb. d. Anat. d. Menschen. Bd. II. 1854.

A rouson, Beiträge zur Kenntnis der zentralen und peripheren Nervenendigungen. Inaug.-Diss. Berlin.

A pathy, Erfahrungen in der Behandlung des Nervensystems für histologische Zwecke. Zeitschr. f. wíssensch. Mikrosk. Bd. IX, 4. 1892.

Axenfeld, Über sogenannte vordere Ciliarnerven. Ber. über d. 24. Vers. d. ophth. Ges. Heidelberg. S. 116-124.

- Vordere, senkrecht perforierende Culiarnervenstämme. IX. intern. ophth, Kongr. in Utreeht, Klin. Monatsbl. f. Auvenheilk. Bd. XXXVII.

- u. Naito, Über intrasklerale Nervenschleifen. Ber. über d.30. Vers. d. ophth. Ges, in Heidelberg. 1902.

Brücke, E., Anatomische Beschreibung des menschlichen Augapfels. 1847.

Bietti, Le fibre nervose delle coroidea studiate col metodo di Golgi. Annali di Ottalm. XXVI.

- Sulla distribuzione e terminazione delle fibre nervose nel corpo ciliare. Pavia 1897. Annali di Ottalm. XXVIr.

Bardelli, Sulla distribuzione e terminazione dei nervi nel tratto ureale. Annali di Ottalm. XXVIII. 1898.

Bochdalek, Uber die Nerven der Selerotica. Prager Vierteljahrsschr. Bd. XXIV. 1849.

- - Prager Zeitschr. 1850. Dit. nach H. Müller.

Bach, Die Nerven der Augenlider und der Sklera beim Menschen und Kaninchen. v. Graefe's Arch. f. Ophth. Bd. XLI. 1895.

- Die Nerven der Hornhaut und der Slklera. Arch. f. Augenheilk. Bd. XXXIII. 1896.

Cohnheim, Über die Endigung des sensiblen Nerven in der Hornhaut der Säugetiere. Arch, f. pathol. Anat, Bd, XXXVIII.

Dogie], A., Die Nerven der Cornea. Anat. Anz. Nr. 16 u. 17. 1890.

- Die Hornhautnerven des Menschen. Ophth. Bote (Westnik Ophth.). 1891 (in russischer Sprache).

- Über die nervösen Elemente in der Retina des Menschen. Arch. f. mikrosk. Anat. Bd. XXXVII u. XL, Anat. Anz. Bd. III.

- Die Nervenendigungen im Lidrande und in der Conjunctiva palp. des Menschen. Arch. f. mikrosk. Anat. Bd. XLIV.

- Die Nervenendigungen in den Tränendrüsen der Säugetiere. Arch. f. mikrosk. Anat. Bd. XLII.

- Die Nervenendkörperchen (Endkolben n. Krause) in der Cornea und Conjunctiva bulbi des Menschen. Arch. f. mikrosk. Anat. Bd. XXXVII.

Dostoiewski, Über den Bau des Corpus ciliare und der Iris von Säugetieren, Arch. f. mikrosk, Anat. Bd. XXVIII.

Drasch, cit, nach E. Müller.

Egorow, I., Über das Ganglion ciliare. Eine anatomisch-physiologische Untersuchung. Diss. Kasan 1886 (in russischer Sprache).

Ehrlich, Über die Methylenblaureaktion der lebenden Nervensubstanz. Dentsche med. Wochenschr. Nr. 4. 1886.

Eleonskaja, W., Über die Nervenendigungen in der Sklera der Säugetiere. Diss. St. Petersburg 1911 (rnssiseh).

Eropheeff, Zur Kenntnis intraokularer Muskeln beim Mensehen. Diss. 1880.

Exner, Über die Funktion des Musculus Cramptonianus. Sitzungsber. d. Wien. Akad. Bd. LXXXV, 3. 1882.

Fritz, Über den Verlauf der Nerven im vorderen Augenabschnitt. Sitzungsber. d. kgl. Akad. d. Wissenseh. in. Wien. Mathem,-naturw. Klasse, Bd. CXIII. 3. Juli. 
Flemming, Über die Ciliarwurzel der Haussüngetiere. Arch. f. mikrosk. Anat. Bd. IV.

Frankenhäuser, Die Nerven der Gebärmutter und ihre Endigung in den glatten Muskelfasem. Jena 1867.

Groenouw, Intrasklerale Nervenschleifen. Klin. Monatsbl. $f_{\circ}$ Augenheilk. Bd. XLIII. S. 637 .

Geberg, A, Über die Nervenendigungen in der Iris und in dem Ciliarkorper bei Vögeln. Diss. Kasan 1883 (russisch).

- Über die Nerven der Iris und des Ciliarkürpers bei Vogeln. Intern. Monatssehr. f. Anat. u. Histol. Bd. I. 1884.

Gerlach, L., Über die Nerven der Gallenblase. Zentralbl. f. med. Wiss. Nr. 36. 1876.

Gescheidlen, $R$., Beiträge zur Lehre von den Nervenendigungen in den glatten Muskelfasern. Arch. f. mikrosk. Anat. Bd. XIV. 1877.

Golgi, Momorie della Reale Accademia delle scienze di Torino. Serie seconda. T. XXXII. p. 359 u. Jahresber. f. Anat. u. Physiol.

Grünhagen, Die Nerven der Ciliarfortsätze des Kaninchens. Arch. f. mikrosk. Anat. Bd. XXII.

Hueck, De mutationibus oculi internis. Cit. n. Fr. Arnold.

Hoyer, a) Uber den Austritt von Nervenfasern in das Epithel der Hornhaut. Arch. f. Anat. u. Physiol. 1866. S. 180.

b) Über die Nerven der Hornhaut. Arch. f. mikrosk. Anat. Bd. IX. S. 220.

Hosch, Ehrlichs Wethylenblaumethode und ihre Anwendung auf das Auge. Mitteil. ans d. norm. anat. Inst. in Basel und v. Graefe's Arch. f. Ophth. Bd. XXXVII, 3.

Helfreich, Über die Nerven der Conjunctiva und Sklera. Würzburg 1870.

Hertz, H, Zur Struktur der glatten Muskelfasern und ihre Nervenendigungen in einem weichen Uterus-Myom. Arch. f. pathol. Anat. u. Physiol. Bd. XLIV. 1869.

Iwan off, Tractus uvealis. Traité complet d'ophtalmologie par Wecker et E. Landolt. T. II, 2.

Jerofejew, Zur Lehre von den Muskeln im Innern des menschlichen Auges. Diss. 1880 (in russischer Sprache).

Kirpitschewa-Leontowitsch, W., Zur Frage der Innervation der Iris beim Kaninchen. v, Graefe's Arch. f. Ophth. Bd. LXXIX, 3. 1911.

Krause, W., Die Anatomie des Kaninchens. Leipzig 1884.

- Anatomische Untersuchungen 1861.

- Allgem. u. mikrosk. Anat. 1876.

- Die Nervenendigungen in den glatten Muskeln. Arch. \&. Anat., Physiol. u. wiss. Med. Nr. 1. 1870.

Knox, Frorieps Notizen. Bd. VII. Cit. nach Fr. Arnold.

Kölliker, A, Über die Nervenendigungen in der Hornhaut. Würzburg. naturwiss. Zeitschr. Bd. VI.

- Über die letzten Endigungen der Nerven in den Muskeln des Frosches. Würzburg. naturwiss. Zeitschr. 1862.

Königstein, Über die Nerven der Sklera. v. Graefe's Arch. f. Ophth. Bd. XVIII, 2.

Klebs, Die Nerven der organischen Nuskelfasern. Arch. f. pathol. Anat, u. Physiol. Bd. XXXII. 1865 .

Klein, Tissus of the nervous system. Handbook for the Physiological Laboratory. 1873.

Luschka, H., Die Struktur der serősen Häute des Menschen. S. 58. 1851.

Leber, Th., Die Cirkulations- und Ernährungsverhaltnisse des Auges. Handb. d. ges. Augenheilk. v. Graefe-Saemisch. 2. Auf, Bd. II. Abt. 2.

Leukart, Chorioidea und Corpus ciliare und Iris. Graefe-Saemisch, Handb. 1. Aufl. Bd. I. Abt. 2.

Löwit, Die Nerven der glatten Muskulatur. Aus d. LXXI. Bd. d. Sitzungsber. d. kgl. Akad. d. Wissensch. III. Abt. April-Heft. 1875. 
Lawdowsky, Weitere Beobachtangen uber die Nervenendigungen auf Grund der vitalen Färbungsmethode. Supplem. zu Memoiren d. kgl. Akad. d. Wiss. Nr. 2. 1889 (russisch).

M.̈̈ller, H., Über Ganglienzellen im Ciliarmuskel des Menschen. Gesammelte u. hinterlassene Schriften zur Anat. u. Physiol.

- Ü̈ber einen ringförmigen Muskel am Ciliarmuskel des Menschen und über den Mechanismus der Accommodation. Gesammelte u. hinterlassene Schriften zur Anat. u. Physiol. d. Auges.

- Uber glatte Muskeln und Nervengeflechte der Chorioidea im menschlichen Auge. Gesammelte u. hinterlassene Schriften zur Anat. u. Physiol. d. Auges.

Neyer, A., Die Nervenendigungen in der Iris. Arch.f. mikrosk. Anat. Bd. XVII und Zentralbl. f. d. med. Wissenseh. Nr. 7. 1878.

Münch, Über die Innervation der Stromazellen der Iris. Zeitschr. f. Augenheilk. Bd. XIV. S. $130-147.1905$.

Müller, Erik, Zur Kenntnis der Ausbreitung und Endigungsweise der Magen-, Darm- und Pankreasnerven. Arch. f. mikrosk. Anat. Bd. XL. 1892.

Melkieh, Zur Kenntnis des Ciliarkörpers und der Iris bei Vögeln. Anat. Anz. Bd. X. Nr. 1.

Naïto. Klin. Monatsbl. f. Augenheilk. Bd. XL, 2.

Obregia, Über die Nervenendigungen in den glatten Muskelfasern des Darms beim Hunde. Verhandl. d. intern. med. Kongr. Berlin, 4.-9. Aug. 1890. Bd. III, 1. Cit. nach Jahresber, f. Anat. u. Physiol. 1891.

Pappenheim, Gewebelehre des Auges. Cit. nach H. Mïller.

Parker, Xylol-Balsam-Präparate vom Zentralnervensystem nach Behandlung mit Methyl. Cit. nach Zeitschr. f. wissensch. Mikrosk. Bd. IX, 4. 1892.

Popow, Die Nerven der Gallenblase. Journ. f. norm. u. pathol. Anat, Pharmakol. u. klin. Med. Redig. v. Prof. Rudneff. Bd. VI. 1872 (russisch).

Porterfield, On the eye. Vol. II. Cit. nach Fr. Arnold.

Retzius, G., Zur Kenntnis der motorischen Nervenendigungen. Biologische Untersuchungen. Neue Folge. III. 1892 u. 1893.

Ranvier, Terminaison des nerfs dans les mucles lisses. Traité technique d'histologie. p. 851.1875.

Roumschewitsch, Intraokulare Muskeln bei Vogeln. Kiew 1876 (russisch).

Schultze, Der Ciliarmuskel der Menschen. Arch. f. mikrosk. Anat. Bd. III.

Schwalbe. Lehrbuch d. Anat. d. Sinnesorg. 1887.

Seidemann, Histologische Untersuchung des Nervensystems der Chorioidea des Auges. Diss. St. Petersburg 1899 (russisch).

Smirnow, A., Die weisse Augenhaut (Sklera) als Stelle der sensiblen Nervenendigungen. Anat. Anz. Bd. XVIII. 1900.

Stepan off, Die Nerven der Iris. Diss. Tomsk 1892 (russisch).

Sehlemm, Canalis Schlemmii und Nerven der Cornea. Zeitschr. f. Ophth. Bd.I.

Saemiseh, Beiträge zur normalen und pathologisehen Histologie des Auges. Leipzig 1862.

Schweiggex, Über die Ganglienzellen und blassen Nerven der Chorioidea. v. Graefe's Arch. f. Ophth. Bd. VI, 2.

Tepliaschin, A., Zur Lehre von den histologischen Veränderungen der Retina nach Verwundungen. Diss. Kasan 1893 (russisch).

Tim ofejew, D. A., Über die Nervenendigungen in den männlichen Genitalorganen bei Säugetieren und Menschen. Kasan 1896 (russisch).

Valentin, Über den Verlauf und die letzten Enden der Nerven. Nova acta physico-medica Academiae Caesareae Leopoldino-Carolinae. T. XII. 1836.

Virchow, H. Graefe-Saemisch, Handb. d. ges. Augenheilk. 2. Auf. T. I. Bd. I. Kap. II.

Waldeyer. Traité d'ophtalmologie par Wecker et Landolt. T. II.

Warlom ond, Le muscle ciliaire. Ann. d'ocul. T. LXXXIII.

Weber, Graefe's u. Walters Journ. Bd. XI. Cit. nach Fr. Arnold. 
Wende, Zur Anatomie des Ciliarmuskels. Inaug. - Diss, und Arch. f. Anat. u. Physiol. Nr. 1. 1870.

Wür dinger. Zeitschr. f. vergleich. Augenheilk, Bd. IV. 1886.

\section{Erklärung der Abbildungen auf Taf. IX-XII.}

\section{Tafel IX.}

Fig. 1. Die Nerven des Muse. ciliaris einer jignentierten Katze. Der Ciliarkörper ist mit der äusseren Obertäche dem Beobachter zugewendet. Man sieht hier zwei Muskelschichten; sie verlaufen in horizontaler und schräger Richtung. Die Nervenfäden divergieren auf ihrem Wege, und deren feine Zweige gehen zwischen den Reihen der Muskelzellen hin; stellenweise vereinigen sich diese Zweige mit querverlaufenden Fäden. Die Nervenfäden $(c, c)$ kommen von links und unten nach oben und rechts; jeder von ihnen livergiert sich in zwei oder drei Äste, welche in ausstrahlender Richtung auseinander gehen, und endigen entweder spitz $(f)$ oder mit einer Verdickung (e). Das feinere Nervenfadchen $(n)$ gelangt bis zum Pole des Muskelkernes und teilt sich in zwei feinere Zweige, welehe die Zelle von beiden Seiten über die Grenzen des Kernes umgehen. Die Yerven des Ciliarkörpers sind mittels der Injektion mit einer $3 \%$ MethylenblauIosung (Carotis) gefarbt; die Färbung ist mit gesättigter Lösung des pikrinsauren Ammoniaks fixiert. Zeiss Kompens. Ok. 4, Obj. F.

Fig. 2. Die Endbäumchen, welche auf der äusseren Oberfläche des Ciliarkörpers in der Schicht der meridionalen Muskeibündel sich befinden. Dieselle Abbildung ist in der Fig. 10, Taf. X bei starker Vergrösserung dargestellt. - Es ist hier ein Teil des Stammes der markhaltigen Nerven $(a)$ angedeutet, und ebenso von ihm eine abgehende markhaltige Nervenfaser, welche an der Stelle des Uberganges (siehe c Fig. 10, Taf. X) sich dichotomisch teilt; der eine von diesen Zweigen $(d)$ richtet sich nach oben, der andere an dem Punkte (e) teilt sich in zwei Zweige; der eine von diesen zerlegt sich sofort in ein Endbäumchen, welches aus feineren Fäden besteht (mit gröberer Varicosität versehen), der andere Zweig setzt sich fort, und etwas weiter an der Übergangsstelle (i) teilt er sich ebenso dichotomisch in kleine Zweige, von denen der eime nach oben geht und bald aufhört, aber der andere richtet sich nach unten, und nach einem langen Verlaufe zerfallt er in feinere varicöse Fäden, welche ein Endbäumchen bilden. Die Behandlung ist dieselbe wie beim vorigen Präparate. Zeiss Ok. 4, Obj. D. Ygl. Fig. 10, Taf. X.

Fig. 3. Die Nerven des Musc. ciliaris ans menschlichem Auge; a Nervenstämmehen, von dem Zweige abgehen und zwischen den Reihen der Muskelzellen verlaufen. Stellenweise vereinigen sich die benachbarten Nerven durch querverlaufende Nervenfäden. Varicöse Nervenfäden $b$ teilen sich nach einigem Verlaufe in feine Fadchen, welche mit einer Verdickung oder spizz in Gebiete des Kernes der Muskelzelle endigen. Das feinere Fädchen $d$, bis zura Kerne verlaufend, teilt sich dort in drei varicöse $Z$ weige, von denen zwei die Zelle über die Grenzen des Kernes umgeben, und der andere an seinem Anfange mit einer Verdickung endigt. Das Präparat ist mit einer Methylenblaulosung 1:5000 auf dem objektträger behandelt. Die Fixierung wie bei dem vorigen. In $d$ sind der MuskelKern und die Nerven bei Vergrösserung gezeichnet. Zeis s Kompens. Ok. 8, Obj. F.

Fig. 4. Die Nerven des Muse. ciliaris in einem Meridionalschnitte des Ciliarkörpers von einer albinotischen Katze. Die Nerven sind mit Metbylenblau mittels der Injeltion in die Carotis behandelt. Die Karne sind mit Pikrokarmin gefärbt. Die feineren varicösen Fäden bilden um die Muskelzellen die Netze, welche mittels varicöser Fäden sich verbinden. Zeiss Obj. Apocrom. homog. immers. 2,0, Kompens. OK. 8 . 
Fig. 5. Die Nerven des Musc. ciliaris in dem Präparate eines Meridionalschuittes des Ciliarkörpers von einer albinotischen Katze. Die Behandlung ist die gleiche wie beim vorhergehenden Präparate. Feinere varicöse Nervenfädlen, eine gewisse Strecke zwischen den Muskelzellen verlaufend, teilen sich in Zweige $d, e$, welche den Muskelzellen entlang über deren Grenzen durchgehen, mehrere Zweige aber - schräg oder quer; $g$ Querschnitt der Muskelzellen, die von den Nervenfäden umgeben sind. $\mathrm{Z}$ eiss Ok. 4 , Obj. F.

Fig. 6. Meridionalschnitt des Ciliarkörpers ron einer pigmentierten Katze. Golg is Verfahren. $J$ ist der vordere Teil des Ciliarkörpers, $c h$ der hintere Teil der Chorioidea zugewendet; $s$ Skleral- und $p$ innere Oberfläche des Ciliarkörpers. Das Stämmchen der markhaltigen Nerven $(a)$ divergiert in zwei Äste: der eine von ihnen (b) geht nach vorn, der getroffene andere - nach innen. Schwarze Fäden, unweit vom Nervenstamme verlaufend, stellen markhaltige Nervenfasern und deren Übergang in Endbäumchen dar. Siehe Fig. 13, Taf. X, $A, B, C, D$. Reichert Ok. 3, Obj. 4.

Fig. 7. Die Nerven des Musc. ciliaris auf einem Flächenpräparate des Ciliarkörpers bei einer albinotischen Katze. Das Verfahren wie bei den Präparaten 4 und 5; a Stämmchen markloser Nerven, an der Teilungsstelle der Kern $b ; c, c$ sind die von dem Stämmchen ausgehenden feinen Fäden, die zwischen den Muskelzellen verlaufen. Der Nervenfaden teilt sich in zwei Fädchen, welche die Zelle von beiden Seiten umgehen $(e)$. Stellenweise $(f)$ läuft der Nervenfaden über die Zelle hinüber, sich auf dem Wege mit Seitenfäden vereinigend. Zeiss $\mathrm{Ok}, 4,0 \mathrm{bj}$. F.

Fig. 8. Die Vasomotoren der Ciliarfortsätze beim albinotischen Kaninchen; $a$ und $b$ marklose Nervenstämmchen mit Kernen versehen; es bildet sich ein Geflecht; $c, c$ feinere varicöse Fäden, die von den Stämmchen herkommen und stellenweise über die Kerne verlaufen. Fürbung mit Methylenblaulösung $1: 10000$ nach K. A. Arnstein. Reichert Ok. 3, Obj. 8.

Fig. 9. Das sensible Nervennetz $A, B$ auf der äusseren Oberfläche des Ciliarkörpers bei einer albinotischen Katze: $a$ das Stämmchen markloser Nervenfasern, $b$ die vom Stämmchen abgehenden. Fasern, welche in $c$ dichotomisch sich teilen; $d$ varicöse Nervenfäden, die von der Einschnürungsstelle markhaltiger Nerven nach der äusseren Oberfläche des Ciliarkörpers verlaufen; sie bilden auf dern Wege ein Geflecht und gehen dann $(f f)$ in das $\operatorname{Netz}(A, B)$ über, welehes aus feineren körnigen. Fäden besteht. Das Verfahren wie beim Präparate 1 . $\mathrm{Ze}$ is s Ok. 8, Obj. D.

\section{Tafel X.}

Fig. 10. Dieselben Endbäumchen wie in der Fig. 2, Taf. IX bei starker Vergrösserung. Zeiss Ok. 4, Obj. F.

Fig. 11. Endbäumchen im Ciliarkörper vom Menschen. zwisehen den Muskelbündeln. Die markhaltige Faser $(a)$ divergiert sich an der Einschnürungsstelle dichotomisch; der eine von diesen Zweigen geht rechts und teilt sich selbst in zwei kleine Äste, von denen der eine in ein Endbäumchen $(A)$ übergeht, der andere $(d)$ geht seitwärts von dem ersten und verschwindet bald. Die markhaltige Faser $(m)$ teilt sich am $k$ in einen Ast $(n)$ und einen varicösen Faden $(p)$, welcher, sich mit dem ersten umschlingend, bis $l$ gelangt, wo die Faser $(n$ ) das Mark verliert und in zwei gröbere varicöse Fädchen zerfällt; sie verlaufen mit dem Faden $(p)$ und endigen mit einer Verdickung. Der markhaltige Nerv $(m)$ gibt noch früher einen $Z$ weig $(t)$ ab, von welchem bald der varicöse Faden $(y)$ sich abzweigt und in ein Endnetz (Gitter) (e) übergeht, aber der Zweig selbst $(t)$ setzt sich nach unten bis zum Bäumchen fort und verschwindet weiter. Einzelne varicöse Fäden $(v, v)$ und der $Z$ weig $z$, welche von $m$ herkommen, lassen sich bis zu ihren Endgebilden nicht verfolgen. Die Nerven sind gefärbt mit Methylenblau in einer Lösung 1:5000 auf dem Objektträger. Zeiss Kompens. Ok. 8 , Obj. D. 
Fig. 12. Endbäumchen, die im Corpus ciliare etwas nach innen rom Musc. ciliaris sich befinden. Der markhaltige Nerv $(a)$ divergiert sich an der Einschnürungsstelle $(b)$ in zwei Äste, welche in die Endbüumchen $(A, B)$ ubergehen. Die Fi gur ist einem Präparate aus dem Ciliarkörper einer pigmentierten Katze entnommen. Golgis Verfahren. Reichert Ok. 3, Obj. 8.

Fig. 13. Endbäumchen in den Schlingen der radiären Muskelbündel im Ciliarkörper einer pigmentierten Katze. Die markhaltigen Nervenfasern $a, a, a$ teilen sich an der Einschnürungsstelle dichotomisch und lösen sich nachher in grobe varicöse Fäden auf, aus welchen die Endbäumchen bestehen $A, B, C, D$; $\varepsilon$ feine varicöse Fäden, welche mit einer Verdickung endigen; die Fndgebilde vereinigen sich mittels varicöser Fäden $(d)$. Querschnitt durch den Ciliarkörper; nach Golgi behandelt. Reichert Ok. 3, Obj. 8.

Fig. 14. Endbäumchen $(A, B$ und $C)$ im bindegewebigen Streifchen des Ciliarkörpers, etwas nach innen vom Ciliarmuskel gelegen. Die markhaltige Nervenfaser (a) teilt sich an der Einschnürungsstelle in mehrere Zweige, und ein jeder von ihnen zerfällt in ein (einziges) Endgebilde. Alle sind in einer Reihe angeordnet und sie nehmen einen engen langen Raum ein; der Zweig (b) lässt sich weiter verfolgen : seine Endigung ist in Fig. 7 dargestellt. Vom Ciliarkörper einer pigmentierten Katze. Behandlung nach Golgi. Reichert Ok. 3, Obj. 8.

Fig. 15. Endbäumchen im Ciliarkörper einer pigmentierten Katze. Es ist hier nur das Endgebilde $A$ abgebildet, welches nahe dem Nervenzweige $(b)$ sich befindet, der von der markhaltigen Faser (a) abgeht (siehe Fig. 6), Golgis Verfahren. Zeiss $0 \mathrm{k} .4,0 b j$.

Fig. 16. Die Vasomotoren der Arterie des Ciliarkörpers einer albinotischen Katze. Feine varicöse Fäden $(a, a, a)$ bilden die Netze $(a, d)$ um die Muskelzellen herum. Mittels der Fäden $(f)$ vereinigen sich diese Netze untereinander. Die Nerven sind behandelt mittels der Injektion mit $3 \%$ Methylenblaulösung (Carotis). Zeiss Ok. 8, Obj. F.

\section{Tafel Xr.}

In allen Figuren sind bezeichnet:

mit $d$ markhaltige Nervenstämmchen.

$n a$ Nervenendigung in Gestalt einer varicösen oder keulenförmigen Verdickung.

"c Nervenendigung in Gestalt von Endplättchen (Plaques).

" $c_{1}$ ebensolche Endigungen wie $c$, aber von grossen Dimensionen,

" $f$ eine pinselförmige Nervenendigung.

, $h$ eine mehr komplizierte Endigung in Netzform.

" $b \quad b$ einzelne varicöse Nervenfäden, deren Endigungen nicht in der Figur dargestellt sind.

" $k$ eine Gewebszelle der Sklera.

"e Endothelzellen der Lamina fusca.

Fig. 17. Nervenendigungen in der Sklera, nahe dem Äquator des Auges von einem weissen Kaninchen; Injektion in die Carotis mit $3 \%$ Methylenblaulösung. Reichert Ok. 3, Obj. 8.

Fig. 18. Nervenendigungen ebenso im mittleren skleralteile des Auges eines weissen Kaninchens; Injektion mit 1\% Methylenblau. Zeiss Ok. 12, Obj. 8.

Fig. 19. Nervenendigungen im Vorderteile der Sklera vom weissen Kaninchen. Farbung nach Prof. K. A. Arnstein, die Methylenblaulösung 1:10000. Reichert Ok. 3, Obj. 8.

Fig. 20. Das Verhalten eines Nervenfadens zu einer Skleralzelle (von einer weissen Katze). Injektion mit $3 \%$ Methylenblau. Reichert OK. 3, Obj. 8 . 
Fig. 21. Nervenfäden in der Lamina fusca (weisse Katze) mit Endothelzellen (e). Injektion von $3 \%$ Methylenblau. Reichert Ok. 2, Obj. 4.

Fig. 22. Vasomotoren und Ganglienzellen der Gefässe (Kaninchen), Reichert Ok. 3, Obj. 4 .

Fig. 23. Vasomotoren und Ganglienzellen der Chorioidealgefässe eines weissen Kaninchens. Färbung mit Methylenblau $1: 10000$ nach K. A. Arnstein.

\section{Tafel XII.}

Fig. 24. Nerven des Ciliarkörpers - Flächenpräparat. Die Abbildung ist nach Präparaten kombiniert, wie sie in den Fig. 2 u. 9 der Taf. IX (Ciliarkörper des Auges einer albinotischen Katze) und in Fig. 11 der Taf. X (Menschenauge) dargestellt sind.

mc meridionale Muskelbündel des Musc. ciliaris.

$a$ starkes markhaltiges Nervenstämmchen.

$b$ die markhaltige Nervenfaser zerfällt (bei $c$ ) in varicöse Fäden $(d)$, welche (bei $f$ ) in das aus feinsten körnigen Fädchen $(A, B)$ bestehende Endnetz zerfallen.

$H$ Nervenendapparat (Endbäumehen) in den Lücken zwischen den Muskelbündeln (Katze).

$H^{\prime}$ ein ähnliches Endbäumchen (aus dem Ciliarkörper des Menschenauges) in den Maschen der meridionalen Muskelbündel des Musc. ciliaris.

Fig. 25. Ciliarkörper des Auges des Menschen im Querschnitt. Die Abbildung wurde nach mehreren Präparaten kombiniert. Nervenfärbung nach Golgi.

mc Muskelbündel des Musc. ciliaris (von einem mit Hämalaun gefärbten Präparate).

a starkes markhaltiges Nervenfaserbündel.

$A, B, D$ Endbäumchen in den Lücken zwischen den radiären Muskelbündeln. Diese Endapparate sind in Fig. 14 (der Taf. X) einzeln dargestellt.

$E$ Endbäumchen in der nach innen vom Musc. ciliaris sich ausbreitenden Bindegewebsschicht. Diese Endbäumchen sieht man in den Fig. 12, 14, 15 der Taf. $X$ einzeln abgebildet.

Hornhautnerven des Auges von einem weissen Kaninchen. Die Nervenfärbung wurde mit Hilfe der lnjektion einer $1 \%$ igen Methylenblaulösung in die Carotis erhalten. Fixierung in der Ammoniumpikratlösung. Einschluss des Präparates in einer Mischung von Glycerin mit wässriger Ammoniumpikratlösung.

Fig. 26. Gezeichnet bei schwacher Vergrösserung (Reichert Obj. 3, Ok.4).

Fig. 27-29. Dasselbe Präparat bei starker Vergrösserung. (Zeiss homog. Immersion 2,0; Komp.-OK. 6 ; T. - 15,0.)

$m$ marklose Nervenbündel, welche in den Bestand der in verschiedenen Höhen die Cornea durchsetzenden Nervenplexus treten.

$d$ interepitheliale Nervenfüdchen in den oberdächlichen Epithellagen.

$l$ Endigung eines Nervenfadens in Form eines Endhäkchens. (Al - bei schwacher, $B l \longrightarrow$ bei starker Vergrösserung.)

a knopfförmige Endanschwellung.

$a_{1}$ keulenförmige Endanschwellung.

Sämtliche Endanschwellungen der Terminalfäden übertreffen in ihren Dimensionen die gewöhnlichen Varicositäten der Nervenfäden und stellen Endapparate der aus dem Plexus subbasalis aufsteigenden Nervenfäden dar.

$b$ ein aus varicösen Fäden bestehendes Gebilde, ähnlich den von Dogiel in der Hornhaut des Menschen beschriebenen lockeren Endknäueln. 
Die Nervenendigungen $l, a, a_{1}, b$ sind sämtlich in den zentralen Hornhautpartien, nahe beieinander liegend, gefunden worden.

Fig. 30-32. Nerven der Iris (von einem albinotischen Kaninchen).

$a f^{*}$ Arterie mit dem perivaskulären Nervenplexus $(p l)$; aus der tiefen Irisschicht.

a markhaltiges Nervenfaserbündel, welches vor den Blutgefässen liegt.

nv vasomotorisches Nervennetz, aus den oberflächlichen Gewebslagen der Iris.

ns oberflachliches Endnetz der sensiblen Nervenfasern; es liegt an der Vorderfläche der Iris, vor dem vasomotorischen Nervenendnetze. $n f$ markbaltige Nervenfasern, die in varicöse Fäden zerfallen; letztere bilden das oberflächliche Endnetz (ns).

$\varepsilon$ Endothelzelle.

Reichert Obj. 4 (b), Ok. 3 (Fig. I u. II); Zeiss Ölimmers. Komp. Ok. 8. Tub. 15 (Fig. III). Die Nervenfärbung gesehah mittels Injektion einer $1 \%$ igen Methylenblaulösung in die Carotis. Fixierung in Ammoniumpikrat. 

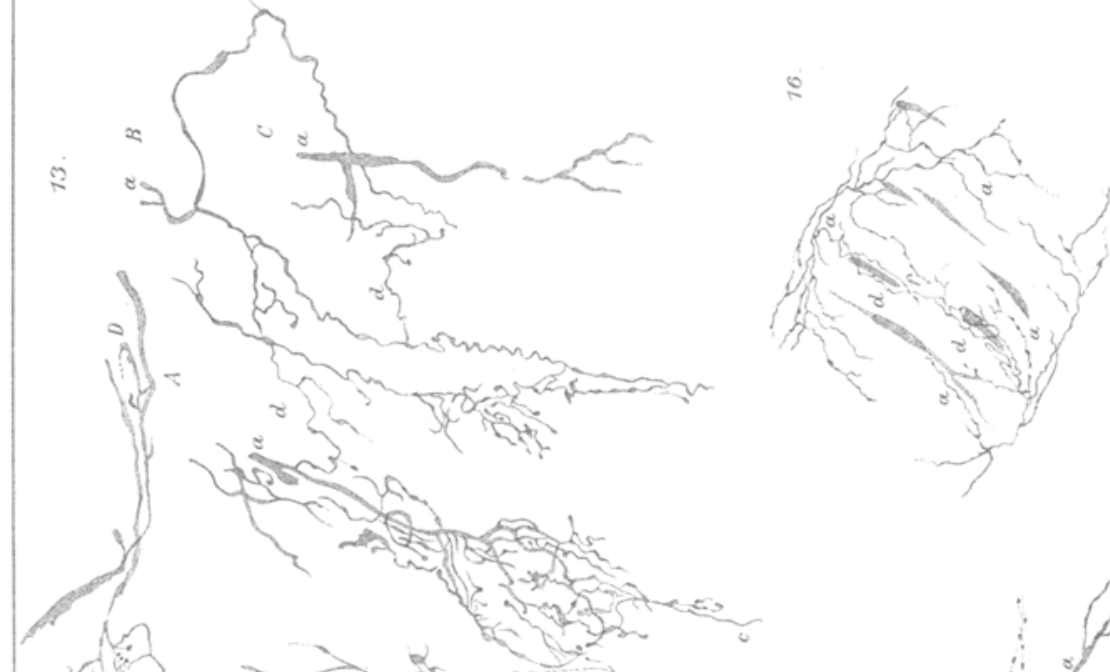

$\int_{2}^{\pi} y^{n}$ ?

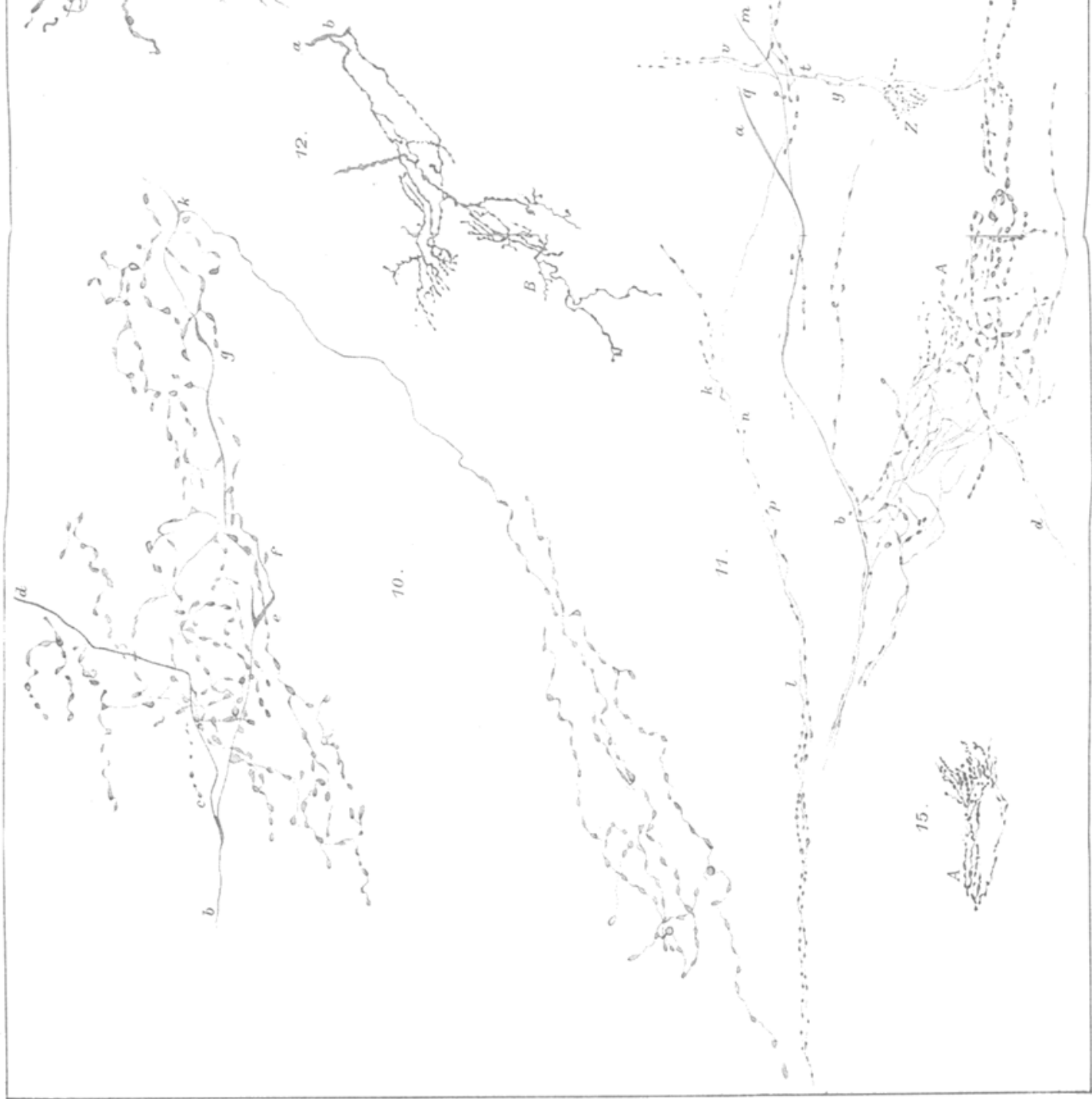




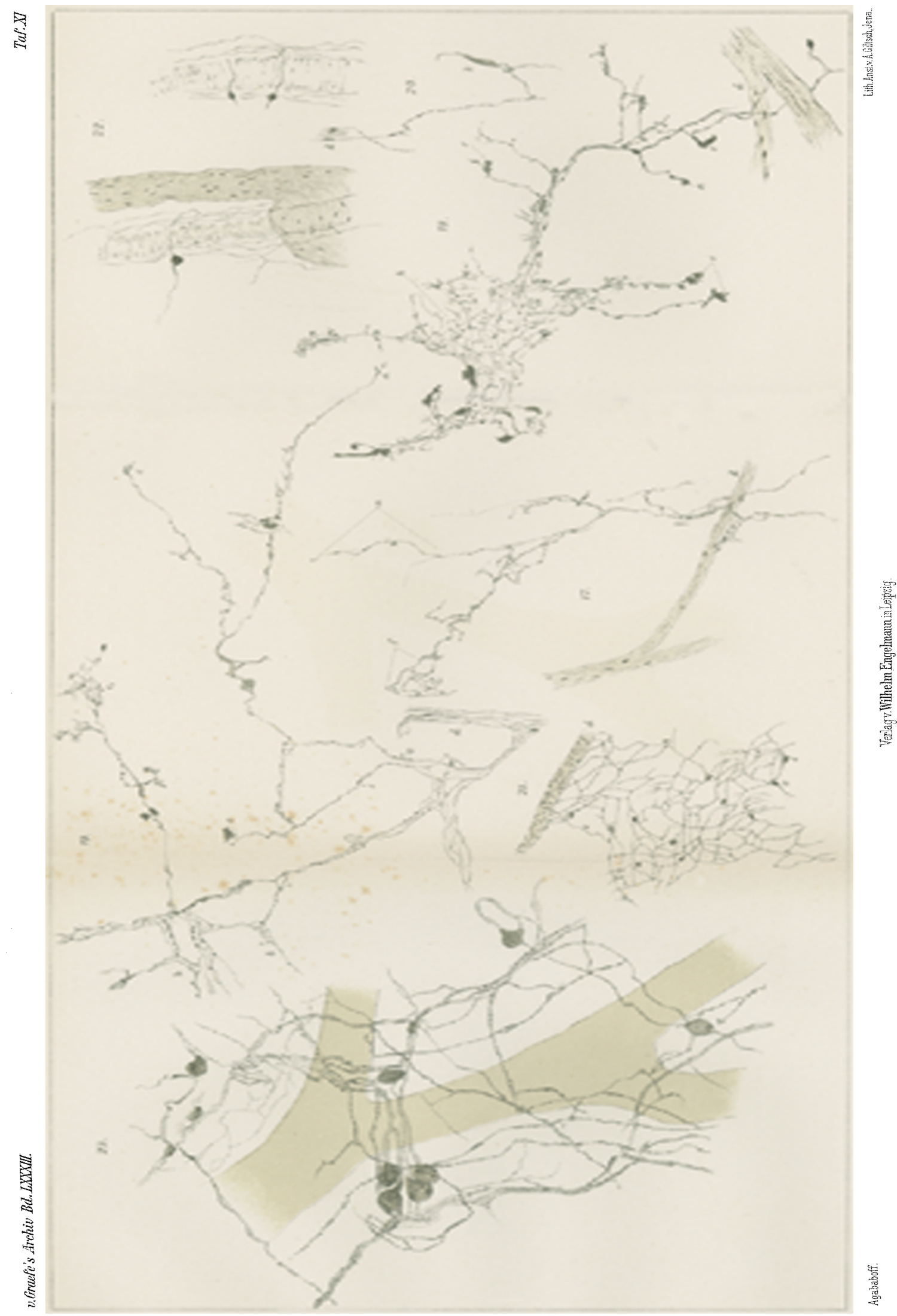




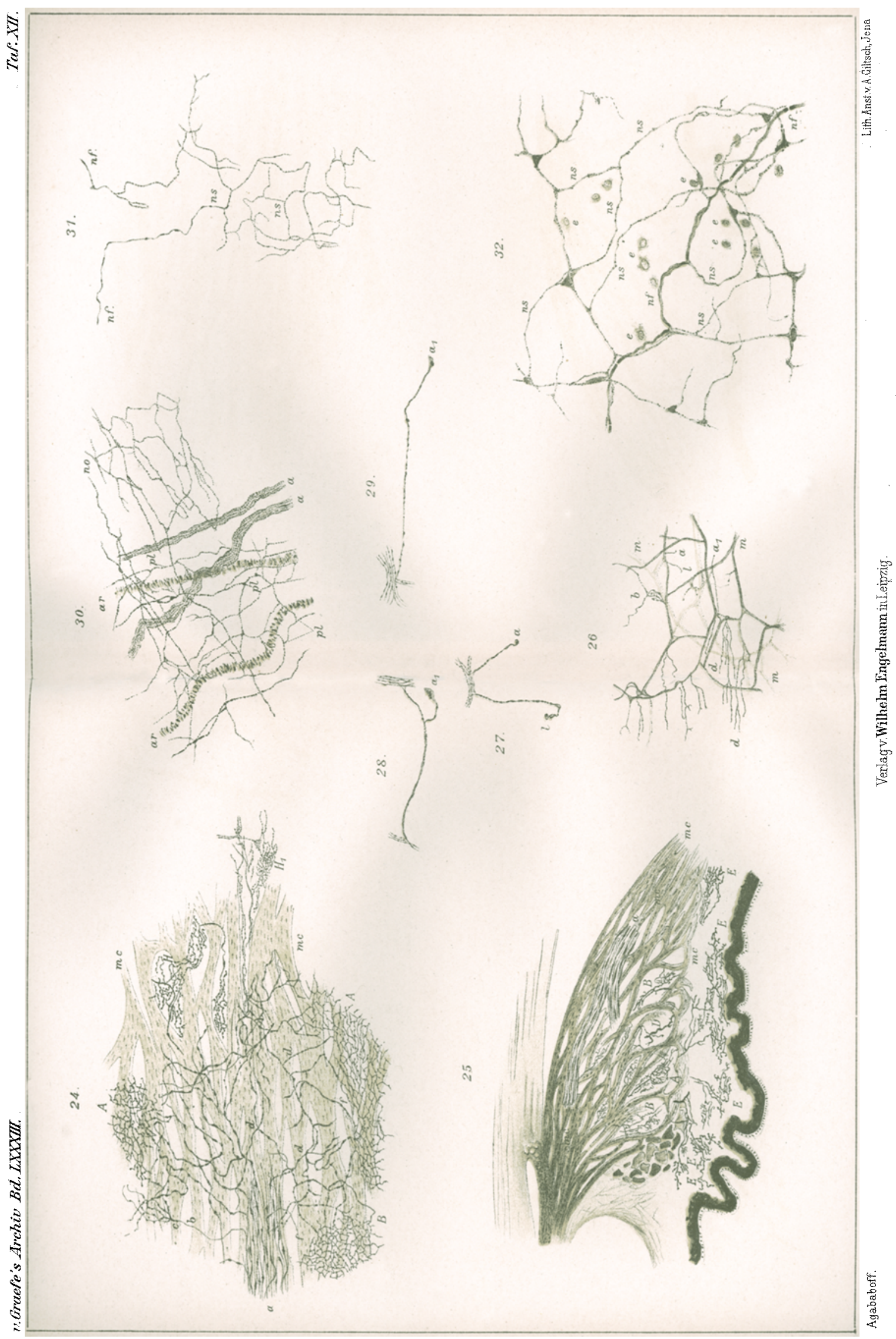

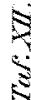

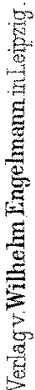

